\title{
WestVirginiaUniversity
}

THE RESEARCH REPOSITORY @ WVU

Graduate Theses, Dissertations, and Problem Reports

2003

\section{Geologic feature prediction using roof bolter drilling parameters}

\author{
Benjamin T. Mirabile
}

West Virginia University

Follow this and additional works at: https://researchrepository.wvu.edu/etd

\section{Recommended Citation}

Mirabile, Benjamin T., "Geologic feature prediction using roof bolter drilling parameters" (2003). Graduate Theses, Dissertations, and Problem Reports. 1389.

https://researchrepository.wvu.edu/etd/1389

This Thesis is protected by copyright and/or related rights. It has been brought to you by the The Research Repository @ WVU with permission from the rights-holder(s). You are free to use this Thesis in any way that is permitted by the copyright and related rights legislation that applies to your use. For other uses you must obtain permission from the rights-holder(s) directly, unless additional rights are indicated by a Creative Commons license in the record and/ or on the work itself. This Thesis has been accepted for inclusion in WVU Graduate Theses, Dissertations, and Problem Reports collection by an authorized administrator of The Research Repository @ WVU. For more information, please contact researchrepository@mail.wvu.edu. 


\title{
GEOLOGIC FEATURE PREDICTION USING ROOF BOLTER DRILLING PARAMETERS
}

\author{
Benjamin T. Mirabile
}

\author{
A Thesis Submitted to the \\ College of Engineering and Mineral Resources \\ At West Virginia University \\ In Partial Fulfillment of the Requirements \\ for the Degree of
}

\author{
Master of Science \\ In \\ Mining Engineering \\ Syd Peng, Ph.D., Chair \\ Yi Luo, Ph.D. \\ Felicia Peng, Ph.D. \\ Department of Mining Engineering \\ Morgantown, West Virginia \\ 2003
}

Keywords: Roof Bolter, Rotary Drilling, Ground Control, Roof Bolting, Drill Bits, Discontinuities, Drilling Parameters 


\title{
ABSTRACT \\ Geologic Feature Prediction Using Roof Bolter Drilling Parameters
}

\author{
Benjamin T. Mirabile
}

The design of a safe and efficient roof support system is essential for any underground coal mining operation. All underground coal mines in the United States install roof bolts with a roof bolter as the primary means of supporting the mine roof. Proper application of roof bolting is dependent upon knowledge of the mine roof geology.

Recently developed control and data acquisition technologies allow the drilling performance of these roof bolters to be monitored on a real-time basis. Drilling data collected from these machines can be used to determine geological features present in the mine roof. A J.H. Fletcher \& Co. roof bolter was fitted with an automated control and data acquisition system. Laboratory and underground tests were conducted to collect drilling data from both simulated and actual in-situ geological conditions. The data analysis methodology was tested using data collected from these drill holes. 


\title{
TABLE OF CONTENTS
}

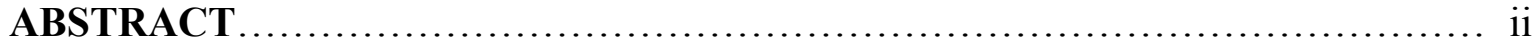

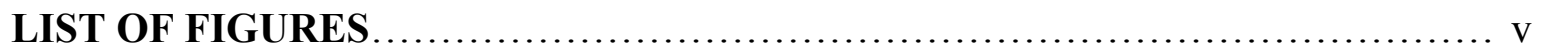

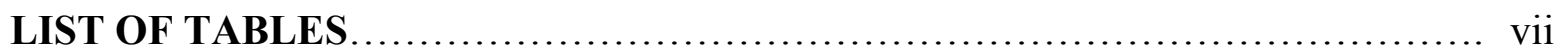

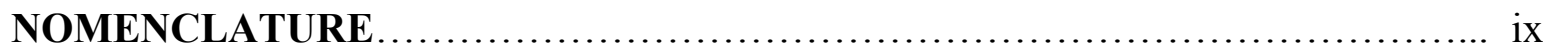

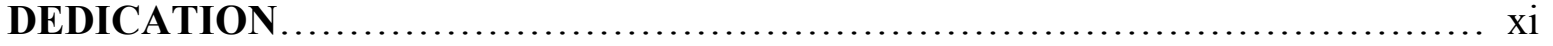

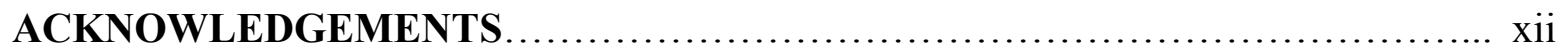

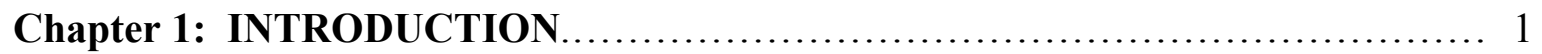

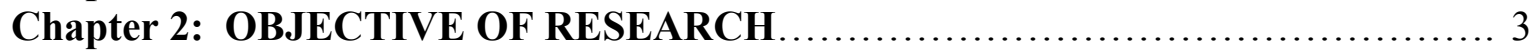

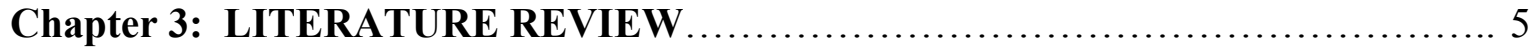

3.1 Development of Specific Energy of Drilling................................ 5

3.2 Research Performed by J.H. Fletcher and West Virginia University............. 8

Control Technology for Roof Drill Operators.............................8

An Approach to Identifying Geological Properties from
Roof Bolter Drilling Parameters.............................................. 9

Estimating Rock Strengths Using Drilling Parameters Collected

During Roof Bolting Operations -Progress Report....................... 11

3.3 Research Performed by Itakura, et al. ..................................... 14

Development of a Roof Logging System by Rock Bolt Drilling.............. 14

Visualization of Geostructure by Mechanical Data Logging

of Rockbolt Drilling and its Accuracy .................................... 16
\end{abstract}

3.4 Applications and Limitation of Previous Research......................... 17

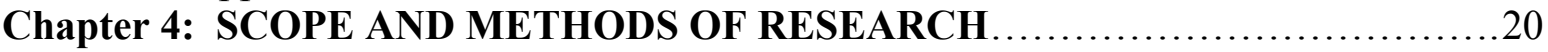

4.1 Simulated Blocks for Laboratory Tests.................................... 23

4.1.1 Homogeneous Block …....................................... 24

4.1.2 Simulated Fracture Block ..................................... 24

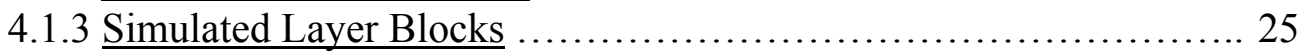

4.2 Experimental Design of Phase 1 Laboratory Tests.......................... 27

4.2.1 Experimental Approach of Phase 1 Laboratory Experiments.......... 28

4.3 Experimental Design of Underground Tests................................. 31

4.3.1 Core Drilling .................................................. 31

4.3.2 Bore Hole Scoping .............................................. 32

4.3.3 Mine A Underground Tests....................................... 34

4.3.4 Mine B Underground Tests...................................... 36

4.3.5 Mine C Underground Tests..................................... 40

4.3.6 Mine D Underground Tests..................................... 42

4.4 Experimental Design of Phase 2 Laboratory Tests............................................. 45

4.4.1 Experimental Approach of Phase 2 Laboratory Experiments........... 46

Chapter 5: DATA COLLECTION AND PREPARATION ....................... 48

5.1 Data Smoothing...................................................... 49

5.2 Higher Order Drilling Parameters....................................... 52

5.2 .1 Bite Depth ................................................ 52

5.2.2 Normal Contact Area and Normal Stress ......................... 52

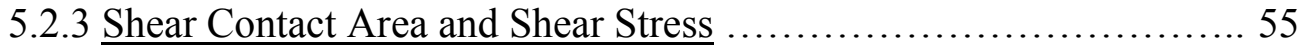

5.2.4 Shear Stress/Normal Stress Ratio ................................ 59 


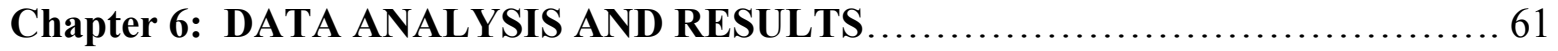

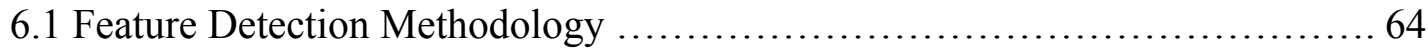

6.1.1 Determination of Shear Stress/Normal Stress Ratio .................. 65

6.1.2 Numerical Calculation of the Slope of Shear Stress/Normal

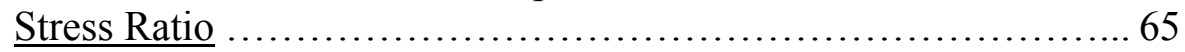

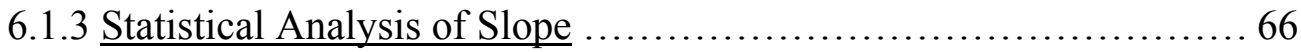

6.2 Results of Data Analysis .................................................. 68

6.2.1 Phase 1 Laboratory Results .......................................... 69

6.2.2 Underground Mine Test Results ............................... 71

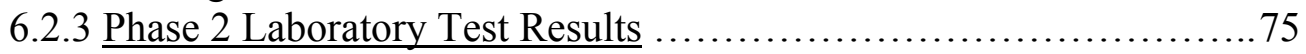

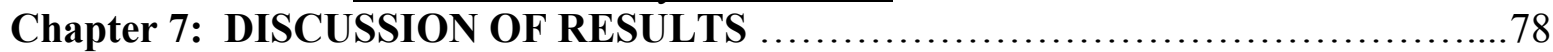

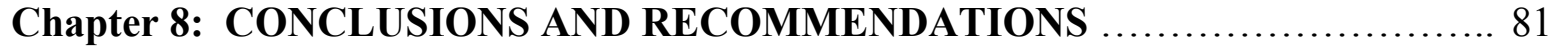

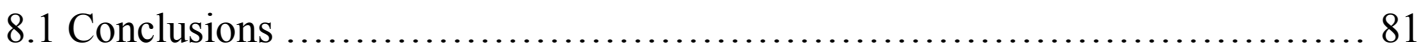

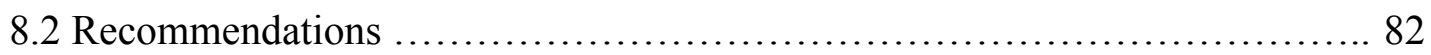

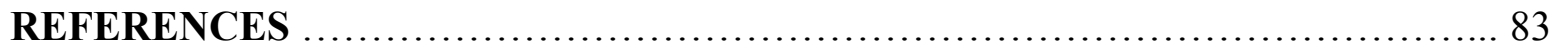

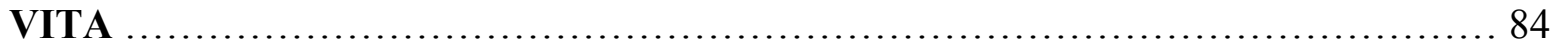




\section{LIST OF FIGURES}

Figure \#

$\underline{\text { Page }}$

3.1

Specific Energy Versus Thrust

7

3.2

Torque Patterns Associated With Geologic Features

15

4.1

J.H. Fletcher \& Co. HDDR Roof Bolter Used in

20

4.2

Drilling Experiments

21

4.3

Drill Control Unit Used in the Research

Drill Bits Used for Drilling Tests

22

4.4

Solid Concrete Block

24

4.5

Simulated Fracture Block

25

4.6

Layer Block 5

26

4.7

Layer Block 6

26

4.8

Core Drilling

32

4.9

Borehole Scope System

33

4.10

Tripod Mount for Borehole Scope

34

4.11

Diagram of Mine B Test Site

Core Log from Mine B 


\section{LIST OF TABLES}

$\underline{\text { Table \# }}$

$\underline{\text { Page }}$

4.1 Physical Properties of Layer Block Materials

Pre-Set Drilling Parameters-Solid Concrete Block

Pre-Set Drilling Parameters-Mine A 


\section{NOMENCLATURE}

Symbol

A

$\mathrm{A}_{\mathrm{n}}$

$\mathrm{A}_{\mathrm{s}}$

b

$b_{i}$

D

$\mathrm{e}_{\mathrm{r}}$

$\mathrm{e}_{\mathrm{t}}$

F

$\mathrm{F}_{\mathrm{s}}$

IQR

$\mathrm{N}$

OFN

OFP

Q1

Q3

$\mathrm{Ri}$

SED

$\sigma$

$\mathrm{T}$

$\tau$
Description

$\underline{\text { Units }}$

Cross-sectional Area of Drill Hole

in $^{2}$

Normal Contact Area

in $^{2}$

Shear Contact Area

in $^{2}$

Bite Depth

in/rev

Slope of Ratio

Bit Diameter

in

Rotational Component of Specific Energy

$\mathrm{lb} / \mathrm{in}^{2}$

Thrust Component of Specific Energy

$\mathrm{lb} / \mathrm{in}^{2}$

Thrust

$\mathrm{lb}$

Shear Force

$\mathrm{lb}$

Interquartile Range

Rotational Speed

rpm

Negative Outer Fence

Positive Outer Fence

First Quartile

Third Quartile

Shear Stress/Normal Stress Ratio

Specific Energy of Drilling

lb/in ${ }^{2}$

Normal Stress

$\mathrm{lb} / \mathrm{in}^{2}$

Torque

in-lb

Shear Stress lb/in ${ }^{2}$ 
u

wj

xi

$\mathrm{Z}_{\mathrm{i}}$ *

$Z_{i+j}$
Penetration Rate

Weighting Factor

Bit Position

in in $/ \mathrm{sec}$

Correct Value

Original Value 


\section{DEDICATION}

TO MY MOTHER AND MY FATHER 


\section{ACKNOWLEDGEMENTS}

I am sincerely grateful for the guidance and assistance given to me by a number of individuals during the course of the project. Professor Syd Peng, WVU and Professor Yi Luo, WVU have both contributed enormously to my research and critical thinking abilities. Fellow graduate students Dr. Gerald Finfinger, Dr. Quanzhong Gu, and David Tang have all given much needed motivation and insight to the completion of this project.

Craig Collins of J.H. Fletcher \& Co. has provided crucial information on countless occasions. Professor Felicia Peng, WVU contributed her extensive knowledge of computer programming when data analysis software was being developed. All of these individuals proved invaluable when conducting this research, and I am thankful for all of their guidance and assistance. 


\section{CHAPTER 1}

\section{INTRODUCTION}

Roof bolting is employed in all U.S. underground coal mines as the primary method for supporting the roof. Most roof bolts are installed on 4 foot spacing throughout the mine. Prior to installation of any bolt, a hole must be drilled. These holes are drilled with roof bolting machines. Experienced roof bolter operators can detect some features in the mine roof based on machine response (noise, drill rate, etc). However, no quantitative method exists to collect and store this information. Recent technological advances in control systems have allowed the drilling process to become automated. In addition to automation, these control systems allow drilling parameters to be recorded and stored for analysis.

Geological features in mine roof are of primary interest to a mine engineer who is designing a roof support system. Particularly, engineers must determine the strength of strata within the bolted horizon, and the location of fractures, weak zones, and interfaces within the bolted horizon. Engineers often rely on core hole logs from surface core holes to find this information. These holes are generally drilled for the purpose of exploration and reserve estimation. However, since coal is generally a tabular ore body, the spacing of core holes is often too large to quantify small-scale geological features in the mine roof. Often, problems with a roof support design can be attributed to undetected geological features in the mine roof.

Data collected from roof bolting machines present a great opportunity to quantify and monitor the geology of mine roof. A typical mine may install more than 100 roof bolts in an operating shift. Consequently, more than 100 holes will be drilled in the mine roof. An automated data collection and analysis system could make it possible to quantify geological features from all of these holes for use in roof support design 
The objective of this research project is to develop an automated system that will analyze collected data and quantify geological features in the mine roof with minimal human input or manipulation of data. This system should be able to analyze data from normal drilling operations conducted during the production cycle. This research will analyze drilling parameters collected during drilling in laboratory conditions, and drilling parameters collected from four underground mine test sites. 


\section{CHAPTER 2}

\section{OBJECTIVE OF RESEARCH}

The central objective of this research project is to develop a methodology capable of displaying the nature of a mine roof using drilling parameters sampled from a roof bolter during routine drilling operations. There are several factors that are essential to understanding the nature of a mine roof. These factors include: the location of boundaries between layers of differing strata; the locations of fractures, voids, or cracks within a layer of strata; and the relative strength of drilled strata.

The drilling and data collection system of the machine used in this research project is capable of controlling various drilling parameters during operation. Thus, another objective of this project is to determine what control scheme provides the most accurate information on the nature of the mine roof.

Due to the large volume of data that roof bolters are capable of collecting, an automated system is necessary for the analysis and display of drilling data. Therefore, algorithms developed in this project will be implemented using various computer programs. The ultimate goal of this project is to develop a software package capable of collecting, storing, retrieving, analyzing, and displaying drilling data.

By more thoroughly understanding the nature of a mine roof, an engineer should be able to design and implement a more effective roof support system for a particular mine. In particular, an engineer can determine the proper anchorage horizon with knowledge of the relative strength of strata in the mine roof. Information on the location of fractures, cracks, voids, and boundaries between layers can be used to determine the proper length of roof bolts to ensure that strata does not separate and fall. Furthermore, areas where the nature of the roof 
changes significantly can be identified, and changes to the roof support design can be implemented if necessary. 


\section{CHAPTER 3}

\section{LITERATURE REVIEW}

Obtaining information concerning the nature of rock surrounding an underground opening is of significant importance to a mine engineer. Since the strata surrounding an underground opening is the primary building material, any information on the physical characteristics of the strata is vital to the design of a safe and suitable mine structure.

Much research has been conducted to develop methods to determine the physical properties of strata in-situ. For the purposes of this research, methods relating to drilling and drilling parameters will be addressed in detail. Specifically, data collection and analysis methods that have been developed in the past 15 years will be reviewed. Additionally, other research that provides a basis for more recent projects will be addressed.

\subsection{Development of Specific Energy of Drilling}

Teale (1964) developed a theoretical analysis method for drilling based on the energy required to excavate a unit volume of rock (1). Rotary drilling is divided into two componentsindentation and rotary cutting. The two components are applied nearly simultaneously, but can be considered to be applied separately and alternately. In cutting a rock mass, the indenter first penetrates the mass by crushing and compacting the rock in front of it. Then, fragments break out from the bottom of the hole back to the original surface.

The Specific Energy for a drilling process is defined as the work done per unit volume.

$$
\mathrm{SED}=(\mathrm{F} / \mathrm{A})+[(2 \mathrm{piNT}) /(\mathrm{Au})], \text { in. } \mathrm{lb} / \mathrm{in}^{3}
$$

Where: 


$\begin{array}{ll}\text { SED - } & \text { specific energy of drilling, } 1 \mathrm{~b} / \mathrm{in}^{2} \\ \mathrm{~F}- & \text { thrust, lbs } \\ \mathrm{A}- & \text { cross-sectional area of hole, } \mathrm{in}^{2} \\ \mathrm{~N}- & \text { rotational speed, } \mathrm{rpm} \\ \mathrm{T}- & \text { torque. in-lbs } \\ \mathrm{u}- & \text { penetration rate, in } / \mathrm{sec}\end{array}$

For a particular rock type, there should be a minimum specific energy required for drilling. Teale (1964) states that actual drilling processes may or may not actually approach this theoretical minimum. Excessive breakage of rock, friction between the bit and rock, and other losses outside the drill system contribute to the deviation from the theoretical minimum.

Specific energy is composed of two components: the thrust component, $\mathrm{e}_{\mathrm{t}}$, and the rotation component, $\mathrm{e}_{\mathrm{r}}$.

$$
\begin{aligned}
& e_{t}=(F / A) \\
& e_{r}=(2 p i N T) /(A u)
\end{aligned}
$$

Where:

$$
\begin{array}{ll}
e_{t}- & \text { thrust component of specific energy, } 1 b / \mathrm{in}^{2} \\
\mathrm{e}_{\mathrm{r}}- & \text { rotational component of specific energy, } l \mathrm{lb} / \mathrm{in}^{2}
\end{array}
$$

Generally, the thrust component is very small and often negligible in comparison with the rotation component.

In actual laboratory tests, Teale (1964) found that torque/penetration rate curves approximate a straight line through the origin. Since torque/penetration rate curves approximate a straight line, their slopes (torque/penetration per revolution) are relatively constant. Therefore, for a large particle size, the specific energy should be relatively constant for a given rock type. 
Based on measurements from a drilling machine, Teale (1964) found that the specific energy is very high at low thrust levels. At very low thrust, there is not enough force to penetrate the bit into the rock mass, and a significant portion of energy is consumed in overcoming friction between the bit and rock. As thrust increases specific energy tends to decrease until it reaches a minimum. Further increases in thrust from this point cause the specific energy to increase as the bit begins to clog; specific energy will continue to increase with increased thrust until the drill system stalls. The point of minimum specific energy represents the maximum efficiency achievable with a particular drill system in a particular rock type. A plot of specific energy versus thrust (Figure 3.1) shows that the point of minimum specific energy is on the order of the uniaxial compressive strength of a rock type.

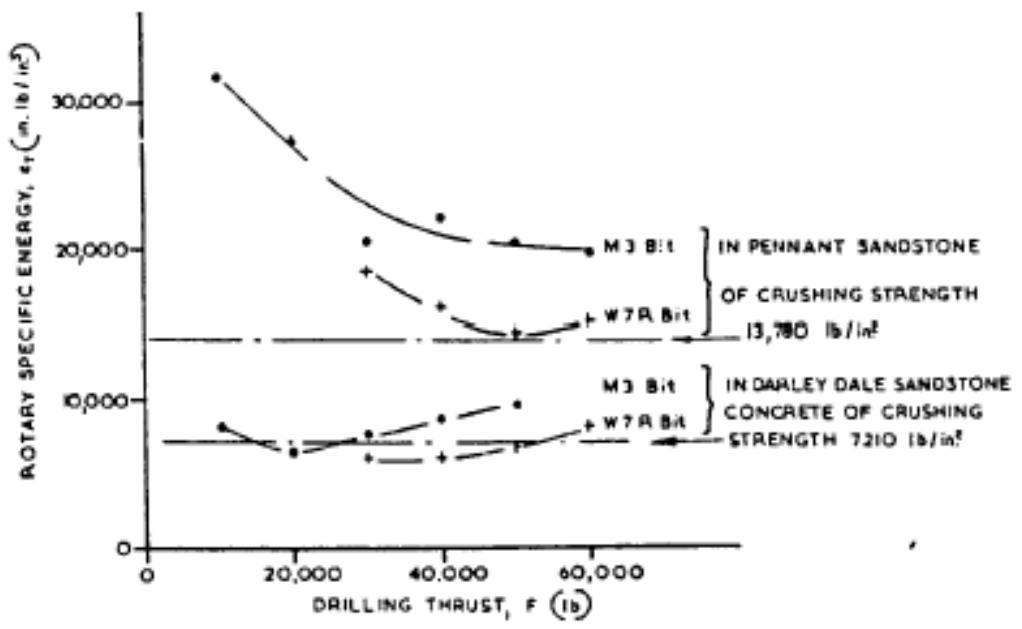

Figure3.1 Specific energy versus thrust 


\subsection{Research Performed by J.H. Fletcher and West Virginia University}

\section{Control Technology for Roof Drill Operators}

Thomas and Wilson (1999) described a computer controlled system used to operate roof bolting machines (2). The control system consists of a dedicated microprocessor mounted in an explosion proof box, a joystick, and solenoids to operate the hydraulic system of the roof bolter. This system replaces conventional mechanically operated control levers on a roof bolting machine. The control system is referred to as the Drill Control Unit (DCU).

To operate the roof bolter, an operator inputs pre-set parameters, and uses the joystick to start the drilling cycle. After starting the drilling cycle, no additional input is needed from the operator until the drilling cycle ends. The micro-processor adjusts drilling parameters automatically to maintain safe and efficient operation. At the time of publication, this system controlled the roof bolter based on a proprietary relationship between drilling thrust and rotation rate. However, the authors note that other control methodologies can be programmed into the control unit. Since publication of this paper, a research control program has been programmed for use in this project.

In addition to automatic control of the roof bolter, this system allows drilling data to be recorded for later analysis. The microprocessor samples 17 different parameters at a time interval of 0.1 seconds. All drilling data analyzed in this research project is provided by this recording system. 


\section{An Approach to Identifying Geological Properties from Roof Bolter Drilling Parameters}

Finfinger et al., (2000) describe a series of laboratory experiments conducted with a J.H. Fletcher roof bolter equipped with a DCU (3). These experiments were conducted at the J.H. Fletcher manufacturing facility with various blocks designed to simulate typical geologic features encountered in underground coal mining.

Two series of drilling experiments were conducted. The first series of tests used blocks with various layers of sandstone, marble, and argillite bedded with concrete to simulate transitions from weak to strong and strong to weak rock layers. The second series of experiments were designed to simulate fractures and separations. These experiments were conducted on a layer block with foam inserts ranging from 2-8 in thick (large separations), a concrete block with embedded cardboard layers from $1 / 8$ in to 1 in thick (horizontal fractures), and a concrete block embedded with inclined cardboard from $1 / 8$ in to 1 in thick (inclined fractures). Material properties for the manufactured blocks were obtained through core testing following ASTM standards.

During these drilling experiments, a control methodology allowing the operator to pre-set both penetration and rotation rates was developed and tested. Prior to these experiments, control of the machine was achieved through a proprietary relationship between the penetration and rotation rates of the roof bolting machine (Feedback Control). The new control methodology (WVU Control) allows the operator to control penetration and rotation rates of the machine independently. Of the 50 tests conducted for this paper, 7 used the feedback system with the other tests using the various settings of the WVU Control system. 
During these tests, clogging of the drill bits and/or drill steel was found to be a problem. In one block, $64 \%$ of the holes drilled were terminated prematurely. It was found that the foam and cardboard used to simulate separations was causing many of the clogs in the drill system.

Two data analysis methodologies were presented in this study. One method analyzed various patterns in the drilling parameters with the intersection of some feature. The second method focused on the variation of specific energy with rock strength.

The patterns of changes of 5 drilling parameters were analyzed in this study. The drilling parameters of thrust, torque, penetration rate, rotation rate, and specific energy were inspected. The patterns in these drilling parameters were analyzed for transitions of strong to weak rock, weak to strong rock, rock to fracture, and fracture to rock.

Eight different patterns were identified for the transition of strong to weak rock. The most frequent pattern occurred $55 \%$ of the time with any other individual pattern occurring with a frequency less than $10 \%$. The transition from weak to strong rock had 9 different associated patterns with the dominant pattern occurring about $55 \%$ of the time. Again, most other patterns occurred less than $10 \%$ of the time. Six patterns were identified for the transition from rock to fracture. The most frequently occurring pattern appeared about $65 \%$ of the time. With other individual patterns occurring no more than $15 \%$ of the time. For the fracture to rock transition, 8 patterns were recognized with the dominant pattern's frequency of $62 \%$. No other individual patterns appeared more than $15 \%$ of the time.

The second data analysis methodology was an attempt at correlation of SED with the Uniaxial Compressive Strength (UCS) of the various layers of the manufactured blocks. SED is calculated for every data point in a hole. The average, minimum, and maximum SED for each rock layer in a hole is the computed and compared to the UCS of the various rock layers. It was 
found that the variation between minimum and maximum SED was much greater than the variation between maximum and minimum UCS for the rock types. In an attempt to improve the results, a statistical approach was used to determine which drilling parameters had the greatest effect on the SED. Penetration rate and rotational speed were found to have the greatest effect, and were therefore given extra weighting. This weighted SED improved the results, but the authors note that it is still not possible to correlate SED with the UCS of the rock layers.

Estimating Rock Strengths Using Drilling Parameters During Roof Bolting Operations Progress Report

Luo et al., (2002) introduces a mathematical model to predict the strength of rock using parameters collected during drilling (4). The model considers the bit geometry and efficiencies associated with the drilling process. Results of the mathematical model are compared with actual drilling data.

The authors find that the bit geometry has a large influence on the energy requirements necessary to cause failure in the rock mass being drilled. For analysis, the cutting action is divided into two components: the normal component and the shear component. Increased bite depth causes an increase in the normal contact area, and consequently, the normal force needed to cause failure. Likewise, increased bite depth requires greater torque to cause failure. For the two sizes of bits used in the project (1 $1 / 32$ " and $13 / 8$ ") the authors derive empirical equations for the normal and shear contact areas: 
$13 / 8 "$ Bit $\quad A_{n}= \begin{cases}0.01085+4.1025 b & \text { for } b<0.16 ” \\ 0.60677+0.3750 b & \text { for } b>0.16 ”\end{cases}$

$11 / 32 "$ Bit $\quad A_{n}= \begin{cases}0.01+2.4083 b & \text { for } b<0.12 ” \\ 0.4562+0.4265 b-0.003 / b^{2} & \text { for } b>0.12 ”\end{cases}$

Where:
$\mathrm{A}_{\mathrm{n}^{-}}$
normal contact area in ${ }^{2}$
b-
bite depth in/rev

One of the first considerations of bit wear is also included in this paper. As the drill bit wears, the normal contact area of the bit will increase, and a correction factor for the empirical contact area equations should be applied.

The compressive strength of rock is determined from the drilling data by equations using the thrust and torque components of drilling. The thrust component is primarily responsible for overcoming the compressive strength of the rock and the effects of confinement. The torque component is responsible for overcoming the shear strength of the rock as well as friction at the bit-rock interface. Additionally specific energy is calculated according to Teale's equation (Equation 1 in p. 6). Energy efficiency is also determined based on the torque component of drilling. 
A simulation program using MathCad was developed to theoretically model the drilling process. The inputs of the program are:

- Empirical equation for normal contact area

- Angle of increment of compressive strength

- Unconfined compressive strength

- Shear strength

- Diameter of drill bit

- Height of bit wear

The outputs of the program are:

- Required thrust

- Required torque

- Required specific energy of drilling

- Energy efficiency

Results of the simulation are discussed in the context of accepted drilling theory. Required thrust for drilling increases significantly with increased unconfined compressive strength of rock drilled. The required torque is not as sensitive to changes in the shear strength of rock drilled. Graphs of the simulated specific energy agree well with Teale's theory. Required SED is very high at low thrusts and decreases with higher thrust. Graphs of the energy efficiency show that no more than $20 \%$ of the consumed energy is actually used to break rock. Most energy is consumed overcoming friction at the bit-rock interface.

Using equations developed in this study, the authors calculate the compressive and shear strengths for two sets of drilling data. Rock strengths are determined at each data point in a drill hole (300-1000 data points per hole). One set of drilling data is obtained from a solid concrete 
block that simulates a homogeneous material. The other set of data is from a layered block that simulates various layers of strata. The determined compressive strength of the concrete block was found to be smaller than the tested strength, while the determined shear strength was found to be larger than typical shear strength values for concrete. The determined strength also varied significantly along the drill hole. Similarly, large variations were found in the determined strengths of various layers in the simulated layer block.

\subsection{Research Performed by Itakura et al.,}

Development of a Roof Logging System By Rock Bolt Drilling

Itakura (1997) describes the development of a measurement while drilling (MWD) machine for characterization of the geologic structure of coal mine roof in Japan (5). The paper describes development of the data logging system, design of laboratory experiments, and underground feasibility studies.

Typically, Japanese coal mines use WOMBATs to install roof bolts. These machines are small, portable drills that can be carried by the operator from place to place. Generally, these machines are powered by compressed air. For this research project, the bolter was equipped with a data sampling system that records values of torque, thrust, rotation rate, and penetration rate at an interval of 20 samples/sec.

Initial laboratory experiments were designed to determine if the drill system could detect the following:

- Rock Type

- Rock Structure

- Distribution of discontinuities (cracks, boundaries of strata layers, separations) 
- Characterization of discontinuities (slope angle, crack widths, orientations)

- Strength of Rock

Laboratory blocks were constructed using coal measure strata from Japanese coal mines. Additionally, blocks were constructed with angled interfaces between strata layers, and with separations between layers to simulate underground geologic conditions.

Results of the laboratory experiments showed a correlation between the average torque or average thrust and rock type encountered. The authors note that the width and angle of a discontinuity are also reflected in the torque and thrust, but the error in estimation is large due to a change in mechanical behavior of the drill system near the discontinuity. Figure 3.2 shows the $\log$ data patterns for various geologic features encountered.

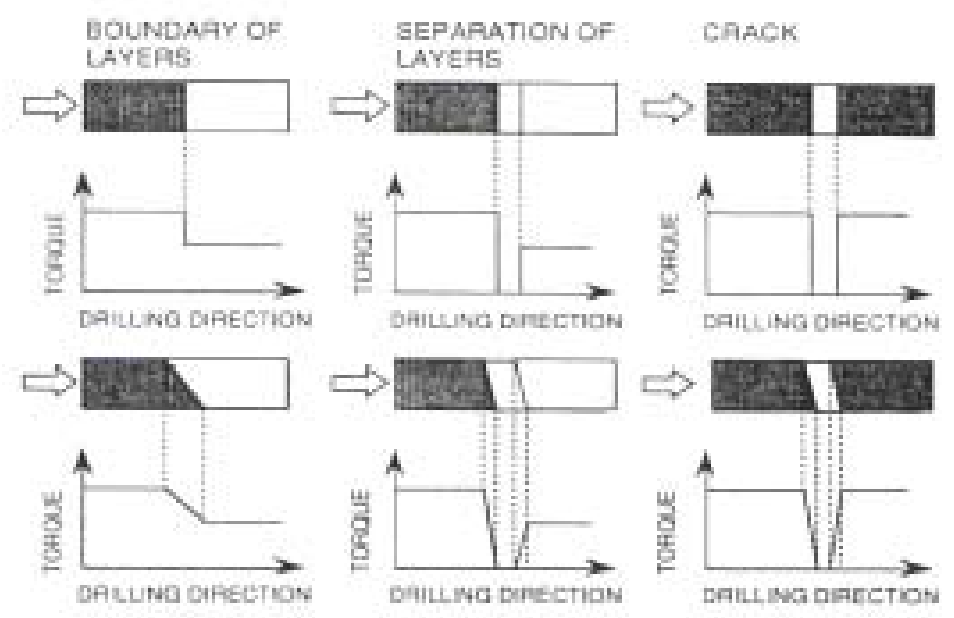

Figure 3.2 Torque patterns associated with geologic features

For underground tests, the patterns were classified using two types of neural network analysis methods. One type of neural network was used to roughly classify the drill data, while a second type of analysis was used to locate cracks and boundary layers. The neural network techniques 
make no distinction between a crack and a boundary between stratigraphic layers. In order to distinguish between cracks and boundaries, the authors average the value of torque/thrust between discontinuity locations. Successive averages are then compared. If the difference between two successive averages is greater than an unspecified threshold value, then the location is classified as a boundary; otherwise the location is classified as a crack.

The authors note that the drilling data predictions do not match core data very well. The difference between the core $\log$ and the drilling data is attributed to changes in the geologic structure over the distance of a few meters. However, the authors do not give any information on the proximity of the core hole to the actual drill hole. Thus, it is difficult to even speculate the level of accuracy of this analysis method.

Visualization of Geostructure by Mechanical Data Logging of Rockbolt Drilling and Its Accuracy

Itakura et al., (2001) published a more detailed description of their research (6). This paper describes more underground testing of the data acquisition and analysis system and its application to a hydraulically powered machine. Additionally, the authors present more data to validate the predictions of their data analysis system, and show a 3-dimensional display of the mine roof geology using both drill data and core logs.

The data collection system is essentially the same as that used in previous research with the exception of sensors used specifically for a hydraulic machine. Additionally, drill data is analyzed using the same method of roughly classifying data with one type of neural network, refining predictions with another type of neural network, and then distinguishing between cracks and interfaces by comparing averaged torque/thrust. 
The authors validated their analysis methodology by comparing drilling data collected during core drilling with the actual rock cores produced from the core hole. The ratio of torque/thrust does correlate with the location of interfaces and cracks in some locations. However, overall, the drill data matches the core log only 60 percent of the time. The authors also estimate the accuracy of prediction locations is $+/-1.75$ inches.

\subsection{Applications and Limitation of Previous Research}

Significant effort has been expended in research to correlate drilling parameters with the properties of material being drilled. However, to date, no system exists that can reliably correlate these two factors. Yet, many of these research projects have contributed significantly to the general understanding of the rotary drilling process. Furthermore, many of the empirical and theoretical relationships developed in this study could prove very useful in development of an effective prediction system

Teale's research (1964) on specific energy of drilling is likely the most widely cited research on correlation of drill parameters with physical properties of drilled material. However, it is highly unlikely that the specific energy of drilling theory can be applied to actual production drilling. Teale (1964) did show a good relationship between the minimum specific energy and the compressive strength of rock drilled. However, he also stated that actual drilling processes may or may not approach the theoretical minimum value. Actual production drilling in a mine likely deviates significantly from the theoretical minimum specific energy. Evidence of this deviation can be found by examining the dust collected during production roof bolter drilling. According to Teale's theory, the broken particle size should be relatively large when drilling at the minimum specific energy. Examination of the dust collected from production drilling 
machines shows a very small particles size. Grinding of the drilling particles to a small size likely causes the specific energy of drilling to be much greater than the theoretical minimum in a production environment.

West Virginia University's research on the variation of the pattern of drilling parameters (3) by itself is not likely to be useful in defining the locations of transitions between layers of differing strengths and transitions from fractures or voids to solid material. Two major factors limit the usefulness of these pattern definitions. First, these patterns were identified using laboratory drilling tests. The blocks used to simulate geologic conditions in these tests all contain sharp transitions from one layer to another or a sharp open fracture, depending on the condition the block was intended to simulate. In an actual mine environment, these transitions are likely to be significantly less clearly defined. Hence, the patterns observed in the laboratory tests may be significantly different from those observed in a mine. Additionally, the authors do not indicate the magnitude of change in the observed drilling parameters or the interval over which the patterns are observed. Therefore, there is little applicability in an actual prediction program.

The research results by Luo et al., on bit geometry, drilling efficiency, and strength prediction (4) potentially have numerous applications in an automated prediction system. Bit geometry is a very important factor in predicting geology using drilling parameters. Observation of drilling data indicates that both thrust and torque increase linearly with increased bite depth in a rock mass. This phenomenon can be explained and accounted for by applying corrections for bit geometry. As bite depth increases, both the normal and shear contact areas increase. These increased contact areas require increased drilling forces in order to maintain a steady-state drilling condition. Using empirical equations for normal and shear contact areas, it should be 
possible to normalize the drilling forces for a particular rock type regardless of the drill rates. Furthermore, bit wear can be accounted for by adding normal contact area to compensate for the worn areas of the carbide insert of the drill bit.

While beyond the scope of this project, the measured drilling efficiencies agree fairly well with Teale's theory. By combining the bit geometry with measured efficiencies, a researcher could determine what bite depth is most efficient in terms of drilling power and bit wear.

Results by Itakura on geologic mapping using drilling parameters are inconclusive. Many of the holes that were predicted using drilling parameters cannot be validated with core log information. However, analysis of data collected in this study shows that the ratio of torque/thrust is a good parameter to differentiate between rock types and locate discontinuities (fractures, voids, and weak zones). The actual implementation of the ratio of torque/thrust by the authors is somewhat questionable. The authors state "...the harder the rock, the higher averaged torque/thrust becomes." (6) Theoretically, this statement may not be true. For a given thrust, say $500 \mathrm{lbs}$, a particular bit will penetrate further into a soft rock than a hard rock. This deeper penetration into the soft rock could require a greater torque to cut, than the torque required to drill the hard rock. Thus, the ratio of torque/thrust would be higher for the soft rock. Data from laboratory experiments confirms this suggestion. 


\section{CHAPTER 4}

\section{SCOPE AND METHODS OF RESEARCH}

This research project encompasses both underground and laboratory tests of the drill and data collection system. Initial tests were conducted in a laboratory setting using manufactured blocks that simulate underground geologic conditions. These tests were used to develop data analysis methodologies. The initial laboratory tests were followed by a series of underground tests designed to validate analysis methodologies, and test their applicability in a mine setting. Finally, underground tests were followed by another series of laboratory tests to further refine data analysis methods and test new procedures developed underground.

All drilling test were conducted with a J.H. Fletcher model HDDR twin-boom roof bolter (Figure 4.1) fitted with a dedicated control and data collection microprocessor unit.

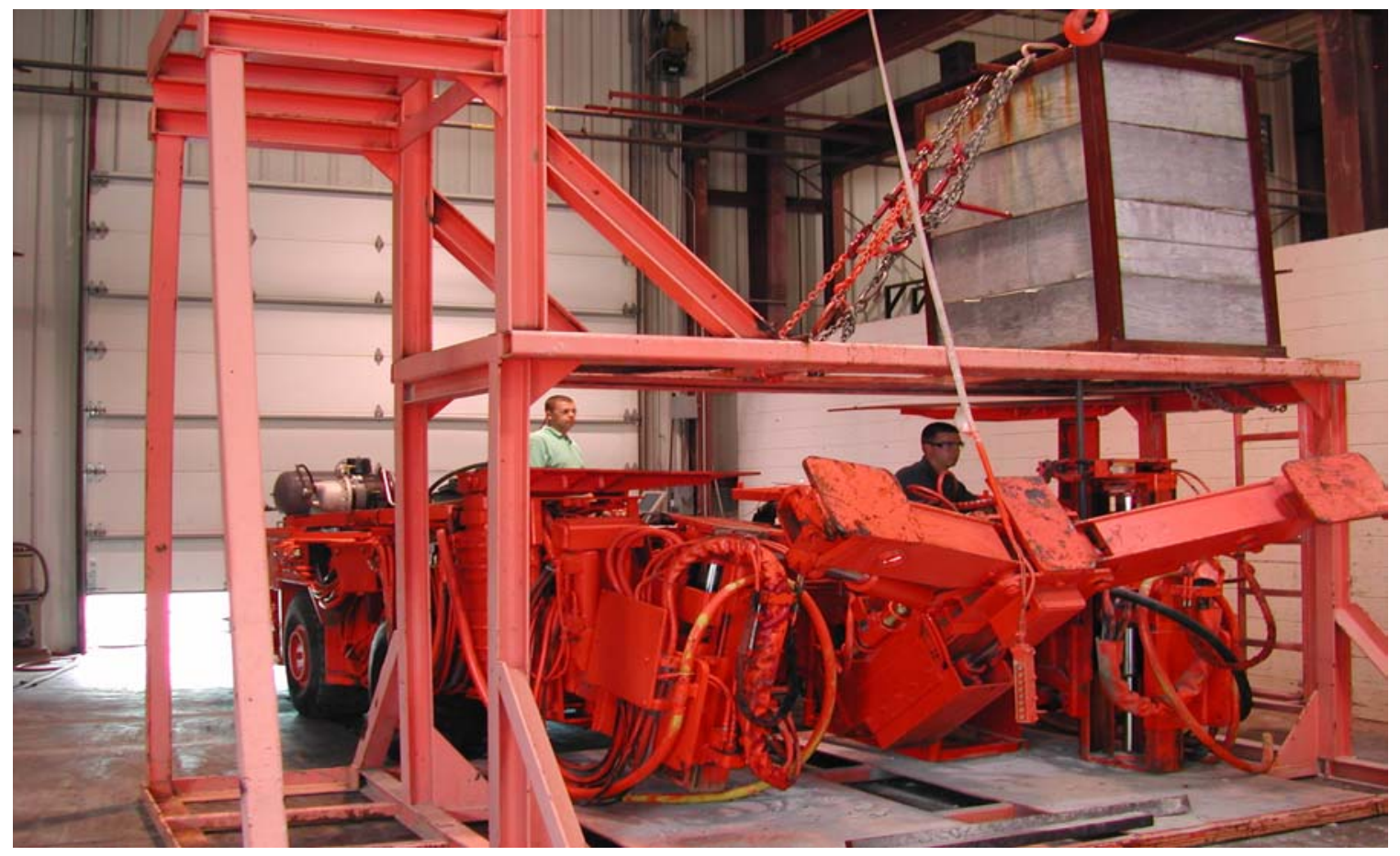

Figure 4.1 J.H. Fletcher \& Co. HDDR Roof Bolter Used in Drilling Experiments 
The microprocessor controls the drilling operation and samples data for off-line analysis (Figure 4.2). The control system is capable of independent control of penetration and rotation rates, or control using a proprietary relationship between thrust and rotation rate. The maximum penetration rate is approximately $5.1 \mathrm{in} / \mathrm{sec}$ and the maximum rotation rate is 700 revolutions per minute.

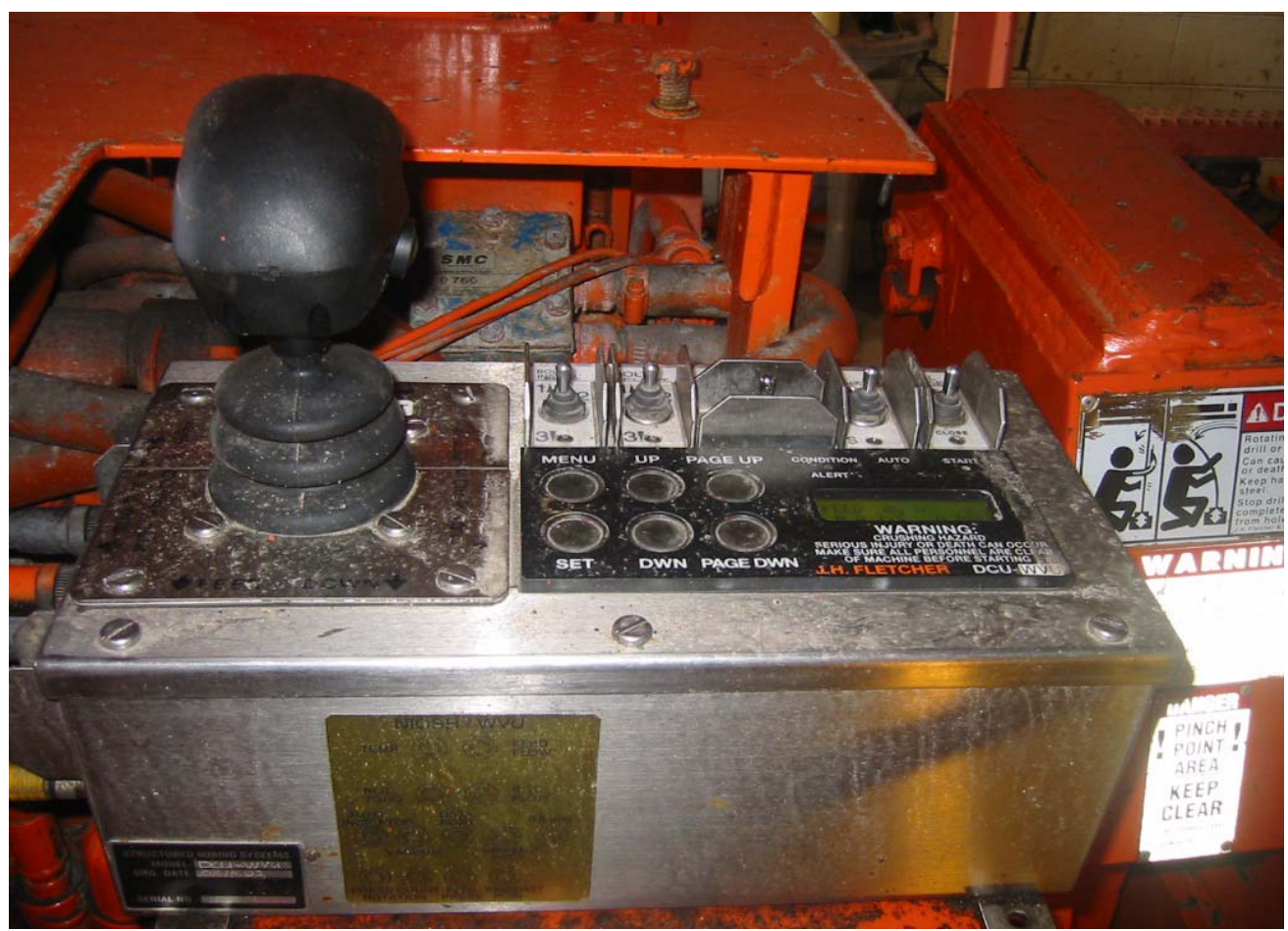

Figure 4.2 Drill Control Unit Used in the Research

Other parameters, such as torque and thrust are not controlled by the processor, but influenced by the strength of material drilled. The maximum achievable thrust is about $10,000 \mathrm{lbs}$, but is normally capped by the operator for safety reasons. The machine is capable of supplying torque up to $350 \mathrm{ft}-\mathrm{lbs}$.

In addition to control of the drill, the DCU samples 17 drilling parameters every 100 milliseconds. Of the 17 parameters, only 5 are used for analysis of roof strata. These parameters are: 
- bit position in

- thrust lbs

- torque in-lbs

- penetration rate in/sec

- rotation rate $\mathrm{rev} / \mathrm{min}$

Data is collected using an array of sensors on the roof bolter. The sensors output scaled values of electrical voltage to the data collection system; these values are then transferred to and stored in ASCII data files using a laptop computer connected to the DCU. The scaled values are then converted to the respective units for each of the parameters using conversion factors supplied by J.H. Fletcher \& Co. Position is determined directly using two position sensors: one on the drill mast, and one on the drill head. Thrust is measured directly using a pressure transducer inside the hydraulic cylinder of the drill mast. Torque is determined by measuring the pressure and flow rate to the hydraulic motor and conversion factors supplied by the motor manufacturer. Penetration rate is measured indirectly using the flow rate to the hydraulic cylinder. Rotation rate is measured directly using a tachometer connected to the drill motor. Other parameters collected using this system are not used in this study

Consumable drilling materials typically used in underground coal mines were used in this project. Consumable materials include drill bits and drill steels. Two sizes of bits were used for this study: 1 3/8" and 1 1/32" (Figure 4.3). 


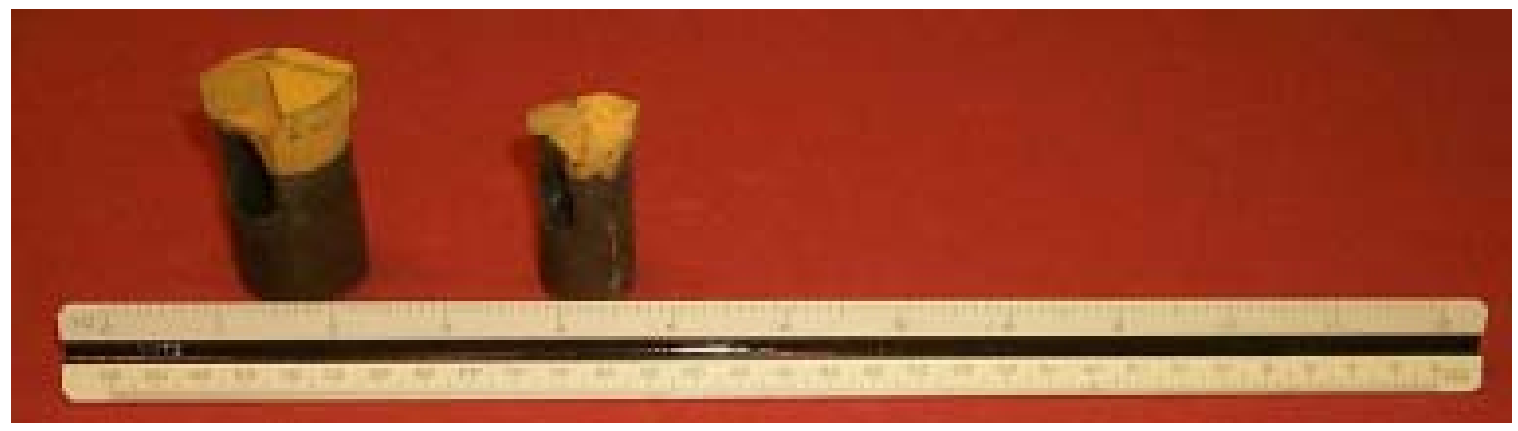

Figure 4.3 Drill Bits Used for Drilling Tests

These sizes are typically used in the coal mining industry for bolt hole drilling. Standard hollow hexagonal drill steels were used to connect the drill bits to the drill head. Drill steels are attached to the bits using a coupler and metal clip; a collar in the drill head accepts the drill steels. These hollow steels allow dust collection using the roof bolter's vacuum dust removal system. Drill bits were changed after every hole in most drilling tests. Some tests involved drilling multiple holes with one bit to assess the effects of bit wear on the data.

\subsection{Simulated Blocks for Laboratory Tests}

All laboratory tests were conducted at J.H. Fletcher's manufacturing facility in Huntington, WV. This facility has a large test stand under which a roof bolter can be parked and drill tests performed. Three types of blocks were used in laboratory tests to simulate various geological conditions. A solid concrete block was used to collect drilling data from a homogeneous medium. A manufactured fracture block containing three sizes of fractures and two layer blocks simulating various bedded strata were drilled to assess their effects on the drill data. 


\subsubsection{Homogeneous Block}

Figure 4.4 shows a schematic of the solid concrete block. This block was constructed to simulate a massive homogeneous material such as a sandstone or limestone layer. Drilling tests conducted on this block were primarily performed to understand the operational characteristics of the roof bolter in a uniform material.

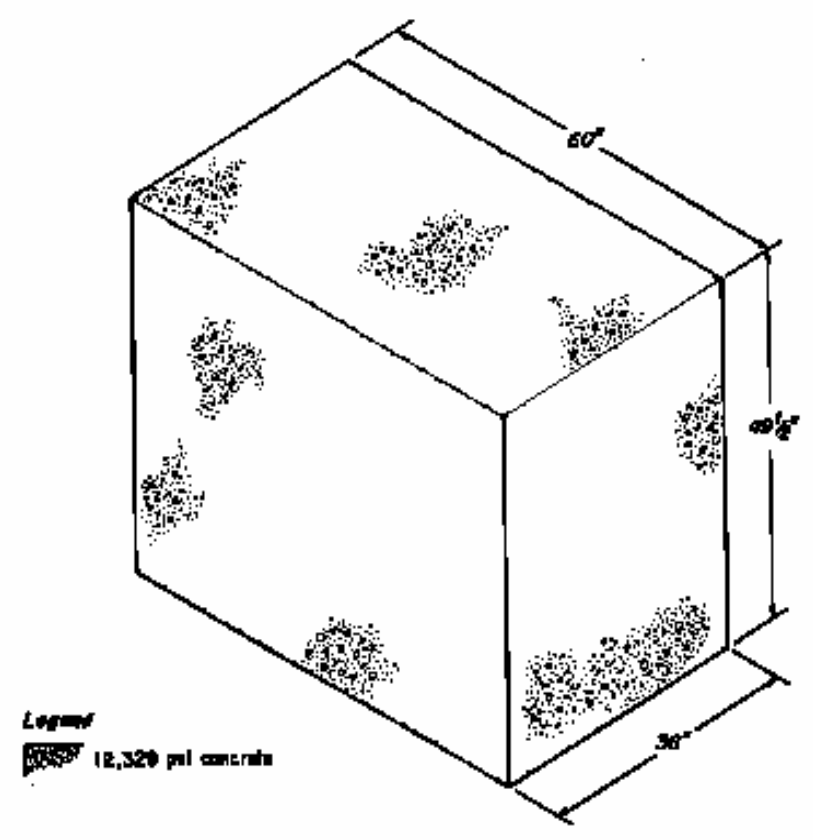

Figure 4.4 Solid Concrete Block

\subsubsection{Simulated Fracture Block}

Small fractures were simulated by stacking 15 -inch blocks of concrete separated by wooden spacers of varying thickness. Figure 4.5 shows a schematic of the constructed fracture block. 


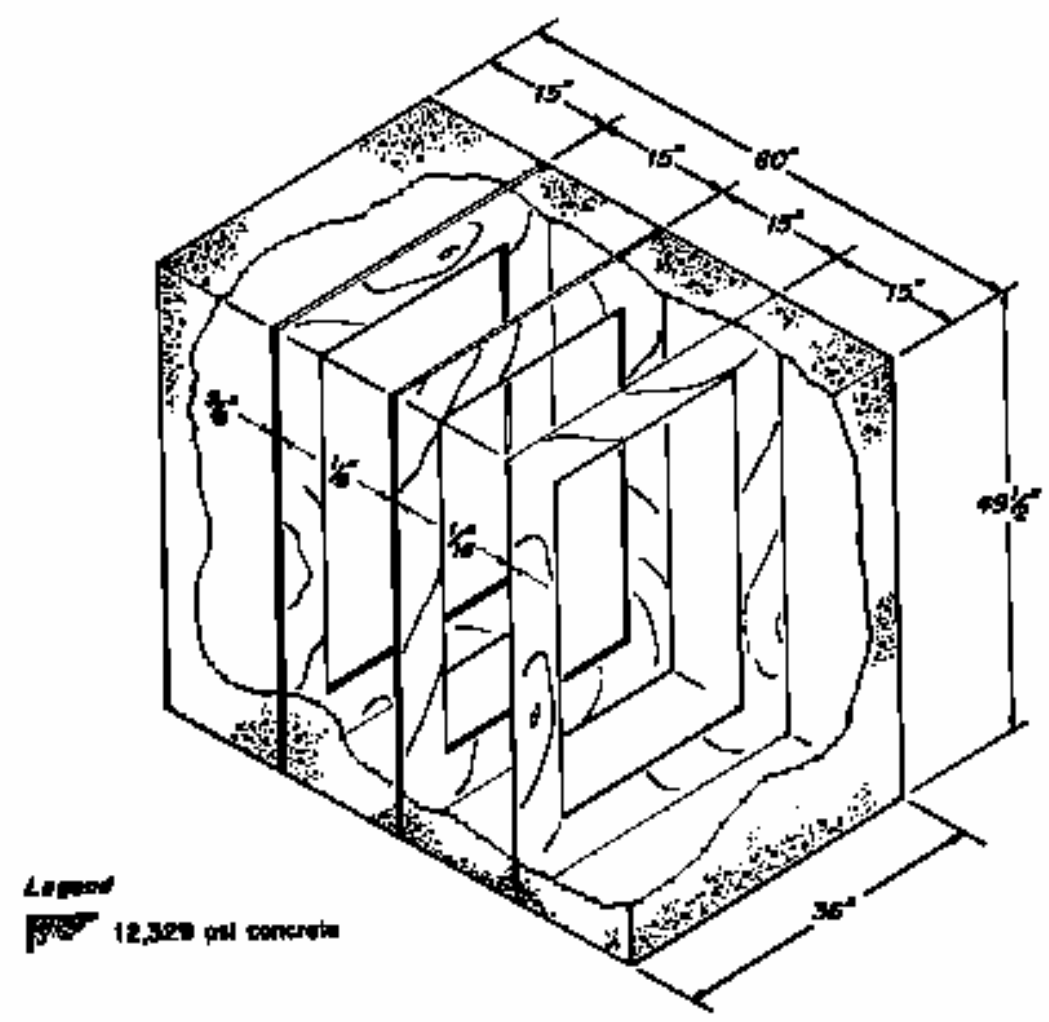

Figure 4.5 Simulated Fracture Block

Three different sizes of fractures were simulated to determine the ability for the system to locate the fracture. The first fracture to be intercepted was 1/16 inch wide; the second fracture was $1 / 8$ inch wide; and the third fracture was $3 / 8$ inch wide.

\section{$\underline{\text { 4.1.3 Simulated Layer Blocks }}$}

Six manufactured layer blocks were constructed for this research project. However, only two manufactured layer blocks (blocks 5 and 6) were drilled in this study. Figures 4.6 and 4.7 show schematics of the layer blocks. 


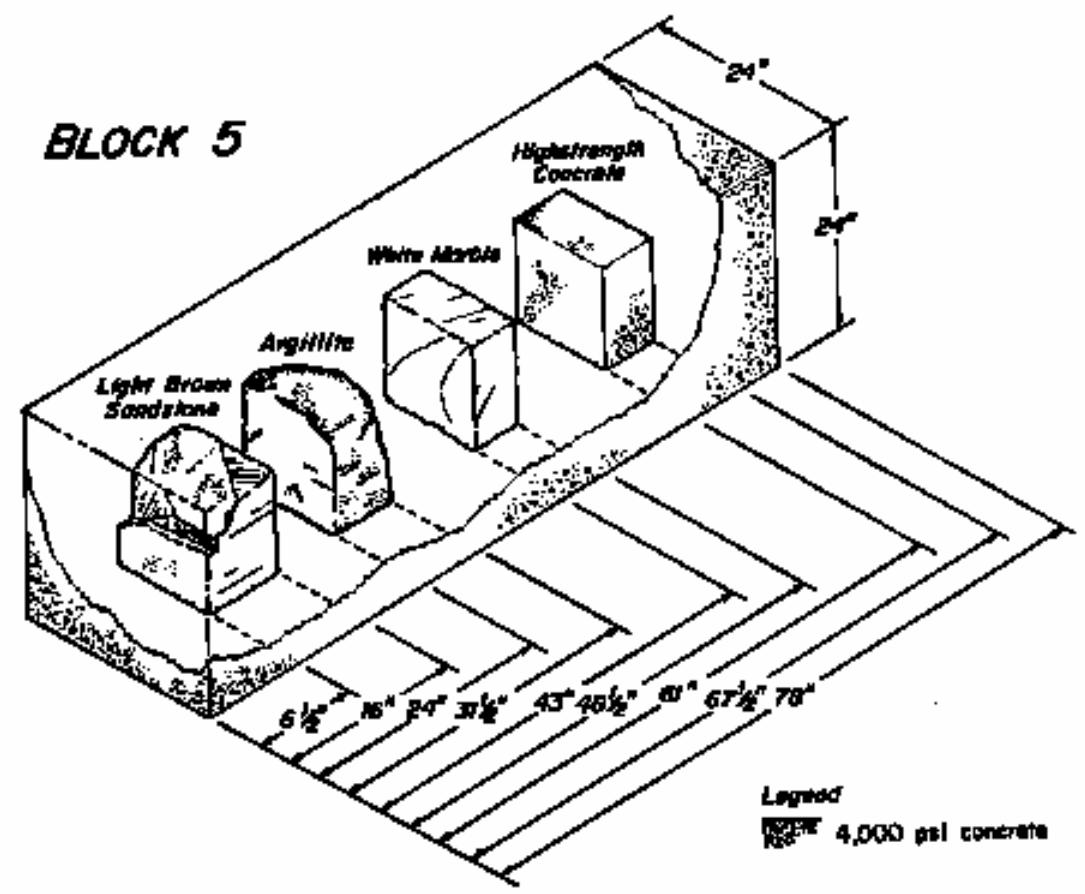

Figure 4.6 Layer Block 5

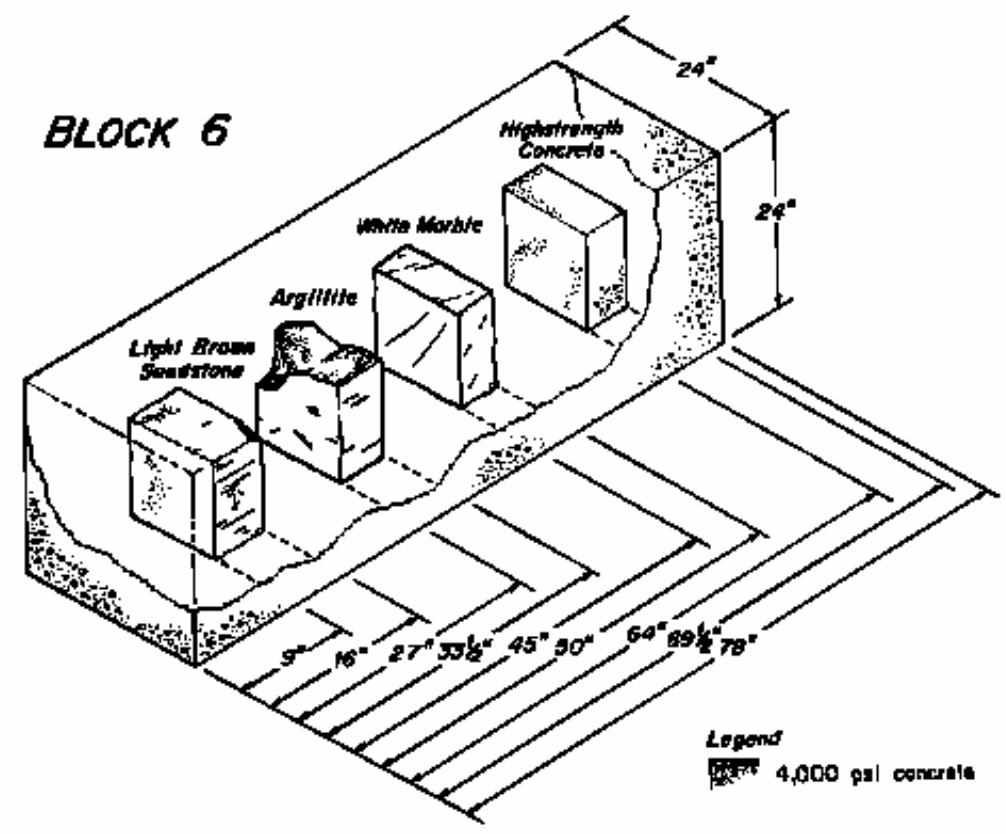

Figure 4.7 Layer Block 6 
The blocks were constructed by embedding various samples of rock in low-strength concrete. Each block contained four rock layers separated by the embedding concrete. Both blocks had a total of nine layers including the concrete. However, not all holes were drilled a sufficient length to intercept all nine layers. All rock layers and concrete were tested according to ASTM standards to determine uniaxial compressive strengths and tensile strengths of the respective units. In some cases there were an insufficient number of samples collected to perform all the physical property tests. Table 4.1 shows the tested physical properties of the layer block materials. For the drilling tests, the blocks were drilled along their long axis in order to intercept the layers at right angles

Table 4.1 Physical Properties of Layer Block Materials

\begin{tabular}{|l|c|c|c|c|c|}
\hline \multicolumn{1}{|c|}{ Rock Type } & $\begin{array}{c}\text { Unconfined } \\
\text { Compressive } \\
\text { Strength, psi }\end{array}$ & $\begin{array}{c}\text { Tensile } \\
\text { Strength } \\
\text { (Brazillian), psi }\end{array}$ & $\begin{array}{c}\text { Shear } \\
\text { Strength, } \\
\text { psi }\end{array}$ & $\begin{array}{c}\text { Youngs' } \\
\text { Modulus, } \\
10^{6} \mathrm{psi}^{\prime}\end{array}$ & $\begin{array}{c}\text { Density, } \\
\text { lbs/ft }^{3}\end{array}$ \\
\hline Rod Sandstone & 6,986 & 1,053 & $\mathrm{~N} / \mathrm{A}$ & 2.77 & 149 \\
\hline Brown Sandstone & 17,104 & 930 & $\mathrm{~N} / \mathrm{A}$ & 1,94 & 160 \\
\hline Lt Brown Sandstone & 27,359 & 1,934 & 2,846 & 2.34 & 155 \\
\hline White Marble & 17,418 & 1,371 & 1,010 & 2.48 & 166 \\
\hline Argillite & 20,473 & 1,044 & 1,395 & 4.24 & 168 \\
\hline Soft Concrete & 2,864 & $\mathrm{~N} / \mathrm{A}$ & $\mathrm{N} / \mathrm{A}$ & $\mathrm{N} / \mathrm{A}$ & $\mathrm{N} / \mathrm{A}$ \\
\hline Embedding Concrete & 4,021 & 474 & $\mathrm{~N} / \mathrm{A}$ & 0.65 & 132 \\
\hline High-strength Concrete & 12,340 & 430 & $\mathrm{~N} / \mathrm{A}$ & 2.07 & 159 \\
\hline
\end{tabular}

$\mathrm{N} / \mathrm{A}=$ Not Available

\subsection{Experimental Design of Phase 1 Laboratory Tests}

Two phases of laboratory tests were conducted in this study. The first phase involved using a large range of pre-set drilling parameters in various blocks. The purpose of the first phase of tests was to understand the behavior of the drill system when encountering various simulated features. Additionally, test plans were developed to determine what type of pre-set 
control scheme provided the most useful data. The second phase of laboratory tests was conducted after four underground tests. The purpose of the second phase of laboratory tests was to obtain easily verifiable laboratory drilling data using pre-set control programs developed in an underground setting. Furthermore, the second phase laboratory data was used to enhance previously developed data analysis techniques.

\subsubsection{Experimental Approach of Phase 1 Laboratory Experiments}

Table 4.2 shows the pre-set drilling parameters for tests on the solid concrete block. Most settings were pre-set to values typically used in a production mine environment.

Table 4.2 Pre-Set Drilling Parameters-Solid Concrete Block, Gray Cells Indicate unusable data

\begin{tabular}{|c|c|c|c|c|c|}
\hline \multirow[b]{2}{*}{ Hole } & \multirow[b]{2}{*}{ Diameter } & \multicolumn{3}{|l|}{ Settings } & \multirow[b]{2}{*}{ Date Drilled } \\
\hline & & P.R. & RPM & Thrust & \\
\hline 1 & 1.375 & 1.1 & 300 & 4851 & $8 / 30 / 2001$ \\
\hline 2 & 1.375 & 1.5 & 400 & 4851 & $8 / 30 / 2001$ \\
\hline 3 & 1.375 & 1.9 & 400 & 4851 & $8 / 30 / 2001$ \\
\hline 4 & 1.375 & 0.7 & 300 & 4851 & $8 / 30 / 2001$ \\
\hline 5 & 1.375 & 0.4 & 300 & 4851 & $8 / 30 / 2001$ \\
\hline 6 & 1.375 & 0.1 & 300 & 4851 & $8 / 30 / 2001$ \\
\hline 7 & 1.375 & 0.4 & 300 & 4851 & $8 / 30 / 2001$ \\
\hline 8 & 1.375 & 1.9 & 500 & 8000 & $8 / 30 / 2001$ \\
\hline 9 & 1.375 & 1.9 & 500 & 8000 & $8 / 30 / 2001$ \\
\hline 10 & 1.375 & 1.1 & 300 & 8000 & $8 / 30 / 2001$ \\
\hline 11 & 1.375 & 1.5 & 400 & 8000 & $8 / 30 / 2001$ \\
\hline 12 & 1.375 & 0.7 & 300 & 8000 & $8 / 30 / 2001$ \\
\hline 13 & 1.375 & 0.4 & 300 & 8000 & $8 / 30 / 2001$ \\
\hline 14 & 1.375 & 1.1 & 300 & 8000 & $8 / 31 / 2001$ \\
\hline 15 & 1.375 & 1.5 & 400 & 8000 & $8 / 31 / 2001$ \\
\hline 16 & 1.375 & 1.9 & 500 & 8000 & $8 / 31 / 2001$ \\
\hline 17 & 1.375 & 0.8 & 300 & 8000 & $8 / 31 / 2001$ \\
\hline 18 & 1.375 & 0.4 & 300 & 8000 & $8 / 31 / 2001$ \\
\hline 19 & 1.375 & 0.6 & 300 & 8000 & $8 / 31 / 2001$ \\
\hline 20 & 1.375 & 0.8 & 400 & 8000 & $8 / 31 / 2001$ \\
\hline 21 & 1.375 & 1.1 & 500 & 8000 & $8 / 31 / 2001$ \\
\hline 22 & 1.375 & 1.3 & 600 & 8000 & $8 / 31 / 2001$ \\
\hline 23 & 1.031 & 0.8 & 300 & 8000 & $8 / 31 / 2001$ \\
\hline 24 & 1.031 & 1.1 & 400 & 8000 & $8 / 31 / 2001$ \\
\hline 25 & 1.031 & 1.3 & 500 & 8000 & $8 / 31 / 2001$ \\
\hline 26 & 1.031 & 1.5 & 600 & 8000 & $8 / 31 / 2001$ \\
\hline
\end{tabular}




\begin{tabular}{|r|r|r|r|r|r|}
\hline 27 & 1.375 & 1.1 & 300 & 5000 & $11 / 20 / 2001$ \\
\hline 28 & 1.375 & 1.1 & 500 & 5000 & $11 / 20 / 2001$ \\
\hline 29 & 1.375 & 1.1 & 300 & 6500 & $11 / 20 / 2001$ \\
\hline 30 & 1.375 & 1.1 & 500 & 6500 & $11 / 20 / 2001$ \\
\hline 31 & 1.375 & 1.1 & 300 & 8000 & $11 / 20 / 2001$ \\
\hline 32 & 1.375 & 1.1 & 500 & 8000 & $11 / 20 / 2001$ \\
\hline 33 & 1.031 & 1.1 & 300 & 4000 & $11 / 20 / 2001$ \\
\hline 34 & 1.031 & 1.1 & 500 & 4000 & $11 / 20 / 2001$ \\
\hline 35 & 1.031 & 1.1 & 300 & 5000 & $11 / 20 / 2001$ \\
\hline 36 & 1.031 & 1.1 & 500 & 5000 & $11 / 20 / 2001$ \\
\hline 37 & 1.031 & 1.1 & 300 & 6000 & $11 / 20 / 2001$ \\
\hline 38 & 1.031 & 1.1 & 500 & 6000 & $11 / 20 / 2001$ \\
\hline
\end{tabular}

Penetration rates were varied between $0.4 \mathrm{in} / \mathrm{sec}$ (the minimum value allowed by the DCU) to $1.9 \mathrm{in} / \mathrm{sec}$. These values represent the approximate range of consistently achievable penetration rates. For most geologic materials, the roof bolter is not capable of consistently drilling at a penetration rate greater than $1.5 \mathrm{in} / \mathrm{sec}$. Rotation rates were varied from $300 \mathrm{rpm}$ to $600 \mathrm{rpm}$. $300 \mathrm{rpm}$ is approximately the minimum rotation rate that can be used without excessive clogging of the dust collection system. In most cases, higher rotation rates of 500 and $600 \mathrm{rpm}$ were used only with penetration rates of 1.5 and $1.9 \mathrm{in} / \mathrm{sec}$. These rotation rates were used to lessen the chances of clogging the dust collection system. Of the 38 holes drilled on this block, 26 holes were unable to be analyzed. A malfunctioning thrust sensor outputted grossly erroneous values to the data file. Table 4.3 shows the pre-set drilling parameters for drilling tests on the simulated fracture block.

Table 4.3: Pre-Set Drilling Parameters-Fracture Concrete Block

\begin{tabular}{|c|c|c|c|c|c|}
\hline & & \multicolumn{3}{|c|}{ Settings } & \\
\cline { 3 - 6 } Hole & Diameter & P.R. & RPM & Thrust & Date Drilled \\
\hline 1 & 1.031 & 0.4 & 300 & 6000 & $10 / 17 / 2001$ \\
\hline 2 & 1.031 & 0.8 & 300 & 6000 & $10 / 17 / 2001$ \\
\hline 3 & 1.031 & 1.5 & 300 & 6000 & $10 / 17 / 2001$ \\
\hline 4 & 1.031 & 0.4 & 400 & 6000 & $10 / 17 / 2001$ \\
\hline 5 & 1.031 & 0.8 & 450 & 6000 & $10 / 17 / 2001$ \\
\hline 6 & 1.031 & 1.5 & 500 & 6000 & $10 / 17 / 2001$ \\
\hline 7 & 1.031 & 1.5 & 300 & 4000 & $10 / 17 / 2001$ \\
\hline
\end{tabular}


Penetration rates were varied from 0.4 to $1.5 \mathrm{in} / \mathrm{sec}$ in these tests. Data from previous drill tests in the solid concrete block indicated that penetration rates above $1.5 \mathrm{in} / \mathrm{sec}$ could not be achieved consistently. Thus for these experiments, and most subsequent experiments, the maximum penetration rate tested was $1.5 \mathrm{in} / \mathrm{sec}$.

Pre-set drilling parameters for Layer Block 6 are shown in Table 4.4. For these tests, two new control methodologies were tested. Each methodology involved controlling only one drilling parameter, and setting the other parameter to its maximum possible value in the DCU. A maximized parameter is indicated by the word "Free" in Table 4.4

Table 4.4: Pre-Set Drilling Parameters-Layer Block 6

\begin{tabular}{|c|c|c|c|c|c|}
\hline & & \multicolumn{3}{|c|}{ Settings } & Date Drilled \\
\cline { 3 - 6 } Hole & Diameter & P.R. & RPM & Thrust & $1 / 16 / 2002$ \\
\hline 1 & 1.031 & 1.1 & 300 & 5000 & $1 / 16 / 2002$ \\
\hline 2 & 1.031 & 1.5 & 300 & 5000 & $1 / 16 / 2002$ \\
\hline 3 & 1.375 & 1.5 & 300 & 8000 & $1 / 16 / 2002$ \\
\hline 4 & 1.375 & 1.5 & 300 & 8000 & $1 / 16 / 2002$ \\
\hline 5 & 1.375 & 1.5 & 300 & 8000 & $1 / 16 / 2002$ \\
\hline 6 & 1.375 & 1.1 & 300 & 8000 & $1 / 16 / 2002$ \\
\hline 7 & 1.375 & 1.1 & Free & 7000 & $1 / 16 / 2002$ \\
\hline 8 & 1.375 & 0.6 & Free & 7000 & $1 / 16 / 2002$ \\
\hline 9 & 1.375 & Free & 400 & 7000 & $1 / 16 / 2002$ \\
\hline 10 & 1.375 & Free & 500 & 7000 & $3 / 20 / 2002$ \\
\hline 11 & 1.375 & Free & 400 & 7000 & $3 / 20 / 2002$ \\
\hline 12 & 1.375 & Free & 500 & 7000 & $3 / 20 / 2002$ \\
\hline 13 & 1.031 & Free & 400 & 7000 & $3 / 20 / 2002$ \\
\hline 14 & 1.375 & Free & 500 & 7000 & $3 / 20 / 2002$ \\
\hline 15 & 1.375 & Free & 500 & 7000 & \\
\hline
\end{tabular}

The two new control methods were developed in an attempt to eliminate some of the control system's influence on the drilling data. When the operator inputs a pre-set penetration or rotation rate, the DCU will continuously adjust hydraulic flow to the respective component in order to maintain drilling at the pre-set value. A parameter is in a "Free" setting when the operator pre-sets the parameter to its maximum value. The maximum numerical values for 
penetration and rotation rates are unachievable when drilling coal measure geologic materials. Therefore, when a particular parameter is maximized, the DCU supplies the maximum available flow rate to the component, thus eliminating any control influence on the data.

\subsection{Experimental Design of Underground Tests}

Four mine sites were selected for testing of the drilling system in this research project. All underground tests were conducted after completion of the first phase of laboratory tests. For each mine site, an attempt was made to drill in an area where the mine roof was known to consist of more than one rock type within the first 60 inches above the roofline. Since roof geology can change significantly, even over a distance of a few feet, two methods of validation were used to define the in-situ geological conditions of a drill hole or drill site. Core drilling was used to define the geology of a particular test site. Bolt hole scoping was used to define the geology of an individual drill hole.

\subsubsection{Core Drilling}

A number of core samples were collected at each mine site. These cores were used to determine the roof geology of a test area, and to collect samples of the roof rock for physical property testing. Cores were collected using a core barrel with diamond bit (Figure 4.8). Water was used to flush cuttings from the core barrel and to cool the drill bit. The diameter of cores collected from the barrel was 2 inches. 


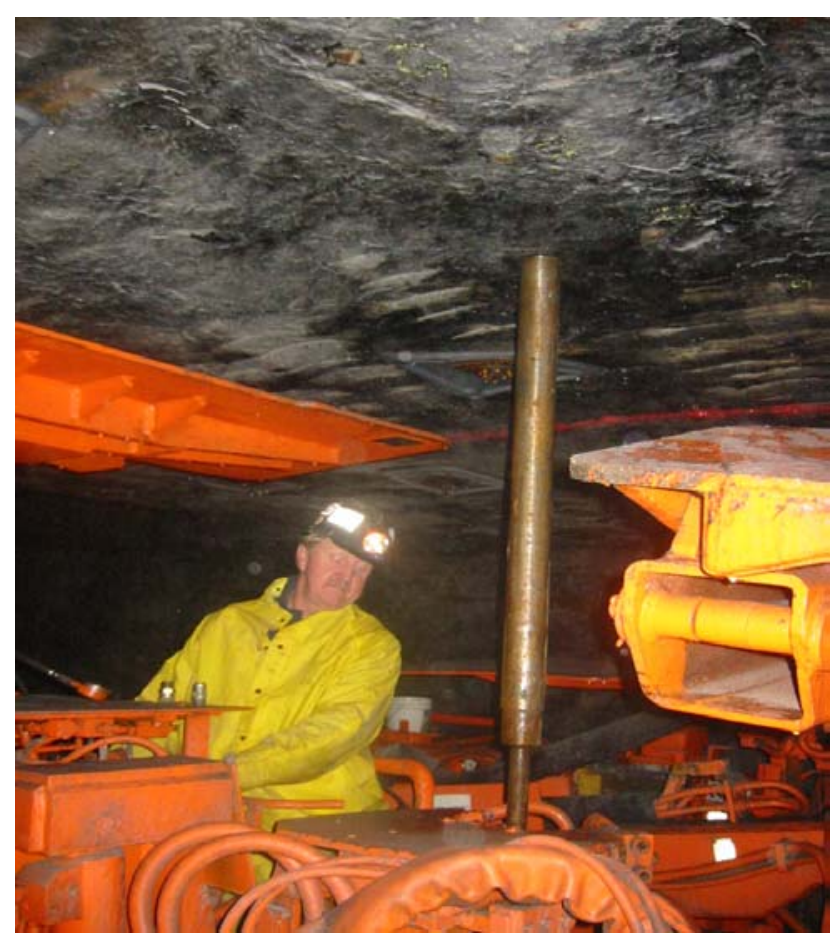

Figure 4.8 Core Drilling

Cores were collected from the barrel, identified, and placed in core boxes for future testing. Finally, after completing a core hole, a log was constructed to identify the geology collected in a test area.

\subsubsection{Bore Hole Scoping}

Although core drilling can be used to define the geology of a test area or group of holes, geology can often change over a distance of a few feet. Thus, drilling data predictions may not match a core log for a given area. Additionally, the process of collecting rock cores from the mine roof is very time consuming. Bore hole scoping allows researchers to visually examine the geology of drill hole from which data is collected. Hence, errors due to the drill data collection hole being drilled some distance from the core hole are eliminated. The bore hole scope consists of four major components as shown in Figure 4.9. 


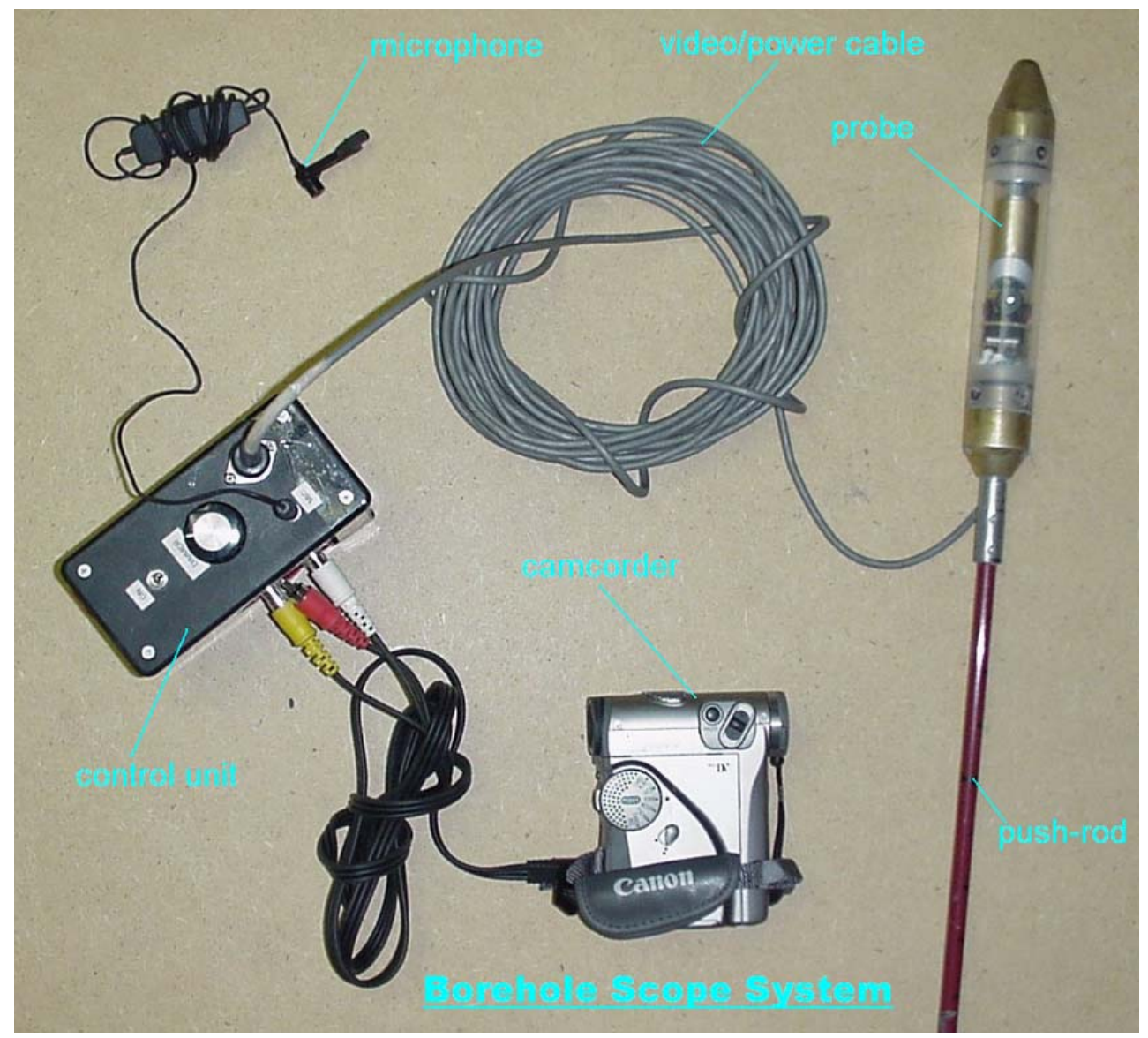

Figure 4.9 Borehole Scope System

The probe of the borehole scope contains a camera, light, and mirror system that allows observation of the wall of the bore hole. The control unit allows the user to adjust the brightness of the light, and has a microphone jack for narration. The digital camcorder records the audio and video data to a tape for subsequent viewing and analysis of the data. A tripod mounting system was developed in this project (Figure 4.10). 


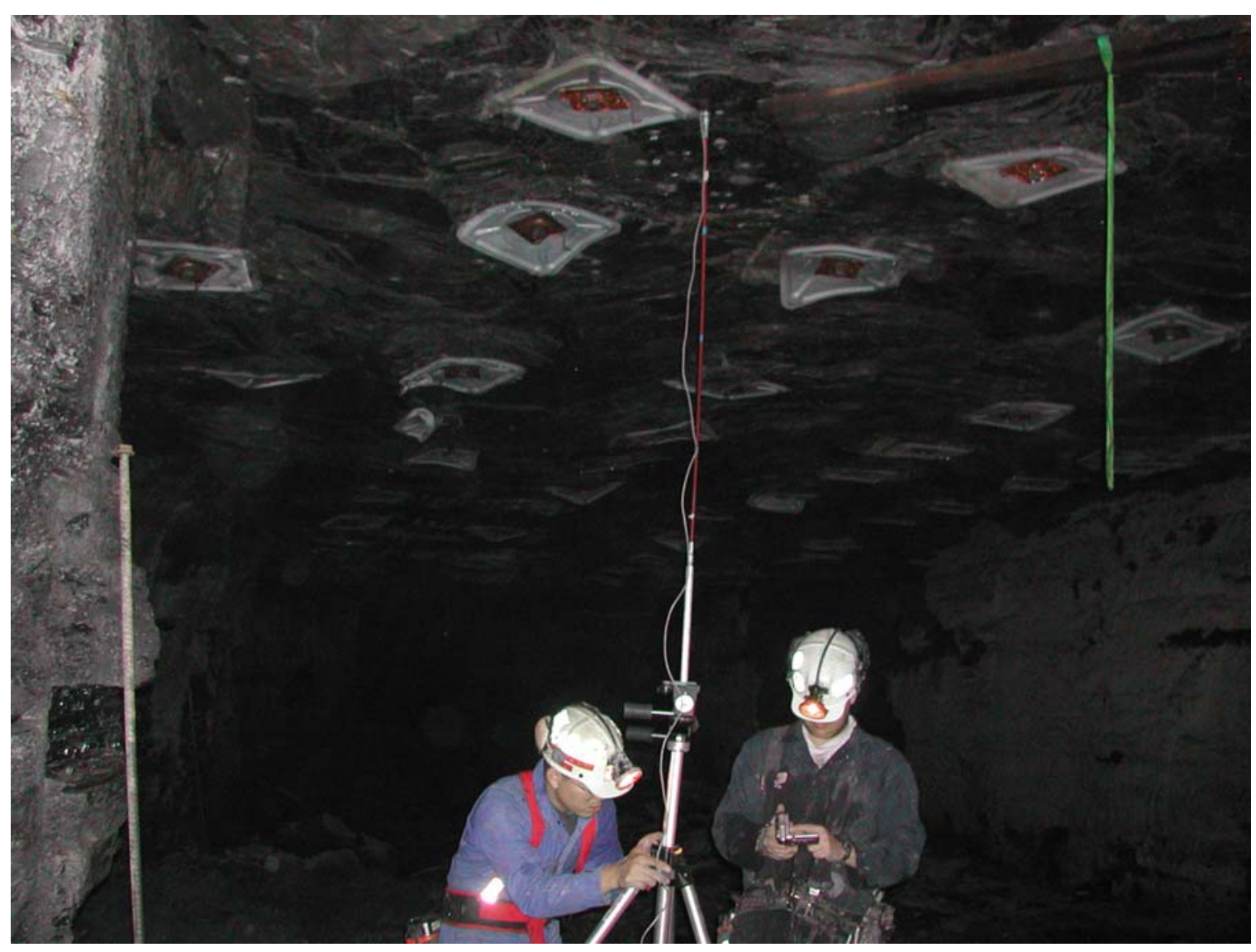

Figure 4.10 Tripod Mount for Borehole Scope

The tripod mount allows for more accurate distance readings from the scope. The tripod also allows the scope to be held in a stable position while observing features in the borehole. When possible, drilling data in this project was validated with logs from the borehole scope.

\section{$\underline{\text { 4.3.3 Mine A Underground Tests }}$}

Mine A was an underground room and pillar mine located in eastern Kentucky. The roof of this mine consisted of approximately 20-30 inches of shale overlain by a sandstone member. However, no reliable source of validation exists for this mine site. The core drilling apparatus was broken during its first use, and reliable borehole scoping methods had not been developed at this point in the study. Table 4.5 shows the pre-set drilling parameters for these tests. 
Table 4.5: Pre-Set Drilling Parameters-Mine A

\begin{tabular}{|c|c|c|c|c|c|}
\hline \multirow[b]{2}{*}{ Hole } & \multirow[b]{2}{*}{ Diameter } & \multicolumn{3}{|c|}{ Settings } & \multirow[b]{2}{*}{ Date Drilled } \\
\hline & & P.R. & RPM & Thrust & \\
\hline 1 & 1.031 & 1.1 & 300 & 5600 & $5 / 20 / 2002$ \\
\hline 2 & 1.031 & 1.1 & 300 & 5600 & $5 / 20 / 2002$ \\
\hline 3 & 1.031 & 0.8 & 300 & 5600 & $5 / 20 / 2002$ \\
\hline 4 & 1.031 & 0.8 & 300 & 5600 & $5 / 20 / 2002$ \\
\hline 5 & 1.031 & 0.8 & 500 & 5600 & $5 / 20 / 2002$ \\
\hline 6 & 1.031 & 0.8 & 500 & 5600 & $5 / 20 / 2002$ \\
\hline 7 & 1.031 & 1.1 & 500 & 5600 & $5 / 20 / 2002$ \\
\hline 8 & 1.031 & 1.1 & 500 & 5600 & $5 / 20 / 2002$ \\
\hline 9 & 1.031 & Free & 400 & 4550 & $5 / 20 / 2002$ \\
\hline 10 & 1.031 & Free & 400 & 2800 & $5 / 20 / 2002$ \\
\hline 11 & 1.031 & Free & 400 & 2800 & $5 / 20 / 2002$ \\
\hline 12 & 1.031 & Free & 500 & 2800 & $5 / 20 / 2002$ \\
\hline 13 & 1.031 & Free & 500 & 2800 & $5 / 20 / 2002$ \\
\hline 14 & 1.031 & 1.1 & Free & 2800 & $5 / 20 / 2002$ \\
\hline 15 & 1.031 & 1.1 & Free & 2800 & $5 / 20 / 2002$ \\
\hline 16 & 1.031 & 0.8 & Free & 2800 & $5 / 20 / 2002$ \\
\hline 17 & 1.031 & 0.8 & Free & 2800 & $5 / 20 / 2002$ \\
\hline 18 & 1.375 & 0.8 & Free & 2800 & $5 / 20 / 2002$ \\
\hline 19 & 1.375 & 0.8 & Free & 2800 & $5 / 20 / 2002$ \\
\hline 20 & 1.375 & 1.1 & Free & 2800 & $5 / 20 / 2002$ \\
\hline 21 & 1.375 & 1.1 & Free & 2800 & $5 / 20 / 2002$ \\
\hline 22 & 1.375 & Free & 500 & 2800 & $5 / 20 / 2002$ \\
\hline 23 & 1.375 & Free & 500 & 2800 & $5 / 20 / 2002$ \\
\hline 24 & 1.375 & Free & 400 & 2800 & $5 / 20 / 2002$ \\
\hline 25 & 1.375 & Free & 400 & 2800 & $5 / 20 / 2002$ \\
\hline 26 & 1.375 & 1.1 & 400 & 2800 & $5 / 20 / 2002$ \\
\hline 27 & 1.375 & 1.1 & 400 & 2800 & $5 / 20 / 2002$ \\
\hline 28 & 1.375 & 0.8 & 400 & 2800 & $5 / 20 / 2002$ \\
\hline 29 & 1.375 & 0.8 & 400 & 2800 & $5 / 20 / 2002$ \\
\hline 30 & 1.375 & 1.1 & 500 & 2800 & $5 / 20 / 2002$ \\
\hline 31 & 1.375 & 1.1 & 500 & 2800 & $5 / 20 / 2002$ \\
\hline 32 & 1.375 & 0.8 & 500 & 2800 & $5 / 20 / 2002$ \\
\hline 33 & 1.375 & 0.8 & 500 & 2800 & $5 / 20 / 2002$ \\
\hline 34 & 1.031 & Free & 500 & 4550 & $5 / 28 / 2002$ \\
\hline 35 & 1.031 & Free & 500 & 4550 & $5 / 28 / 2002$ \\
\hline 36 & 1.031 & Free & 400 & 4550 & $5 / 28 / 2002$ \\
\hline 37 & 1.031 & Free & 400 & 4550 & $5 / 28 / 2002$ \\
\hline 38 & 1.031 & 1.1 & Free & 4550 & $5 / 28 / 2002$ \\
\hline 39 & 1.031 & 1.1 & Free & 4550 & $5 / 28 / 2002$ \\
\hline 40 & 1.031 & 0.8 & Free & 4550 & $5 / 28 / 2002$ \\
\hline 41 & 1.031 & 0.8 & Free & 4550 & $5 / 28 / 2002$ \\
\hline 42 & 1.375 & 0.8 & Free & 4550 & $5 / 28 / 2002$ \\
\hline 43 & 1.375 & 0.8 & Free & 4550 & $5 / 28 / 2002$ \\
\hline 44 & 1.375 & 1.1 & Free & 4550 & $5 / 28 / 2002$ \\
\hline
\end{tabular}




\begin{tabular}{|l|l|l|l|l|l|}
\hline 45 & 1.375 & 1.1 & Free & 4550 & $5 / 28 / 2002$ \\
\hline 46 & 1.375 & Free & 500 & 4550 & $5 / 28 / 2002$ \\
\hline 47 & 1.375 & Free & 500 & 4550 & $5 / 28 / 2002$ \\
\hline 48 & 1.375 & Free & 400 & 4550 & $5 / 28 / 2002$ \\
\hline 49 & 1.375 & Free & 400 & 4550 & $5 / 28 / 2002$ \\
\hline
\end{tabular}

For this mine site, a wide variety of pre-set drilling parameters were tested. Simultaneous penetration and rotation control schemes developed in the laboratory were tested. In this case, the penetration rate ranged from a minimum of $0.8 \mathrm{in} / \mathrm{sec}$ to a maximum of $1.1 \mathrm{in} / \mathrm{sec}$. Rotation rates ranged from 300 to 500 revolutions per minute. Additionally, penetration-only and rotation-only control schemes were tested. For penetration-only control, rates of 0.8 and 1.1 in/sec were tested. Rotation rates of 400 and 500 revolutions per minute were tested for rotation only control. The first day of testing produced unusable data as indicated by the gray areas of Table 4.5. In this case, a malfunctioning torque sensor outputted values of zero torque to the data file. The sensor was replaced and tests were conducted using the penetration-only and rotation-only control schemes.

\subsubsection{Mine B Underground Tests}

Mine B was a room and pillar coal mine in southern West Virginia. This mine operated in the Coalburg seam. A diagram of the test area is shown in Figure 4.11. 


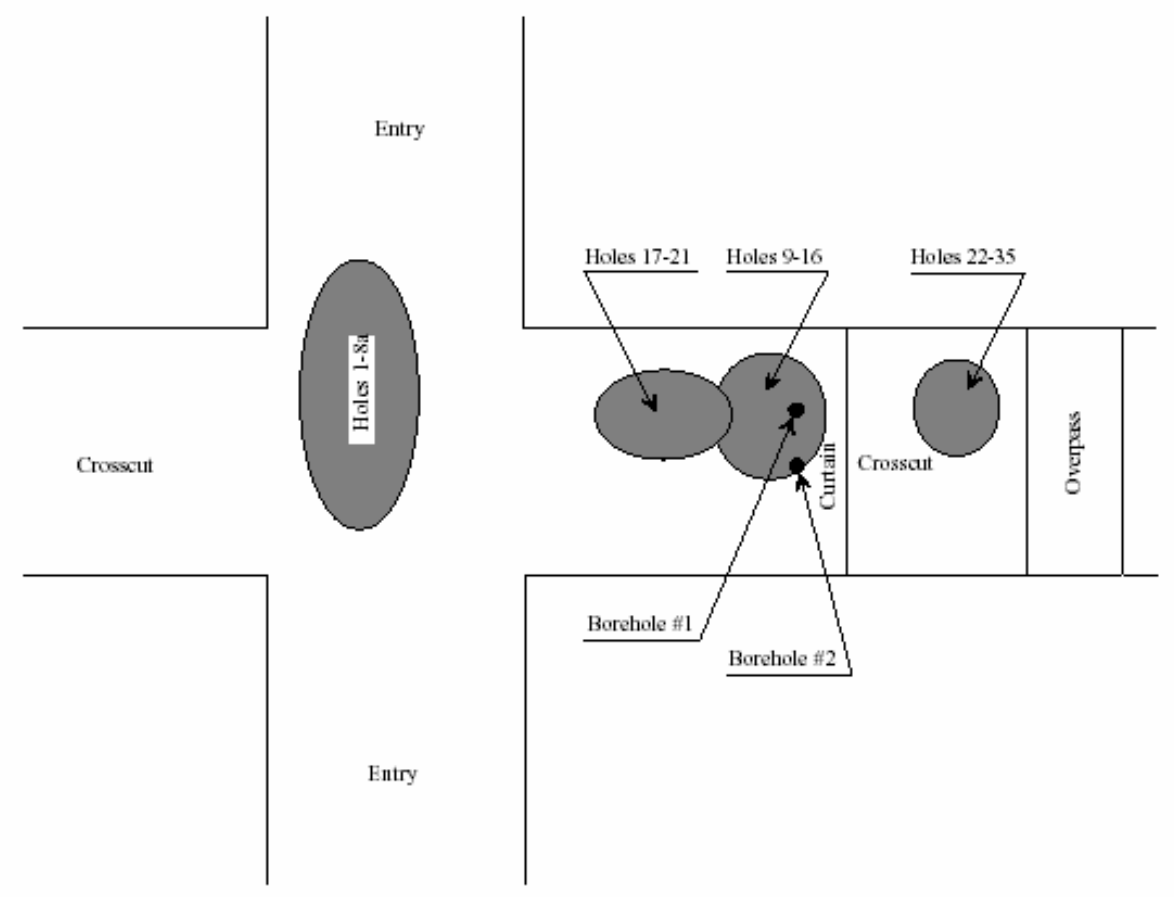

Figure 4.11 Diagram of Mine B Test Site

During the period between testing at Mine A and Mine B, the core drill system was repaired and borehole scoping methods were developed and refined. Two core holes were drilled in the mine. However, only one core was successfully recovered and logged. Figure 4.12 shows the core log developed from rock cores obtained in this mine. 


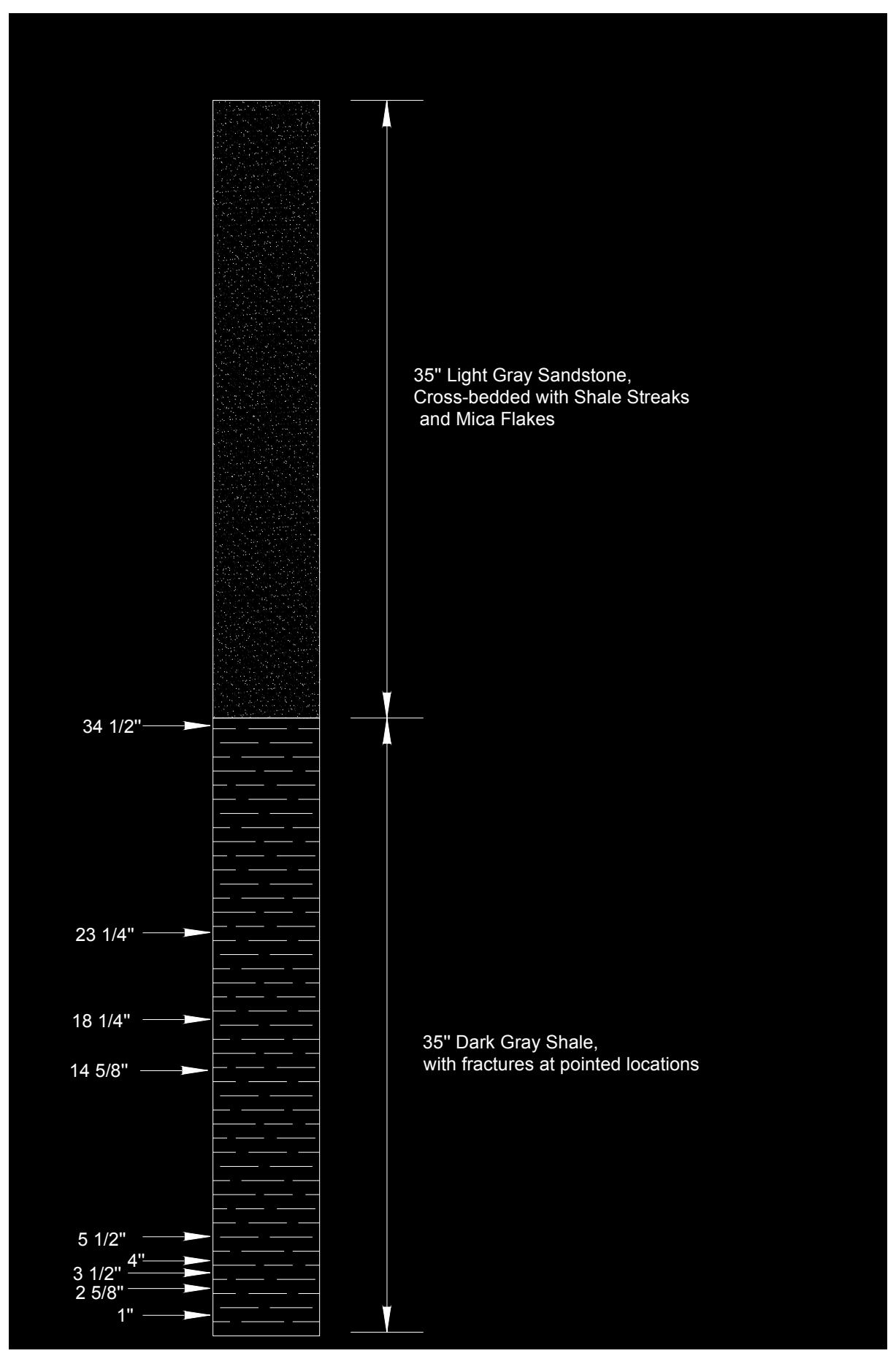

Figure 4.12 Core Log from Mine B

As shown in Figure 4.12, the roof of the test area consists of about 35 inches of shale overlain by a sandstone layer that extends at least 35 inches above the shale. In addition to the core log, some drill holes were examined with the borehole scope system. Since the probe of the 
scope will not fit into the 1.031-inch diameter holes, only the 1.375 inch diameter holes were examined. When possible, drilling data was validated with a scope log; otherwise, data was validated with the core log. A total of 36 holes were drilled at this site over two days of testing. All data collect during these tests was usable, and was analyzed. For this test site, penetrationonly and rotation-only control schemes were examined. Table 4.6 shows the pre-set drilling parameters for this test site.

Table 4.6: Pre-set Drilling Parameters-Mine B

\begin{tabular}{|c|c|c|c|c|c|}
\hline \multirow[b]{2}{*}{ Hole } & \multirow[b]{2}{*}{ Diameter } & \multicolumn{3}{|c|}{ Settings } & \multirow[b]{2}{*}{ Date Drilled } \\
\hline & & P.R. & RPM & Thrust & \\
\hline 1 & 1.375 & 1.1 & Free & 4550 & $7 / 25 / 2002$ \\
\hline 2 & 1.375 & 1.1 & Free & 4550 & $7 / 25 / 2002$ \\
\hline 3 & 1.375 & 0.8 & Free & 4550 & $7 / 25 / 2002$ \\
\hline 4 & 1.375 & 0.8 & Free & 4550 & $7 / 25 / 2002$ \\
\hline 5 & 1.375 & 0.8 & Free & 1400 & $7 / 25 / 2002$ \\
\hline 6 & 1.375 & 0.8 & Free & 1400 & $7 / 25 / 2002$ \\
\hline 7 & 1.375 & 1.1 & Free & 1400 & $7 / 25 / 2002$ \\
\hline 8 & 1.375 & 5.1 & Free & 1400 & $7 / 25 / 2002$ \\
\hline $8 a$ & 1.375 & 5.1 & Free & 1400 & $7 / 25 / 2002$ \\
\hline 9 & 1.375 & Free & 502 & 1400 & $7 / 25 / 2002$ \\
\hline 10 & 1.375 & Free & 502 & 1400 & $7 / 25 / 2002$ \\
\hline 11 & 1.375 & Free & 405 & 1400 & $7 / 25 / 2002$ \\
\hline 12 & 1.375 & Free & 405 & 1400 & $7 / 25 / 2002$ \\
\hline 13 & 1.375 & Free & 502 & 4550 & $7 / 25 / 2002$ \\
\hline 14 & 1.375 & Free & 502 & 4550 & $7 / 25 / 2002$ \\
\hline 15 & 1.375 & Free & 405 & 1400 & $7 / 25 / 2002$ \\
\hline 16 & 1.375 & Free & 405 & 1400 & $7 / 25 / 2002$ \\
\hline 17 & 1.375 & 1.1 & Free & 4550 & $7 / 26 / 2002$ \\
\hline 18 & 1.375 & 0.8 & Free & 4550 & $7 / 26 / 2002$ \\
\hline 19 & 1.375 & 5.1 & 502 & 4550 & $7 / 26 / 2002$ \\
\hline 20 & 1.031 & 1.5 & Free & 4550 & $7 / 26 / 2002$ \\
\hline 21 & 1.031 & 1.5 & Free & 4550 & $7 / 26 / 2002$ \\
\hline 22 & 1.031 & 0.8 & Free & 4550 & $7 / 26 / 2002$ \\
\hline 23 & 1.031 & 0.8 & Free & 4550 & $7 / 26 / 2002$ \\
\hline 24 & 1.031 & Free & 500 & 4550 & $7 / 26 / 2002$ \\
\hline 25 & 1.031 & Free & 500 & 4550 & $7 / 26 / 2002$ \\
\hline 26 & 1.031 & Free & 400 & 4550 & $7 / 26 / 2002$ \\
\hline 27 & 1.031 & Free & 400 & 4550 & $7 / 26 / 2002$ \\
\hline 28 & 1.031 & 1.5 & Free & 2800 & $7 / 26 / 2002$ \\
\hline 29 & 1.031 & 1.5 & Free & 2800 & $7 / 26 / 2002$ \\
\hline 30 & 1.031 & 0.8 & Free & 2800 & $7 / 26 / 2002$ \\
\hline 31 & 1.031 & 0.8 & Free & 2800 & $7 / 26 / 2002$ \\
\hline
\end{tabular}




\begin{tabular}{|l|l|l|l|l|l|}
\hline 32 & 1.031 & Free & 500 & 2800 & $7 / 26 / 2002$ \\
\hline 33 & 1.031 & Free & 500 & 2800 & $7 / 26 / 2002$ \\
\hline 34 & 1.031 & Free & 400 & 2800 & $7 / 26 / 2002$ \\
\hline 35 & 1.031 & Free & 400 & 2800 & $7 / 26 / 2002$ \\
\hline
\end{tabular}

\section{$\underline{4.3 .5}$ Mine C Underground Tests}

Mine $\mathrm{C}$ was another room and pillar mine located in southern West Virginia. This mine operated in the Coalburg seam. A sandstone channel was observed by the mine geologist. Drilling tests were focused in and around this sandstone channel. Because the edges of the channel had a steep slope, data could be collected from three different geological conditions within close proximity. Drilling occurred in the sandstone channel yielding drilling data that intercepted only sandstone. Drilling was also conducted outside the sandstone channel, but near its edge, yielding drilling data the intercepted shale and sandstone, respectively. Finally, drilling was conducted at some distance from the channel, yielding drilling data that only intercepted shale. Figure 4.13 shows a diagram of the test area. 


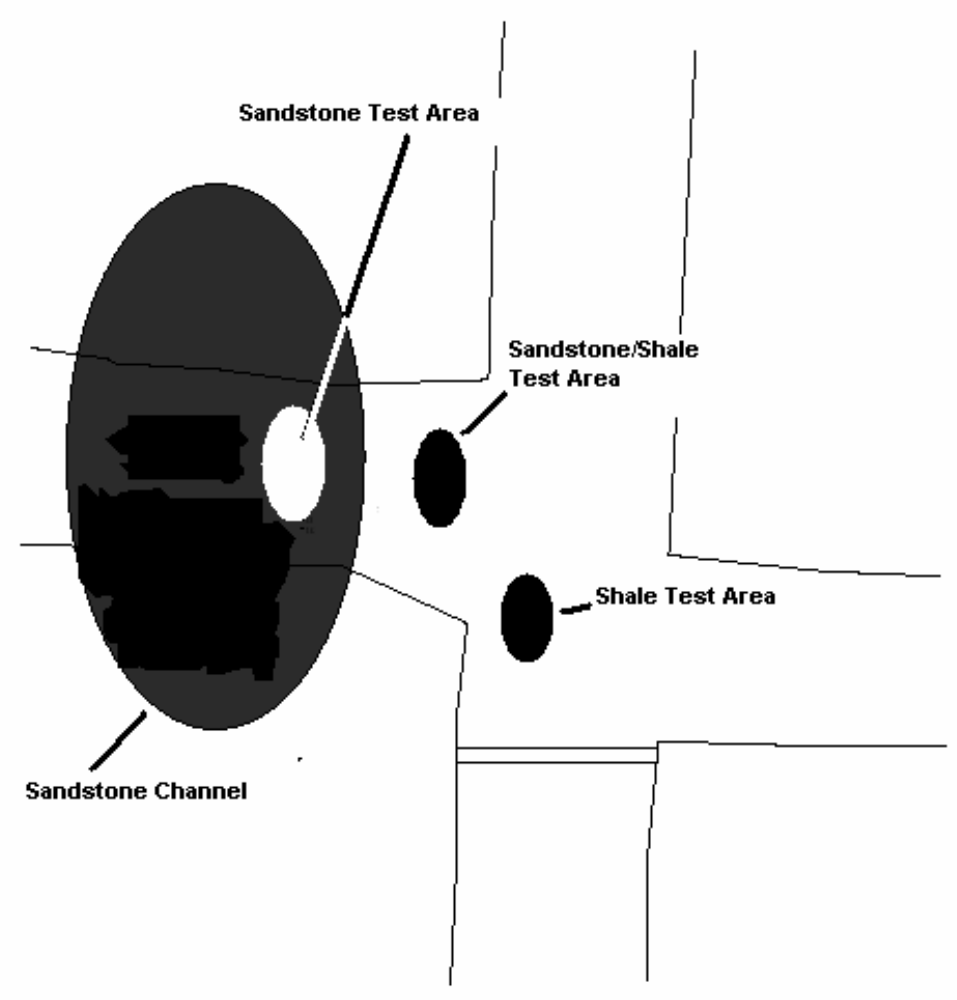

Figure 4.13 Diagram of Mine C Test Areas

A total of six core holes were drilled at this mine. However, not all of the cores were used to validate drilling data. The core holes were drilled to define the geology of the test site, and to determine appropriate test areas in the mine. Once an appropriate test area was located, data collection holes were drilled in a circular pattern around the core hole. In addition to core logs, some of the test holes were observed with the bore hole scope system.

Table 4.7 lists the pre-set drilling parameters tested at this mine. During the period between tests at Mine B and Mine C, analysis of drilling data indicated that penetration-only control holes produced the most meaningful representation of the roof geology. Therefore, these tests focused on determining the optimum penetration rate, and testing the performance of the pre-set control scheme under differing geologic conditions. 
Table 4.7 Pre-Set Drilling Parameters-Mine C

\begin{tabular}{|c|c|c|l|c|c|}
\hline \multirow{2}{*}{ Hole } & Diameter & P.R. & RPM & Thrust & Date Drilled \\
\cline { 3 - 6 } & 1.375 & 0.8 & Free & 4550 & $12 / 17 / 2002$ \\
\hline 1 & 1.375 & 0.8 & Free & 4550 & $12 / 17 / 2002$ \\
\hline 2 & 1.375 & 1.1 & Free & 4550 & $12 / 17 / 2002$ \\
\hline 3 & 1.375 & 1.1 & Free & 4550 & $12 / 17 / 2002$ \\
\hline 4 & 1.375 & 1.5 & Free & 4550 & $12 / 17 / 2002$ \\
\hline 5 & 1.375 & 1.5 & Free & 4550 & $12 / 17 / 2002$ \\
\hline 6 & 1.375 & 0.8 & Free & 5600 & $12 / 17 / 2002$ \\
\hline 7 & 1.375 & 0.8 & Free & 5600 & $12 / 17 / 2002$ \\
\hline 8 & 1.375 & 1.1 & Free & 5600 & $12 / 17 / 2002$ \\
\hline 9 & 1.375 & 1.1 & Free & 5600 & $12 / 17 / 2002$ \\
\hline 10 & 1.375 & 1.5 & Free & 5600 & $12 / 17 / 2002$ \\
\hline 11 & 1.375 & 1.5 & Free & 5600 & $12 / 17 / 2002$ \\
\hline 12 & 1.375 & 1.1 & Free & 5600 & $2 / 11 / 2003$ \\
\hline 13 & 1.375 & 1.1 & Free & 5600 & $2 / 11 / 2003$ \\
\hline 14 & 1.375 & 1.1 & Free & 5600 & $2 / 11 / 2003$ \\
\hline 15 & 1.375 & 1.1 & Free & 5600 & $2 / 11 / 2003$ \\
\hline 16 & 1.375 & 1.1 & Free & 5600 & $2 / 11 / 2003$ \\
\hline 17 & 1.375 & 1.5 & Free & 5600 & $2 / 11 / 2003$ \\
\hline 18 & 1.375 & 1.5 & Free & 5600 & $2 / 11 / 2003$ \\
\hline 19 & 1.375 & 1.5 & Free & 5600 & $2 / 11 / 2003$ \\
\hline 20 & 1.375 & 1.5 & Free & 5600 & $2 / 11 / 2003$ \\
\hline 21 & 1.375 & 1.5 & Free & 5600 & $2 / 11 / 2003$ \\
\hline 22 & 1.375 & 1.7 & Free & 5600 & $2 / 11 / 2003$ \\
\hline 23 & 1.375 & 1.7 & Free & 5600 & $2 / 11 / 2003$ \\
\hline 24 & 1.375 & 1.7 & Free & 5600 & $2 / 11 / 2003$ \\
\hline 25 & 1.375 & 1.7 & Free & 5600 & $2 / 11 / 2003$ \\
\hline 26 & 1.375 & 1.7 & Free & 5600 & $2 / 11 / 2003$ \\
\hline 27 & & & & & \\
\hline & & & & \\
\hline
\end{tabular}

Penetration rates ranged from 0.8 to $1.7 \mathrm{in} / \mathrm{sec}$ in these tests. All rotation rates were set to the maximum allowable value by the DCU. All bits used in these tests were 1.375 in diameter to facilitate observation with the bore hole scope.

\subsubsection{Mine D Underground Tests}

Mine D was the final underground test site for this study. The mine was located in southern West Virginia, and mined in the Coalburg seam. This mine was a room and pillar operation, but was inactive at the time of the tests. The roof at this mine was a consistent 
sandstone layer within the range of drilling of the roof bolter. Eight vertical holes were drilling into the sandstone roof. Despite the consistent roof strata, 3 different geologic conditions were drilled using the angle drilling features of the roof bolter (Figure 4.14)

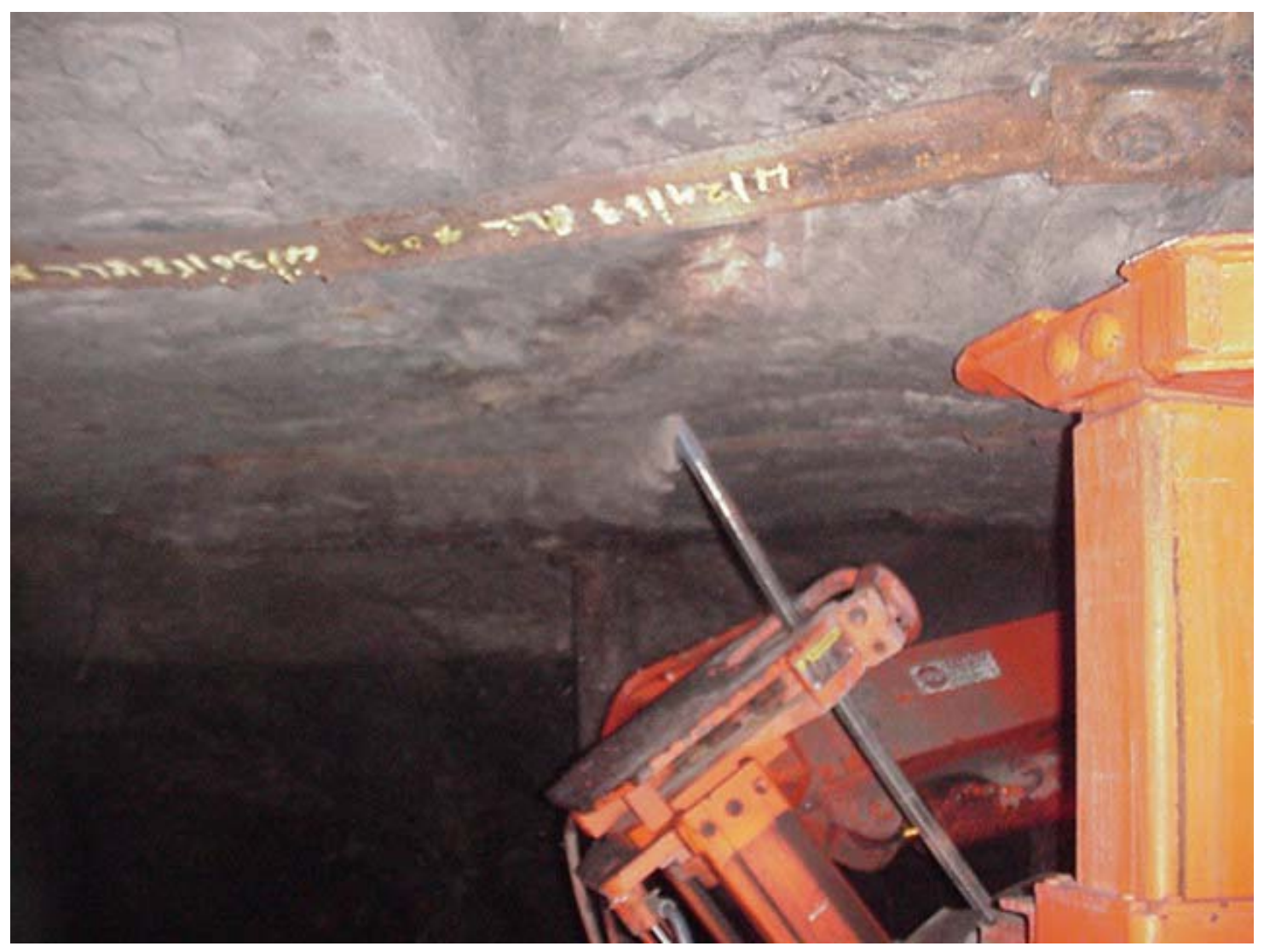

Figure 4.14 Angle Drilling With Roof Bolter

The angle drilling feature of the roof bolter allows holes to be drilled at any angle from the vertical up to 90 degrees. Two geologic features were intercepted using this feature. A high angle (approximately 75 degrees from horizontal) fracture induced by previous mining activities was present along a weak joint line in the roof. Four holes were drilled to intercept this feature using the angle drilling feature of the roof bolter. The angle drilling feature was also used to begin drilling in the coal rib of the mine. As drilling proceeded, the drill bit intercepted the sandstone roof some distance into the hole. This procedure enabled the data collection system to 
monitor drilling through two distinct layers of strata in one hole. Three holes were drilled in this fashion. Figure 4.15 shows a diagram of the test area in Mine D.

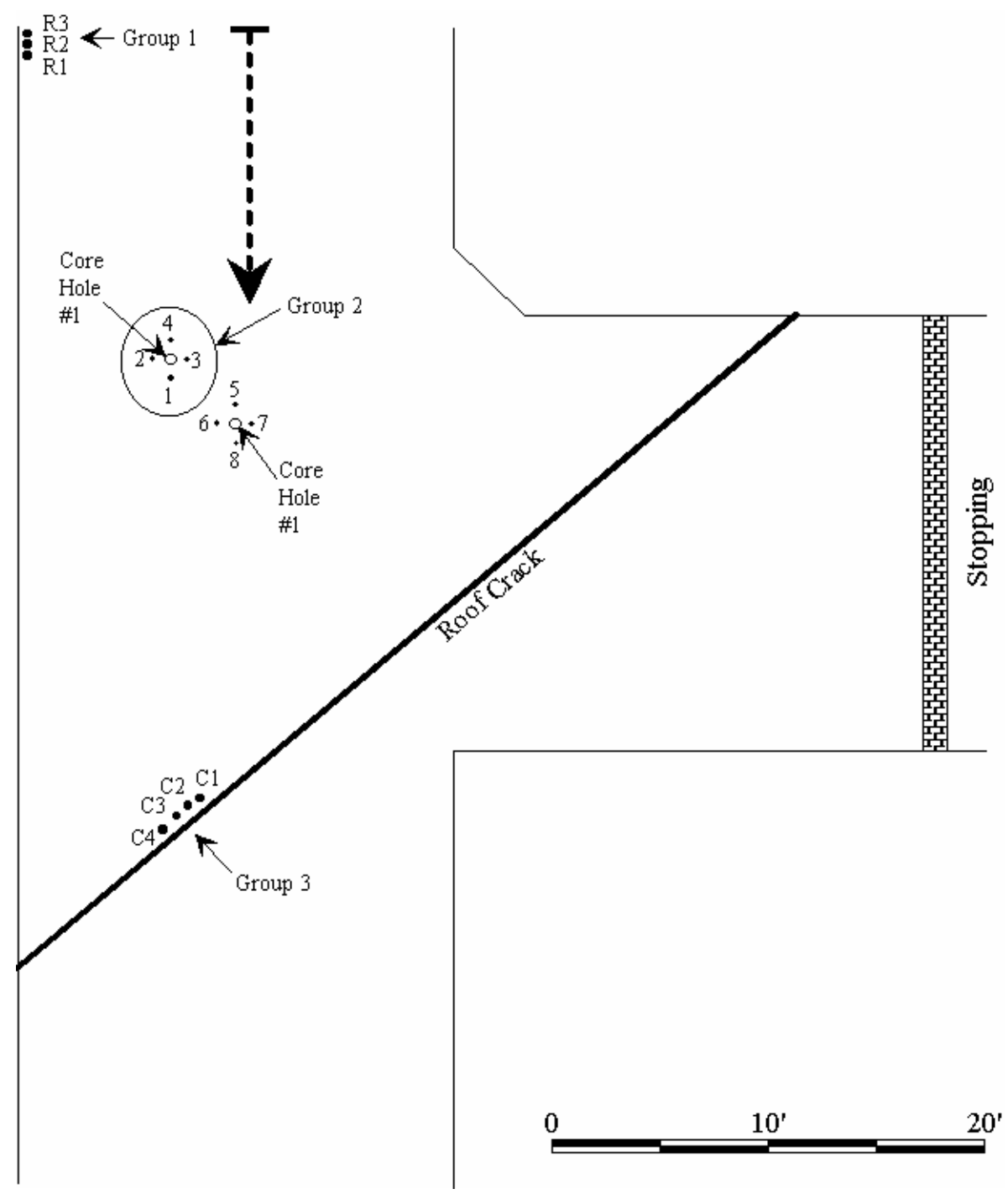

Figure 4.15 Diagram of Test Area-Mine D

The original test plan called for two core holes to be drilled. However, after observing the consistency of the roof through the bore hole scope, the second core hole was deemed unnecessary. Table 4.8 lists the pre-set drilling parameters tested in Mine D. Again, drilling data indicated that penetration-only control yielded the most reliable drilling data. At the time that these tests were conducted, it was believed that the $1.5 \mathrm{in} / \mathrm{sec}$ penetration rate gave the best 
quality drilling data. Thus, this setting was used for all tests to determine its performance under a variety of conditions.

Table 4.8: Pre-Set Drilling Parameters-Mine D

\begin{tabular}{|c|c|c|c|c|c|}
\hline \multirow{2}{*}{ Hole } & \multirow{3}{*}{ Diameter } & \multicolumn{3}{|c|}{ Settings } & Date Drilled \\
\cline { 3 - 6 } & 1.375 & P.R. & RPM & Thrust & $4 / 9 / 2003$ \\
\hline 1 & 1.5 & Free & 5600 & $4 / 9 / 2003$ \\
\hline 2 & 1.375 & 1.5 & Free & 5600 & $4 / 9 / 2003$ \\
\hline 3 & 1.375 & 1.5 & Free & 7000 & $4 / 9 / 2003$ \\
\hline 4 & 1.375 & 1.5 & Free & 7000 & $4 / 9 / 2003$ \\
\hline 5 & 1.375 & 1.5 & Free & 7000 & $4 / 9 / 2003$ \\
\hline 6 & 1.375 & 1.5 & Free & 7000 & $4 / 9 / 2003$ \\
\hline 7 & 1.375 & 1.5 & Free & 7000 & $4 / 9 / 2003$ \\
\hline 8 & 1.375 & 1.5 & Free & 7000 & $4 / 30 / 2003$ \\
\hline C1 & 1.375 & 1.5 & Free & 8000 & $4 / 30 / 2003$ \\
\hline C2 & 1.375 & 1.5 & Free & 8000 & $4 / 30 / 2003$ \\
\hline C3 & 1.375 & 1.5 & Free & 8000 & $4 / 30 / 2003$ \\
\hline C4 & 1.375 & 1.5 & Free & 8000 & $4 / 30 / 2003$ \\
\hline R1 & 1.375 & 1.5 & Free & 8000 & $4 / 30 / 2003$ \\
\hline R2 & 1.375 & 1.5 & Free & 8000 & $4 / 30 / 2003$ \\
\hline R3 & 1.375 & 1.5 & Free & 8000 & $4 / 30 / 2003$ \\
\hline 16 & 1.375 & 1.5 & Free & 8000 & $4 / 30 / 2003$ \\
\hline 17 & 1.375 & 1.5 & Free & 8000 & $4 / 30 / 2003$ \\
\hline 18 & 1.375 & 1.5 & Free & 8000 & \\
\hline
\end{tabular}

The prefix $\mathrm{C}$ denotes holes drilled across the roof fracture, while holes with the prefix $\mathrm{R}$ denote drilling in the coal rib. Regularly numbered holes indicate vertical roof drilling. For holes 16-18, drilling began at the top end of holes 1-3 respectively. This drilling was an attempt to extend the holes into another layer of strata above the sandstone that was observed at the mine portal. However, the holes were not drilled a sufficient length to extend out of the sandstone.

\subsection{Experimental Design of Phase 2 Laboratory Tests}

The second phase of laboratory tests was conducted after the completion of the four underground tests. Data from the underground tests indicated that the penetration-only control scheme was most likely to be useful in a prediction program. Since only a small number of 
penetration-only holes had been drilled in the lab, it was decided to test the methodology in a laboratory setting. Furthermore, most of the data analysis methods had been developed using data collected from the underground test using the penetration-only control. Finally, a number of refinements were made to the hardware on-board the roof bolter. Laboratory test were thus designed to test the data analysis methodology with easily validated manufactured blocks. In addition to the penetration-only control schemes, tests were conducted using the slowest possible penetration rate $(0.4 \mathrm{in} / \mathrm{sec})$ with a variety of rotation rates.

\subsubsection{Experimental Approach of Phase 2 Laboratory Experiments}

Two manufactured rock blocks were used for the second phase of the laboratory experiments. The blocks selected for these experiments were the simulated fracture block (Figure 4.5) and layer block 5 (Figure 4.6). The purpose of these tests was to test and refine the data analysis methodology for detecting geologic features. Therefore, blocks containing some type of simulated feature were tested. All the area for drilling in layer block 6 was used in Phase 1 tests, so the remaining space for drilling on layer block 5 was used to test the data analysis methodology in simulated bedded strata. The manufactured fracture block contained space for additional holes. Therefore, it was used to test the data analysis methodology in simulated fractures. Tables 4.9 and 4.10 show the pre-set drilling parameters for the second phase of laboratory tests.

Table 4.9: Pre-Set Drilling Parameters for Simulated Fracture Block—Phase 2 Lab Tests

\begin{tabular}{|c|c|c|c|c|c|}
\hline \multirow{2}{*}{ Hole } & \multirow{2}{*}{ Diameter } & \multicolumn{3}{|c|}{ Settings } \\
\cline { 3 - 6 } & 1.375 & P.R. & RPM & Thrust & Date Drilled \\
\hline 1 & 1.5 & Free & 7000 & $7 / 19 / 2003$ \\
\hline 2 & 1.375 & 1.5 & Free & 7000 & $7 / 19 / 2003$ \\
\hline 3 & 1.5 & Free & 7000 & $7 / 19 / 2003$ \\
\hline
\end{tabular}




\begin{tabular}{|c|c|c|c|c|c|}
\hline 4 & 1.375 & 1.1 & Free & 7000 & $7 / 19 / 2003$ \\
\hline 5 & 1.375 & 1.1 & Free & 7000 & $7 / 19 / 2003$ \\
\hline 6 & 1.375 & 1.1 & Free & 7000 & $7 / 19 / 2003$ \\
\hline 7 & 1.375 & 1.1 & Free & 7000 & $7 / 19 / 2003$ \\
\hline 8 & 1.375 & 0.8 & Free & 7000 & $7 / 19 / 2003$ \\
\hline 9 & 1.375 & 0.8 & Free & 7000 & $7 / 19 / 2003$ \\
\hline 10 & 1.375 & 0.8 & Free & 7000 & $7 / 19 / 2003$ \\
\hline 11 & 1.375 & 1.1 & Free & 7000 & $8 / 19 / 2003$ \\
\hline 12 & 1.375 & 1.1 & Free & 7000 & $8 / 19 / 2003$ \\
\hline 13 & 1.375 & 1.1 & Free & 7000 & $8 / 19 / 2003$ \\
\hline 14 & 1.375 & 0.4 & Free & 7000 & $8 / 19 / 2003$ \\
\hline 15 & 1.375 & 0.4 & Free & 7000 & $8 / 19 / 2003$ \\
\hline 16 & 1.375 & 0.4 & 400 & 7000 & $8 / 19 / 2003$ \\
\hline 17 & 1.375 & 0.4 & 400 & 7000 & $8 / 19 / 2003$ \\
\hline 18 & 1.375 & 0.4 & 300 & 7000 & $8 / 19 / 2003$ \\
\hline
\end{tabular}

Table 4.10: Pre-Set Drilling Parameters for Layer Block 5-Phase 2 Lab Tests

\begin{tabular}{|c|c|c|c|c|c|}
\hline \multirow{2}{*}{ Hole } & \multirow{2}{*}{ Diameter } & P.R. & RPM & Thrust & Dettings \\
\cline { 3 - 6 } & 1.375 & 1.1 & Free & 7000 & $7 / 19 / 2003$ \\
\hline 1 & 1.375 & 1.1 & Free & 7000 & $7 / 20 / 2003$ \\
\hline 2 & 1.375 & 1.5 & Free & 7000 & $7 / 21 / 2003$ \\
\hline 3 & 1.375 & 1.5 & Free & 7000 & $7 / 19 / 2003$ \\
\hline 4 & 1.375 & 0.4 & Free & 7000 & $8 / 19 / 2003$ \\
\hline 5 & 1.375 & 0.4 & Free & 7000 & $8 / 19 / 2003$ \\
\hline 6 & 1.375 & 0.4 & 400 & 7000 & $8 / 19 / 2003$ \\
\hline 7 & 1.375 & 0.4 & 400 & 7000 & $8 / 19 / 2003$ \\
\hline 8 & 1.375 & 0.4 & 300 & 7000 & $8 / 19 / 2003$ \\
\hline 9 & 1.375 & 0.4 & 300 & 7000 & $8 / 19 / 2003$ \\
\hline 10 & & & & & \\
\hline
\end{tabular}




\section{CHAPTER 5}

\section{DATA COLLECTION AND PREPARATION}

Data collected by the DCU is acquired by and saved in text files on a laptop PC onboard the roof bolter. Data contained in each of the text files are scaled values of sensor outputs in volts in integer form. This type of data is referred to as machine data. Using a spreadsheet (MS Excel) or other data analysis package, (MATLab) sensor outputs are converted to engineering units using conversion factors supplied by J.H. Fletcher \& Co. This data is referred to as raw data.

Although the DCU samples 17 sensor outputs, only 6 outputs are used in this project. As mentioned in Chapter 4, five drilling parameters are analyzed in this study. Determination of the bit position requires data from two sensors, thus there are six outputs used to determine the five basic drilling parameters. Table 5.1 shows the six sampled outputs as they appear in a drilling data file.

Table 5.1: Machine Data

\begin{tabular}{|c|c|c|c|c|c|}
\hline Data_2 & Data_3 & Data_4 & Data_6 & Data_8 & Data_9 \\
\hline 19 & 80 & 36 & 74 & 6 & 107 \\
\hline 24 & 95 & 40 & 80 & 6 & 108 \\
\hline 29 & 118 & 44 & 87 & 6 & 110 \\
\hline 32 & 126 & 45 & 90 & 6 & 111 \\
\hline 34 & 127 & 45 & 93 & 6 & 113 \\
\hline 35 & 127 & 46 & 94 & 6 & 114 \\
\hline 33 & 129 & 47 & 95 & 6 & 116 \\
\hline 31 & 135 & 51 & 94 & 6 & 117 \\
\hline 31 & 133 & 50 & 93 & 6 & 119 \\
\hline 34 & 128 & 45 & 94 & 6 & 120 \\
\hline
\end{tabular}

Data in this chart represents approximately 2 inches of drilling. The pre-set penetration rate for this test was $1.5 \mathrm{in} / \mathrm{sec}$. Data 2 represents the pressure sensor output for thrust. Data 3 is the flow rate to the hydraulic cylinder in the drill mast. This data is used to determine the 
penetration rate. Data 4 is the pressure sensor output for torque. Data 6 is the flow rate to the hydraulic motor, and is used to calculate the rotation rate. Data 8 and Data 9 are position sensor outputs used to determine the bit position.

Table 5.2 shows the sensor data converted to engineering units. Conversion formulae and constants supplied by J.H. Fletcher \& Co are used in these conversions.

Table 5.2: Raw Data

\begin{tabular}{|c|c|c|c|c|}
\hline Bit Position & Penetration Rate & Rotation Speed & Thrust & Torque \\
\hline in & in/sec & rpm & lbs & lbs-in \\
\hline 0.000 & 2.153 & 516.30 & 1645.2 & 985.98 \\
\hline 0.159 & 2.556 & 558.16 & 2078.2 & 1095.53 \\
\hline 0.478 & 3.175 & 607.00 & 2511.1 & 1205.08 \\
\hline 0.637 & 3.391 & 627.93 & 2770.9 & 1232.47 \\
\hline 0.956 & 3.418 & 648.86 & 2944.1 & 1232.47 \\
\hline 1.115 & 3.418 & 655.84 & 3030.7 & 1259.86 \\
\hline 1.433 & 3.471 & 662.82 & 2857.5 & 1287.25 \\
\hline 1.593 & 3.633 & 655.84 & 2684.3 & 1396.80 \\
\hline 1.911 & 3.579 & 648.86 & 2684.3 & 1369.41 \\
\hline 2.071 & 3.444 & 655.84 & 2944.1 & 1232.47 \\
\hline
\end{tabular}

\subsection{Data Smoothing}

Before using raw data to calculate higher order drilling parameters, a data smoothing technique is applied. Data smoothing is used to reduce excessive fluctuations in the drill data and rounding errors formed in the conversion of machine data to raw data while maintaining the general trend of the data. An exponential data smoothing technique is used. This technique uses the data point of interest and the five data points before and the five points after the point of interest to obtain a smoothed data value. Varying weighting factors are applied to the data points within the selected range. The equation for data smoothing is: 


$$
\mathrm{z}_{\mathrm{i}}^{*}=\frac{\sum_{j=-5}^{+5} w_{j}{ }^{*} z_{i+j}}{\sum_{j=-5}^{+5} w_{j}}
$$

Where:

$\mathrm{Z}_{\mathrm{i} *-} \quad$ correct value at $i$ th point

$\mathrm{Z}_{\mathrm{i}+\mathrm{j}}$ - the original value at $j$ th point ahead (-) or behind (+) the $i$ th point

$\mathrm{w}_{\mathrm{j}}$ - $\quad$ the weighting factor for the $j$ th point ahead or behind the $i$ th point

Table 5.3 lists the weighting factors used for smoothing drilling data. The furthest data points from the point of interest are to receive a $0.87 \%$ weighting. Points closer to the point of interest receive increasing weight up to $17.7 \%$ for the points adjacent to the point of interest.

Table 5.3: Weighting Factors for Data Smoothing

\begin{tabular}{|c|c|}
\hline $\begin{array}{c}\text { Location of Data Point with } \\
\text { Respect to Point of Interest }\end{array}$ & Weighting Factor, wj \\
\hline-5.00 & 0.0087 \\
\hline-4.00 & 0.0269 \\
\hline-3.00 & 0.0649 \\
\hline-2.00 & 0.1216 \\
\hline-1.00 & 0.1773 \\
\hline $0--P o i n t$ of Interest & 0.2011 \\
\hline 1.00 & 0.1773 \\
\hline 2.00 & 0.1216 \\
\hline 3.00 & 0.0649 \\
\hline 4.00 & 0.0269 \\
\hline 5.00 & 0.0087 \\
\hline
\end{tabular}

All the raw data parameters (bit position, penetration rate, rotation rate, thrust, and torque) are smoothed using this method. Figures 5.1 and 5.2 show the machine torque versus bit position before and after the data smoothing is applied. 


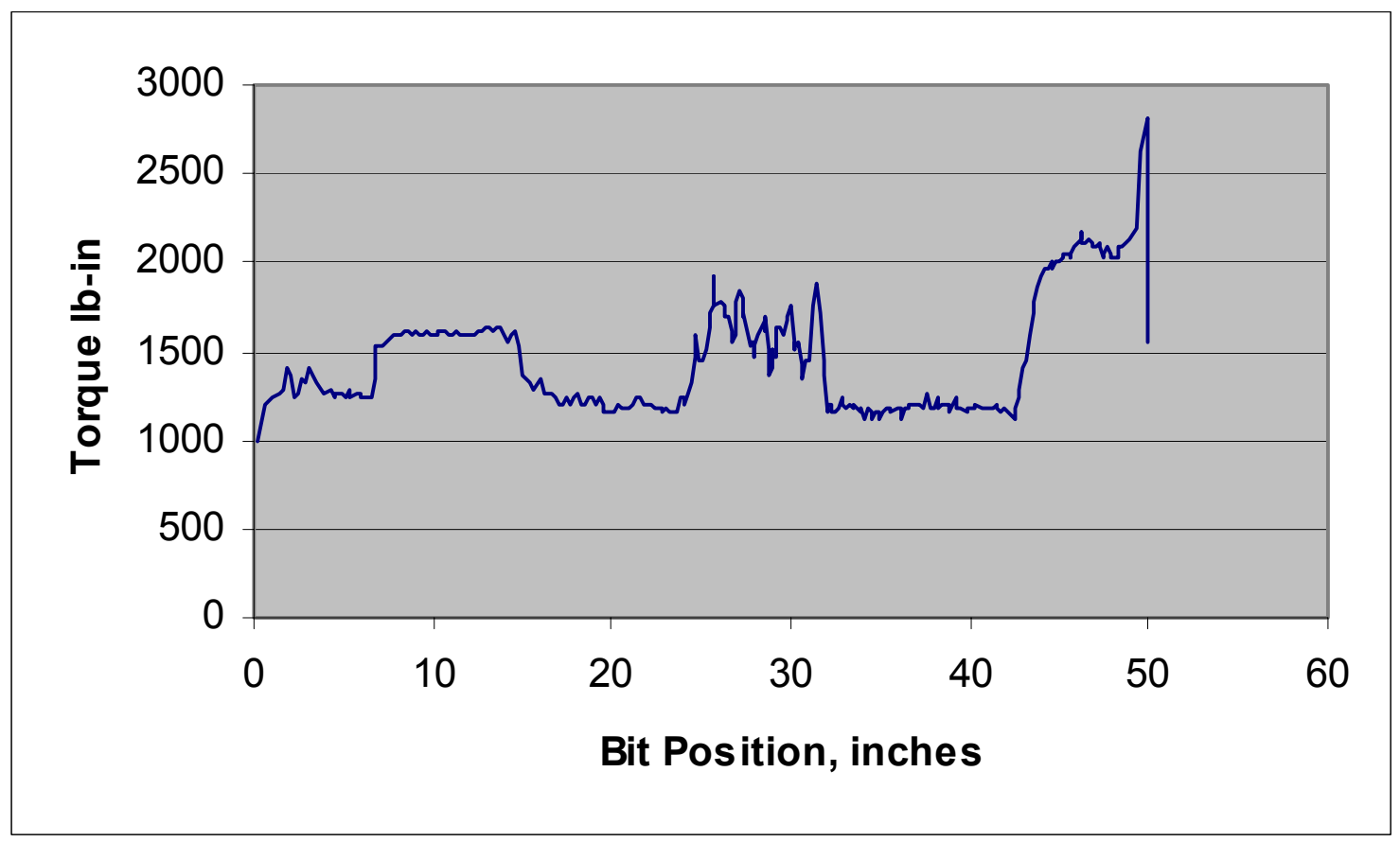

Figure 5.1 Raw Torque

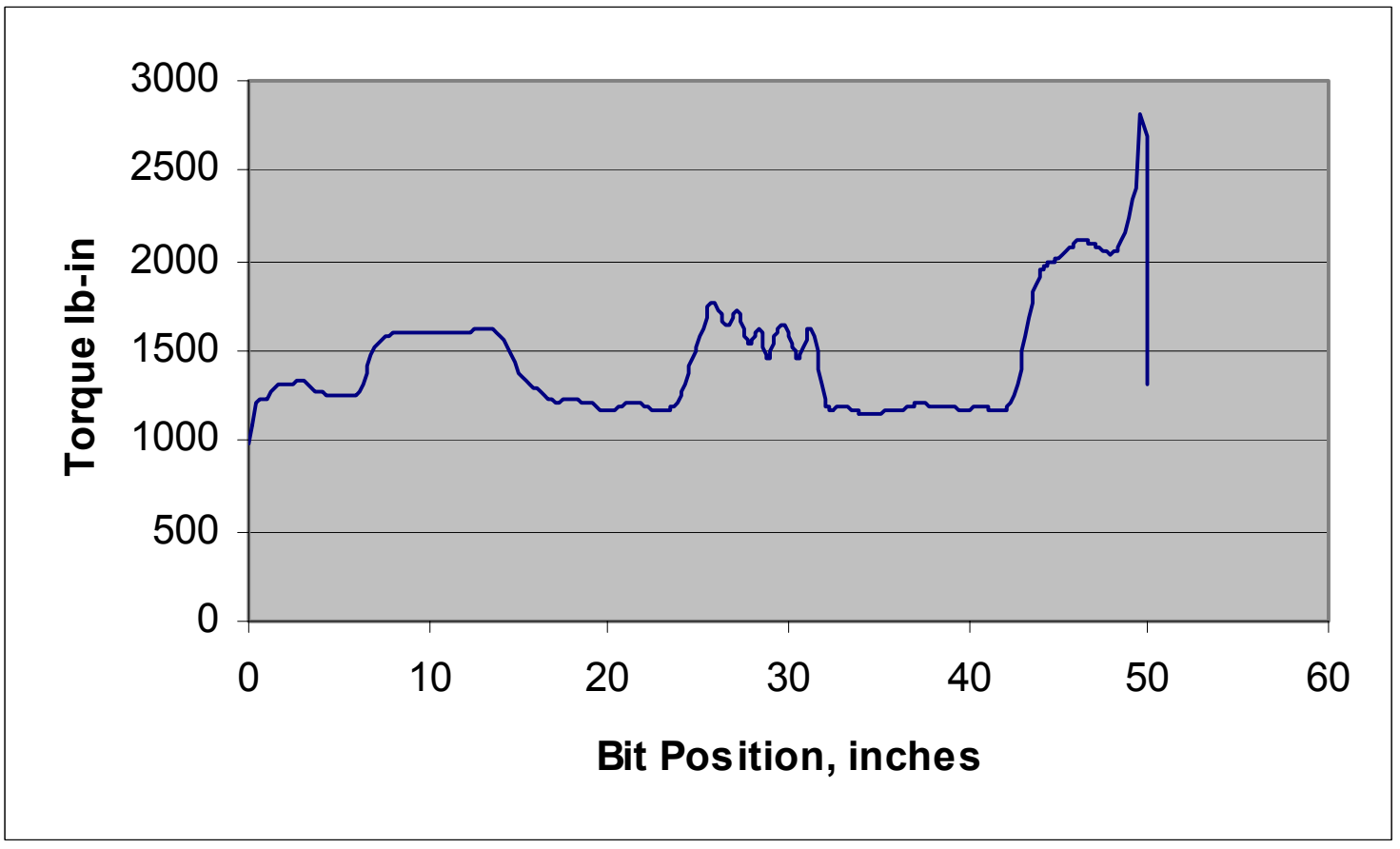

Figure 5.2 Smoothed Torque 


\subsection{Higher Order Drilling Parameters}

Six higher order drilling parameters are calculated from the smoothed data. These higher order parameters represent theoretical indices used to analyze the drilling process. Higher order drilling parameters include: bite depth, normal contact area, shear contact area, normal stress, shear stress, and stress ratio.

\section{$\underline{\text { 5.2.1 Bite Depth }}$}

The bite depth is defined as the distance the bit travels into the rock mass during one revolution. Bite depth is calculated by the equation:

$$
\mathrm{b}=60 \mathrm{v} / \mathrm{w}
$$

Where:

$$
\begin{aligned}
& \text { b- } \quad \text { bite depth, in/rev } \\
& \text { v- } \quad \text { penetration rate, in/sec } \\
& \text { w- rotation rate, } \mathrm{rpm}
\end{aligned}
$$

Bite depth is used in determining the empirical equations for normal and shear contact areas. In previous research, 3-dimensional computer models of the two bits used in this study were constructed. Using the models, empirical equations relating bite depth to normal and shear contact areas were developed

\subsubsection{Normal Contact Area and Normal Stress}

Figure 5.3 shows a plot of thrust versus bite depth for a hole drilled in the solid concrete block. The graph shows that as bite depth increases, the thrust also increases in a somewhat 
linear fashion. This data indicates that the thrust is influenced by the drill rate in addition to the hardness of material drilled.

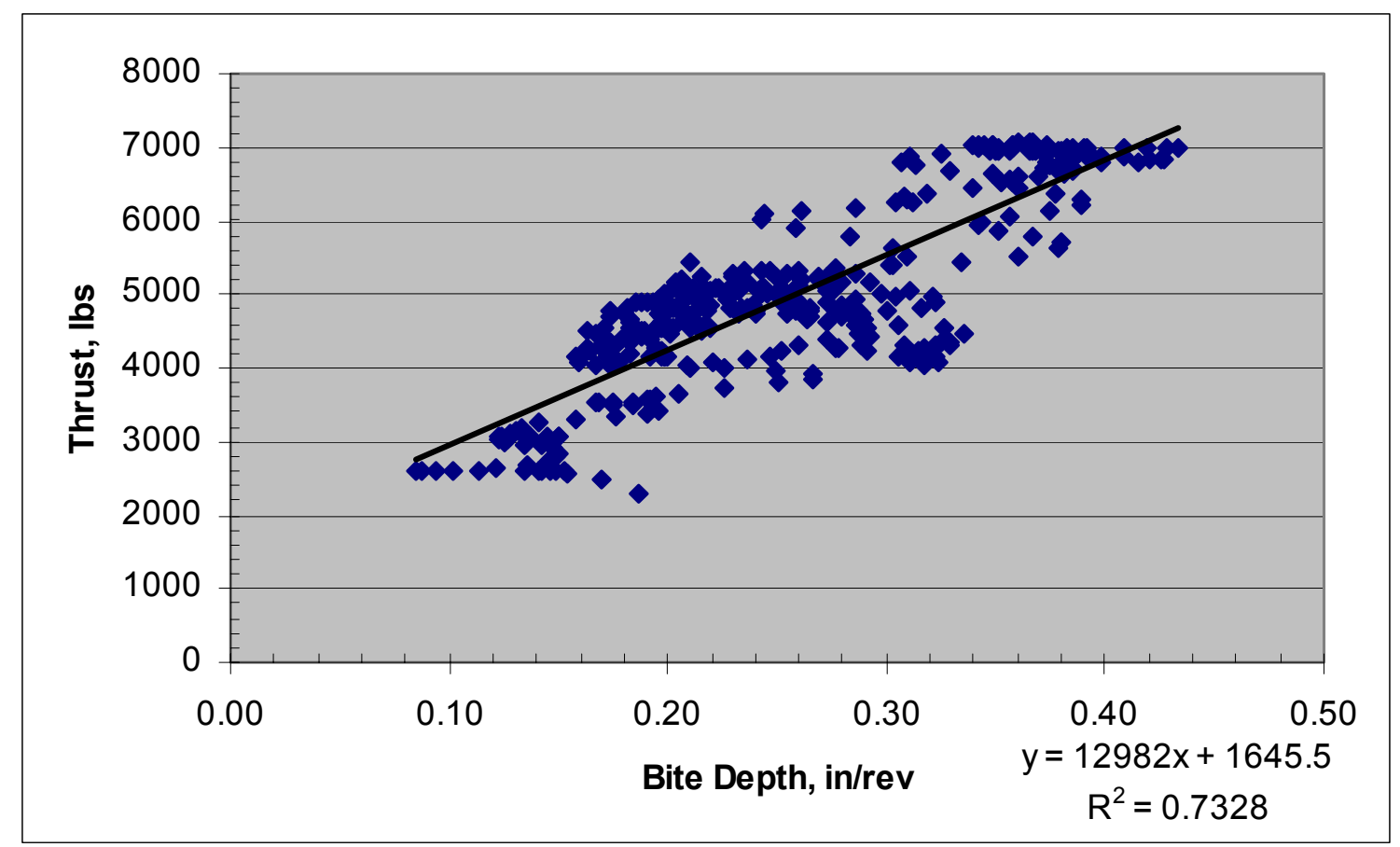

Figure 5.3 Thrust versus Bite depth—Solid Concrete Block

Since it is difficult to discern between changes in thrust due to material hardness and changes in thrust due to drill rates, an effort was made to eliminate or reduce the drill rate effect.

Empirical equations developed by Luo (4) were used to relate the bite depth to the normal contact area of the bit. These equations were developed using 3-dimensional computer models of the bits used in this project. Using the model, normal contact areas were measured at a number of bite depths. These data points were then connected by trend lines. The equations of these trend lines are used to calculate the normal contact area at a given bite depth: 
$13 / 8 "$ Bit $\quad A_{n}= \begin{cases}0.01085+4.1025 b & \text { for } b<0.16 ” \\ 0.60677+0.3750 b & \text { for } b>0.16 ”\end{cases}$

$11 / 32 "$ Bit $\quad A_{n}= \begin{cases}0.01+2.4083 b & \text { for } b<0.12 ” \\ 0.4562+0.4265 b-0.003 / b^{2} & \text { for } b>0.12 ”\end{cases}$

Where:
$\mathrm{A}_{\mathrm{n}}-\quad$ normal contact area, $\mathrm{in}^{2}$
b - bite depth, in/rev

After determining the normal contact area at a given bite depth, the normal stress is calculated by the equation:

$$
\sigma=\mathrm{F} / \mathrm{A}_{\mathrm{n}}
$$

Where:

$$
\begin{array}{ll}
\sigma- & \text { normal stress, psi } \\
\mathrm{F}-\quad \text { thrust, } \mathrm{lb} \\
\mathrm{A}_{\mathrm{n}}-\quad \text { normal contact area, } \mathrm{in}^{2}
\end{array}
$$

This method helps to reduce some of the influence of penetration rate on drill thrust. Figure 5.4 shows the normal stress versus bite depth. 


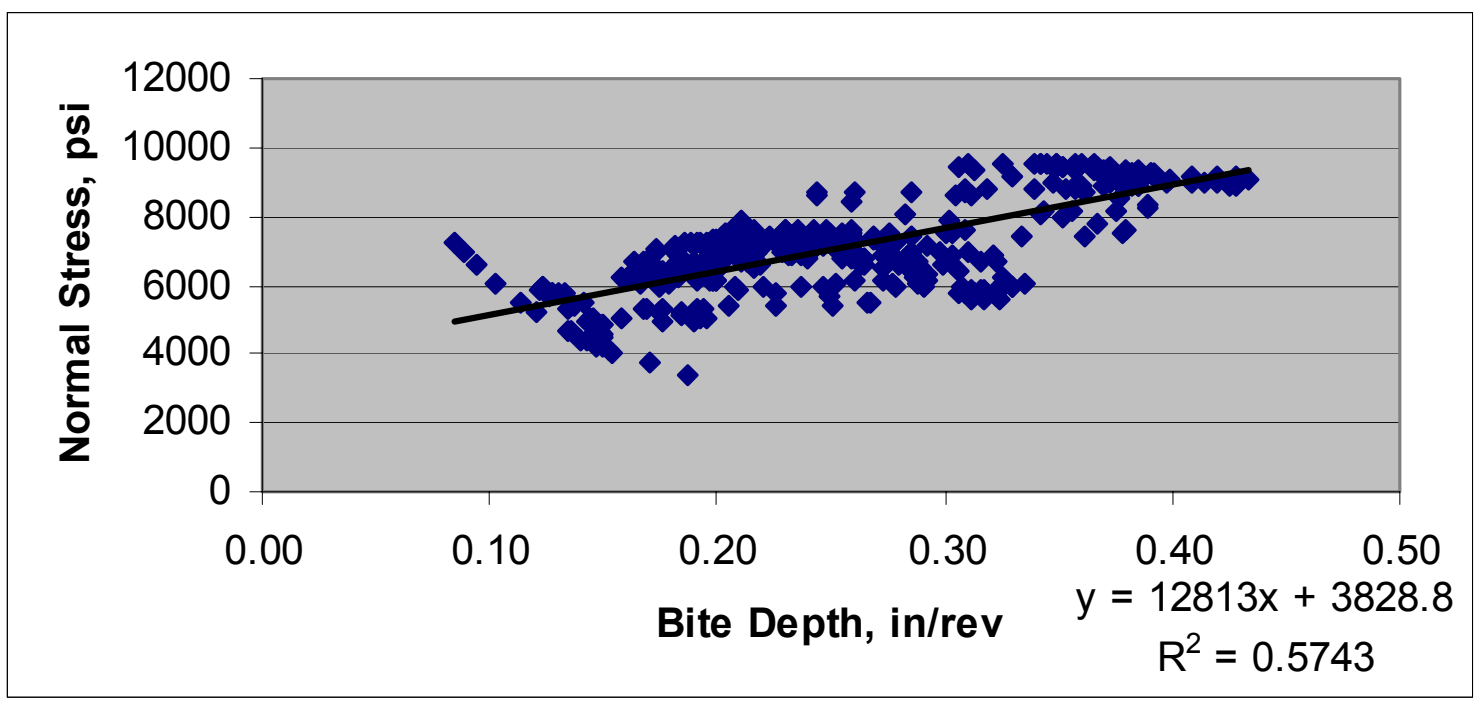

Figure 5.4 Normal Stress versus Bite Depth

Ideally, this graph should approximate a horizontal line for the concrete block. Hence, the slope of the trend line equation should be zero. There is a slight decrease in the slope of the trend line, however other factors affect the stress to bite depth relationship. Increased confinement at higher bite depths also affects the stress level needed to drill. This factor likely significantly increases the normal stress at higher bite depths. The confinement factor may be investigated in future research.

\subsubsection{Shear Contact Area and Shear Stress}

The torque/bite depth relationship when drilling the concrete block also appears to follow a straight line. Figure 5.5 shows the torque versus bite depth for the same data sets as Figures

\section{3 and 5.4}




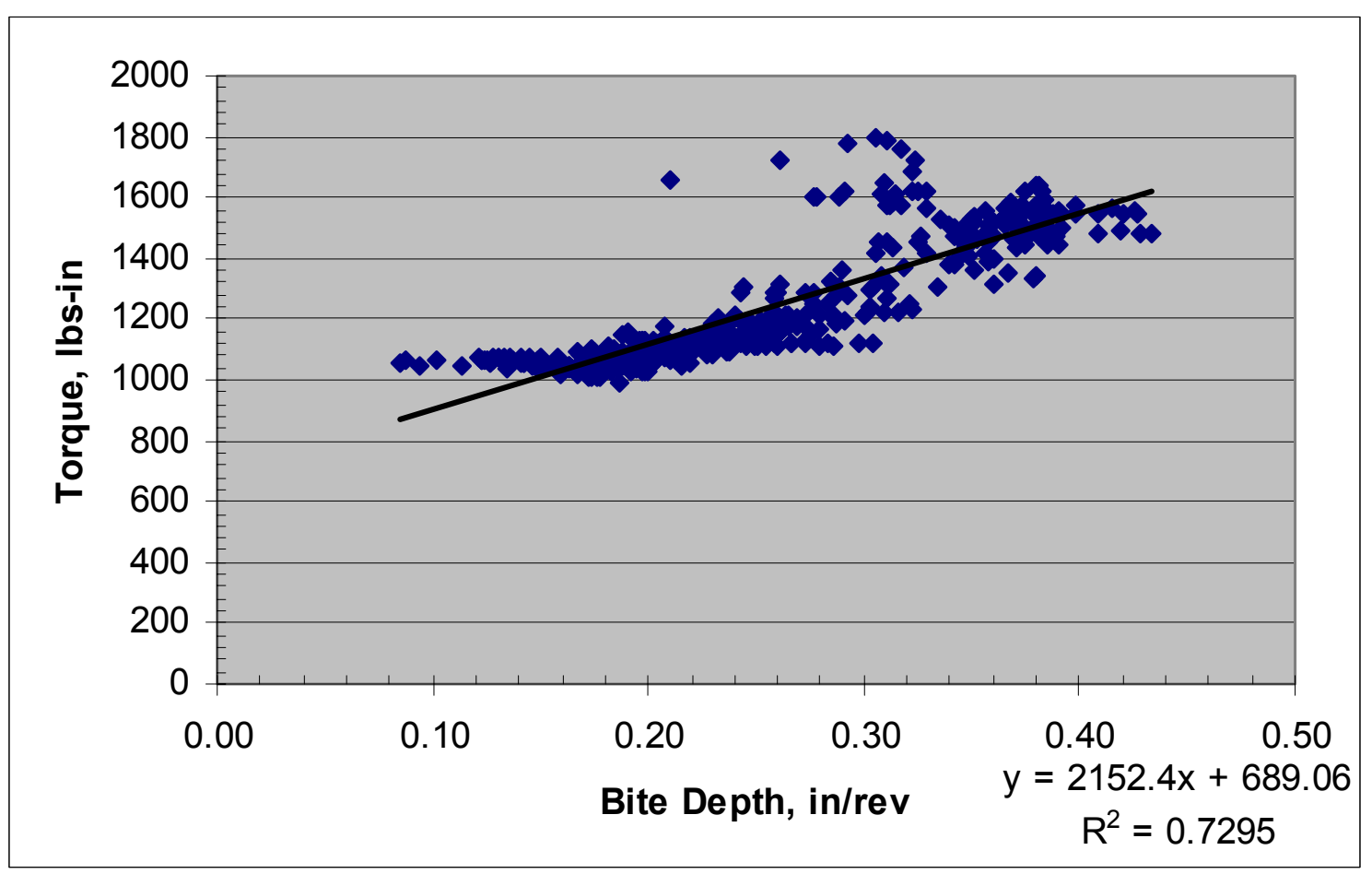

Figure 5.5 Torque versus Bite Depth

Similar to the thrust, the torque increases somewhat linearly with bite depth in a consistent material. Again, this data indicates that the penetration rate also has some effect on the torque level in addition to the strength of material drilled. In addition to equations for normal contact area, Luo (4) developed an equation for the shear contact area:

$$
\mathrm{A}_{\mathrm{s}}=\mathrm{b} * \mathrm{D}
$$

Where:
$A_{s}-\quad$ shear contact area in ${ }^{2}$
b- bite depth in/rev
D- bit diameter, in 
Shear contact area is calculated for each data point. For the purposes of analysis in this study, all the torque is assumed to act at the edges of the bit. Therefore, the torque is divided by the bit diameter to obtain a shear force in pounds:

$$
\mathrm{F}_{\mathrm{s}}=\mathrm{T} / \mathrm{D}
$$

Where:

$$
\begin{array}{ll}
F_{S}- & \text { shear force, } l b \\
T- & \text { torque, in- } l b \\
D- & \text { bit diameter, in }
\end{array}
$$

This shear force is then divided by the shear contact area to obtain shear stress:

$$
\tau=\mathrm{F}_{\mathrm{s}} / \mathrm{A}_{\mathrm{s}}
$$

Where:

$$
\begin{array}{ll}
\tau- & \text { shear stress, psi } \\
F_{S}- & \text { shear force, } l b \\
A_{s}- & \text { shear contact area, in }{ }^{2}
\end{array}
$$

Figure 5.6 shows shear stress versus bite depth. 


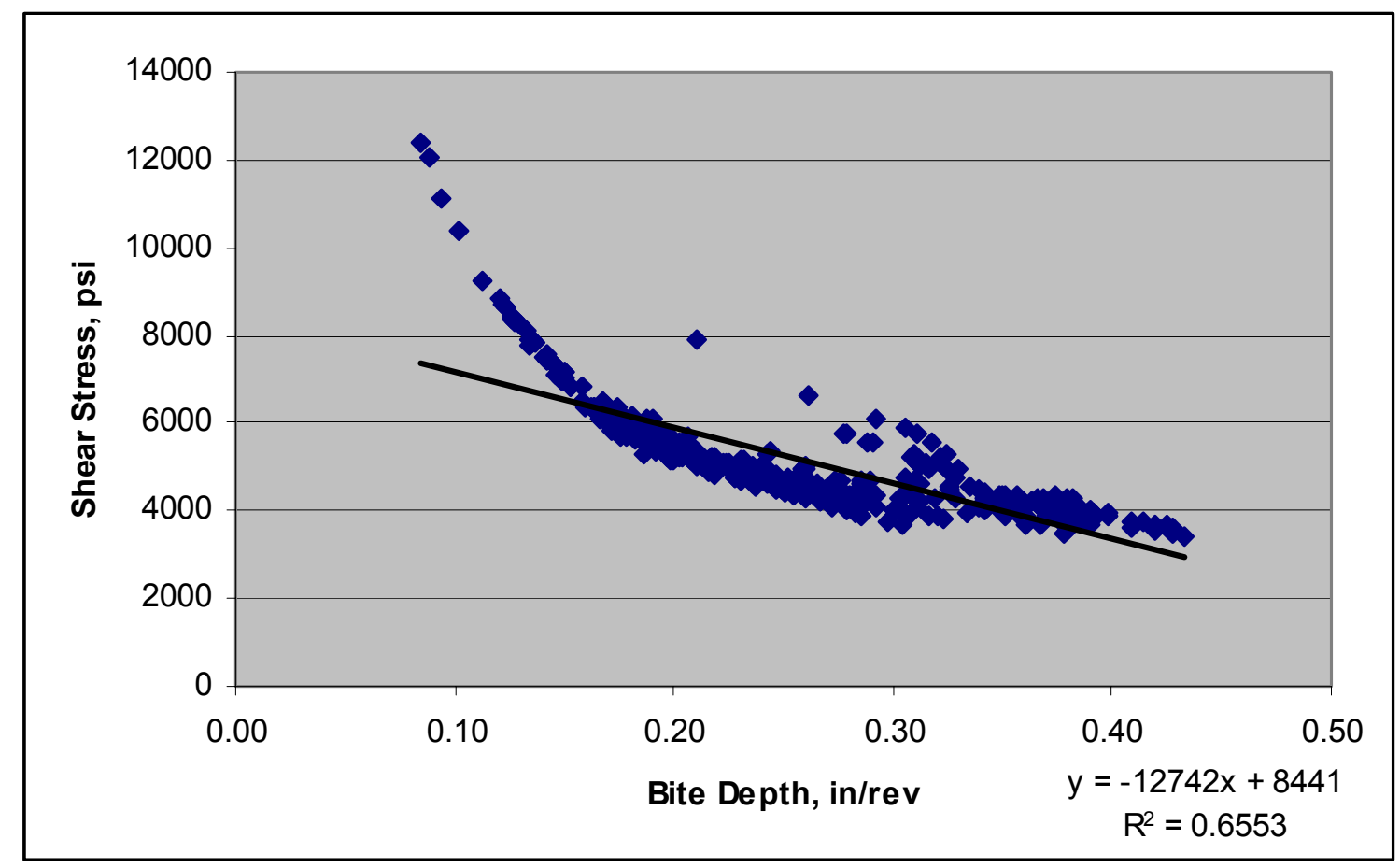

Figure 5.6 Shear stress versus Bite Depth

The linear relationship between shear stress and bite depth in Figure 5.6 appears to be less pronounced than that of torque and bite depth in Figure 5.5. Yet, consideration of Teale's theory on specific energy lends credence to the data in Figure 5.6. Teale (1) stated that specific energy is very high at low thrusts due to frictional losses at the bit-rock interface. Additionally, since torque constitutes the largest portion of specific energy, any point where the torque or shear stress is very large should have a large specific energy. Since lower thrusts in a homogeneous material indicate a lower bite depth, the shear stress should be very high at low bite depths. Examination of Figure 5.6 indicates that the data follows a linear relationship at bite depths higher than $0.15 \mathrm{in} / \mathrm{rev}$. This bite depth equates to the point where the carbide insert of the bit is fully immersed into the rock mass. At this point, most of the shear stress should theoretically be consumed in breaking rock rather than overcoming friction. Inclusion of the shear contact area likely emphasizes this factor. At small bite depths the shear contact area is small. Since there is 
little change in the torque up to a bite depth of $0.20 \mathrm{in} / \mathrm{rev}$ (Figure 5.5). The shear stress is very high and decreases exponentially up to a bite depth of $0.15 \mathrm{in} / \mathrm{rev}$. This friction factor should also be investigated in future research.

\subsubsection{Shear Stress/Normal Stress Ratio}

The ratio of shear stress and normal stress forms the basis for predicting discontinuities and the relative strength of rock. The theory of predicting features using this ratio will be discussed in Chapter 6. Figure 5.7 shows the torque/thrust ratio versus bite depth.

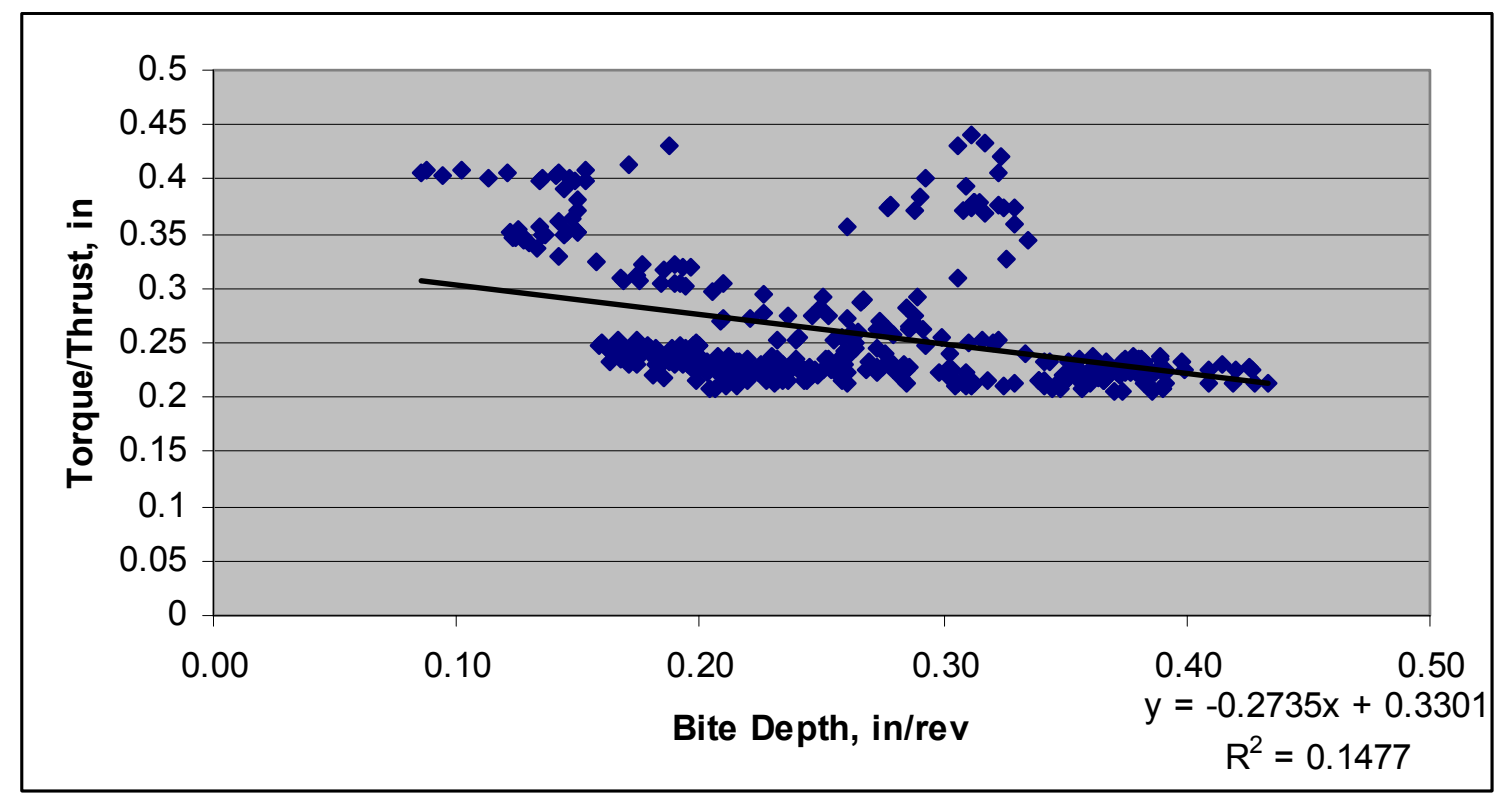

Figure 5.7 Torque/Thrust versus Bite Depth

Some of the data approaches a linear relationship. However, the $\mathrm{R}^{2}$ value is very low, and there are a large number of outliers in the data. Using the shear and normal contact areas, an attempt was made to improve the relationship of the data by examining the ratio of shear stress/normal stress. Figure 5.8 shows the shear stress/normal stress ratio versus bite depth. 


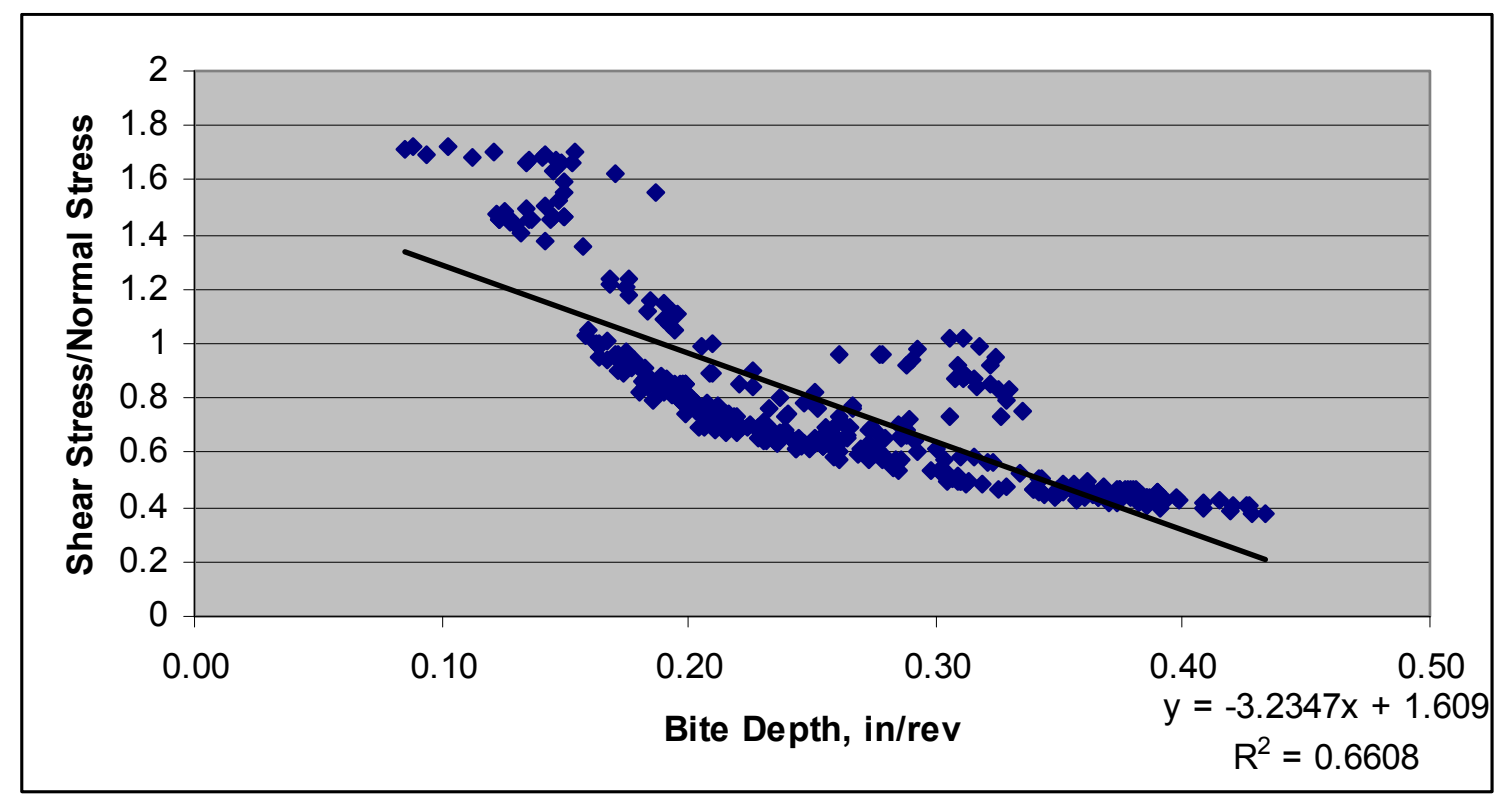

Figure 5.8 Shear Stress/Normal Stress versus Bite Depth

The decreasing trend in Figure 5.8, up to a bite depth of approximately $0.15 \mathrm{in} / \mathrm{rev}$, is likely due to the significant frictional losses at lower bite depths. The negative slope of the line beyond $0.15 \mathrm{in} / \mathrm{rev}$ indicates that the normal stress accounts for an increasing portion of rock breakage as bite depth increases. In this case, the $\mathrm{R}^{2}$ value is significantly improved compared to that of the torque/thrust ratio.

Since this data is obtained from a homogeneous material, the trend line should have a slope approaching zero. Figure 5.8 depicts the shear stress/normal stress ratio versus bite depth. Bite depth is a measure of both the penetration and rotation rates of the roof bolter. Therefore, a trend line slope approaching zero would indicate that factors affecting the shear stress/normal stress ratio due to drill rates were all accounted for, and the only changes in the ratio would be due to changes in the material properties. Thus, any effort to decrease the slope of the trend line would yield more meaningful prediction results. 


\section{CHAPTER 6}

\section{DATA ANALYSIS AND RESULTS}

As stated in Chapter 5, the ratio of Shear Stress/Normal stress forms the basis for interpretation of the drilling data. Theoretically, some relationship should exist between the shear stress and normal stress required to drill a given material. Consider the drawings in Figure 6.1:

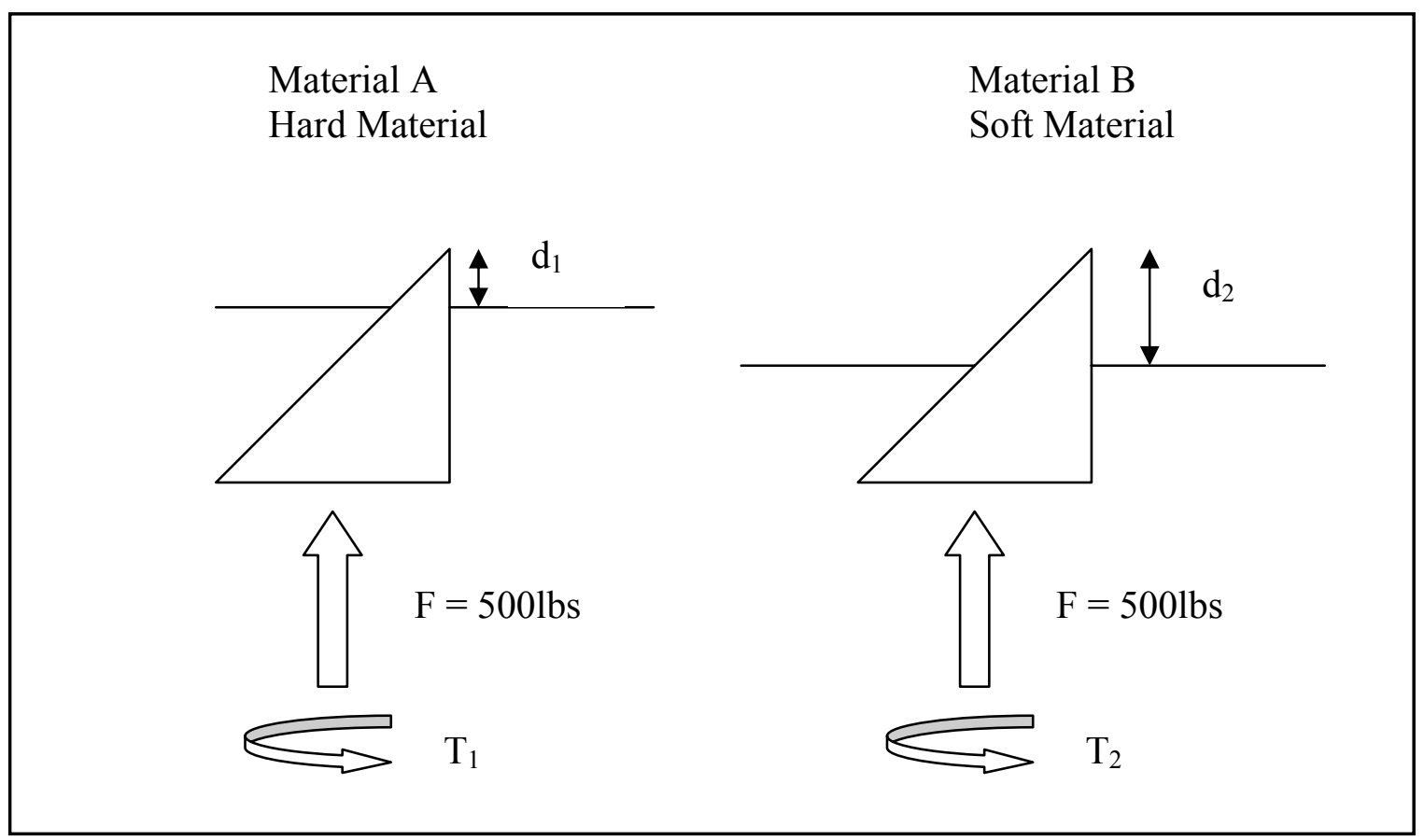

Figure 6.1 Thrust and Torque relationships for Two Materials

The same bit geometry is used to drill both materials. An equal thrust of $500 \mathrm{lbs}$ is applied to both bits. For a hard material, the penetration distance, $d_{1}$, will be smaller than that of the soft material $\mathrm{d}_{2}$. Thus, the torque, $\mathrm{T}_{1}$, required to drill material A should be smaller than the torque required to drill material B. Therefore, the ratio of torque/thrust should be smaller for material A and larger for material B. The ratio of normal stress/shear stress should follow a similar pattern. 
To test the validity of this assumption, drilling data from the manufactured laboratory blocks was analyzed. Shear stress and normal stress were calculated for each drilling data point in the block. Figure 6.2 shows the shear stress versus normal stress for 3 different layers of the manufactured block.

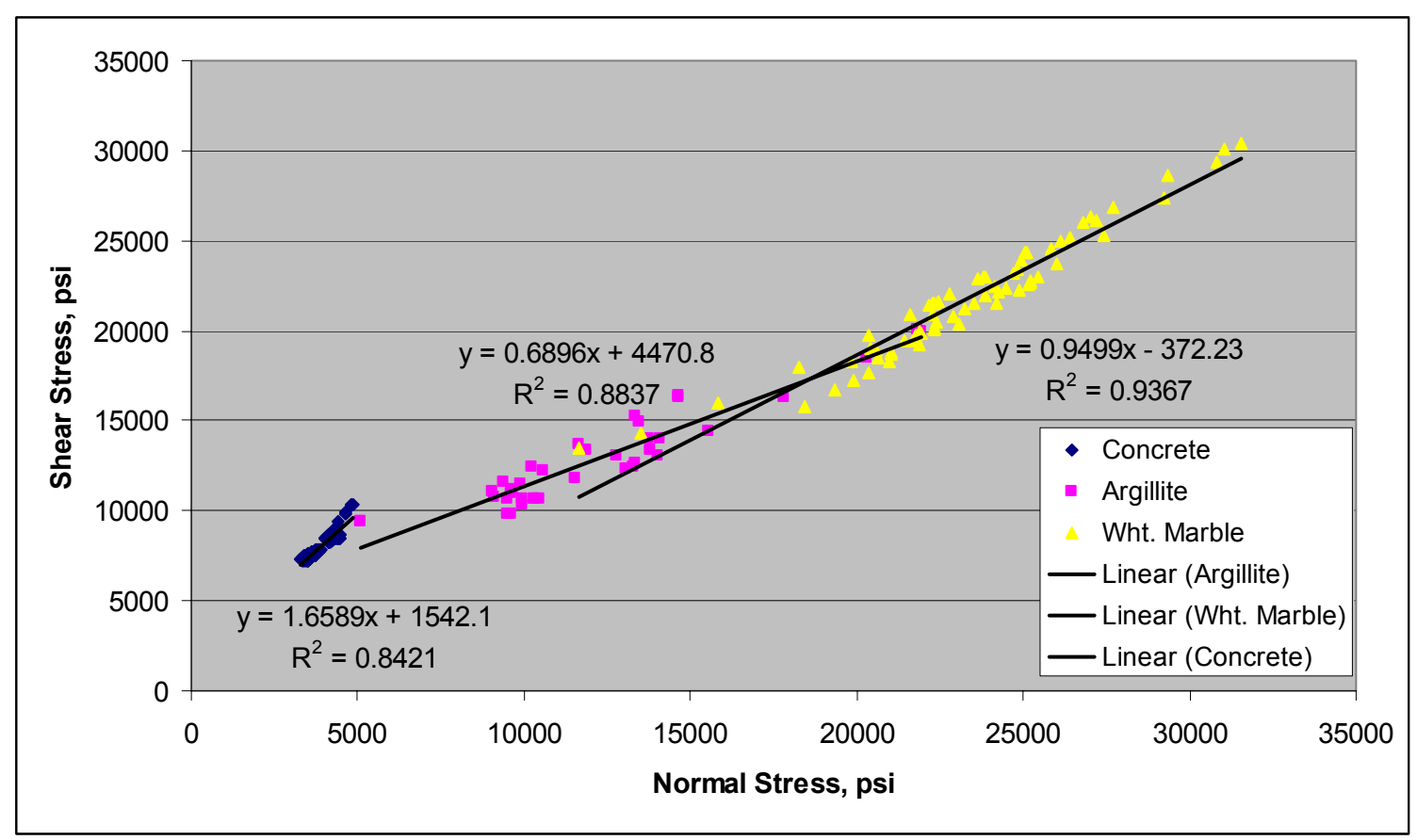

Figure 6.2 Shear Stress versus Normal Stress-Layer Block \#5

Three layers of varying strength are shown in this figure: concrete, argillite, and white marble. The average unconfined compressive strengths of the materials are 2,864, 20,473, and 17,418 psi respectively. Trend lines were constructed for each data set. The slope of the trend line should represent the average ratio of shear stress/normal stress for the data set. The trend line slopes confirm the assumed behavior of the shear/normal stress ratio. The concrete has the greatest slope and is the lowest strength material; the argillite has the smallest slope and is the highest strength material; the white marble shows intermediate slope and strength. 
Figure 6.3 shows a plot of shear stress/normal stress versus bit position for data collected from layer block \#5.

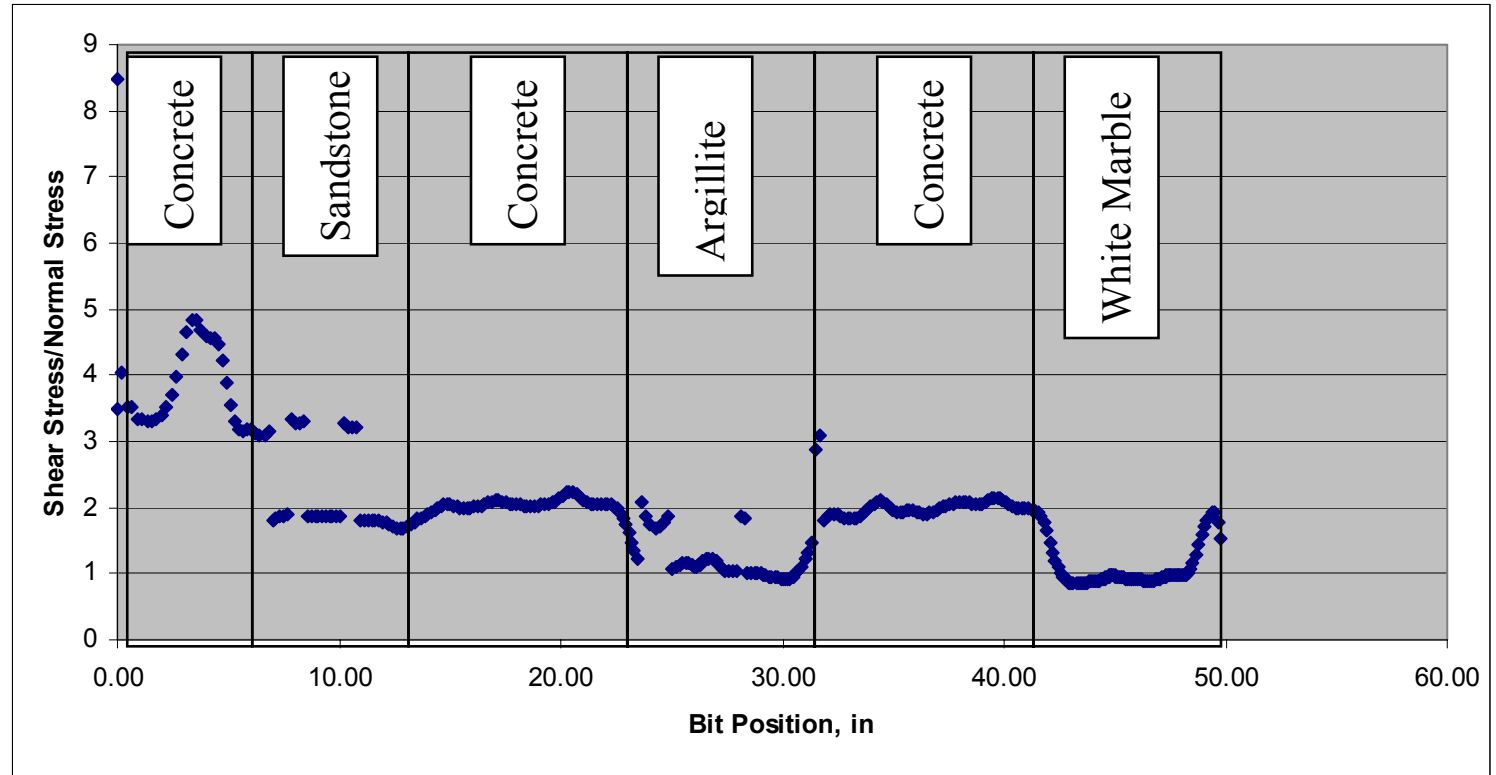

Figure 6.3 Shear Stress/Normal Stress versus Bit Position—Layer Block \#5

The dark gray areas of Figure 6.3 represent the position concrete layers in the block. The various layers of strata within the block are annotated in Figure 6.3. With the exception of the first seven inches of drilling, the shear stress/normal stress ratio appears to correspond well with the positions of the various rock layers. When beginning the drilling of a new hole, the DCU ramps the penetration rate and rotation rate up to their pre-set values over the first ten inches of drilling. This ramp-up feature is the likely cause for the unusable data at the beginning of the hole. Additionally there are some outlier data points in the sandstone and argillite domains. The cause of these outliers is not known

The applicability of the shear stress/normal stress ratio to the detection of fractures was also examined. Fractures represent a small zone of weakness within a rock mass. Consequently, the shear stress/normal stress ratio should increase significantly near the fracture, then decrease back to its level before encountering the fracture. Therefore, a fracture or void in a continuous 
material should appear as a small region of high shear stress/normal stress ratio on a plot of ratio versus bit position. Figure 6.4 shows the shear stress/normal stress ratio for the simulated fracture block.

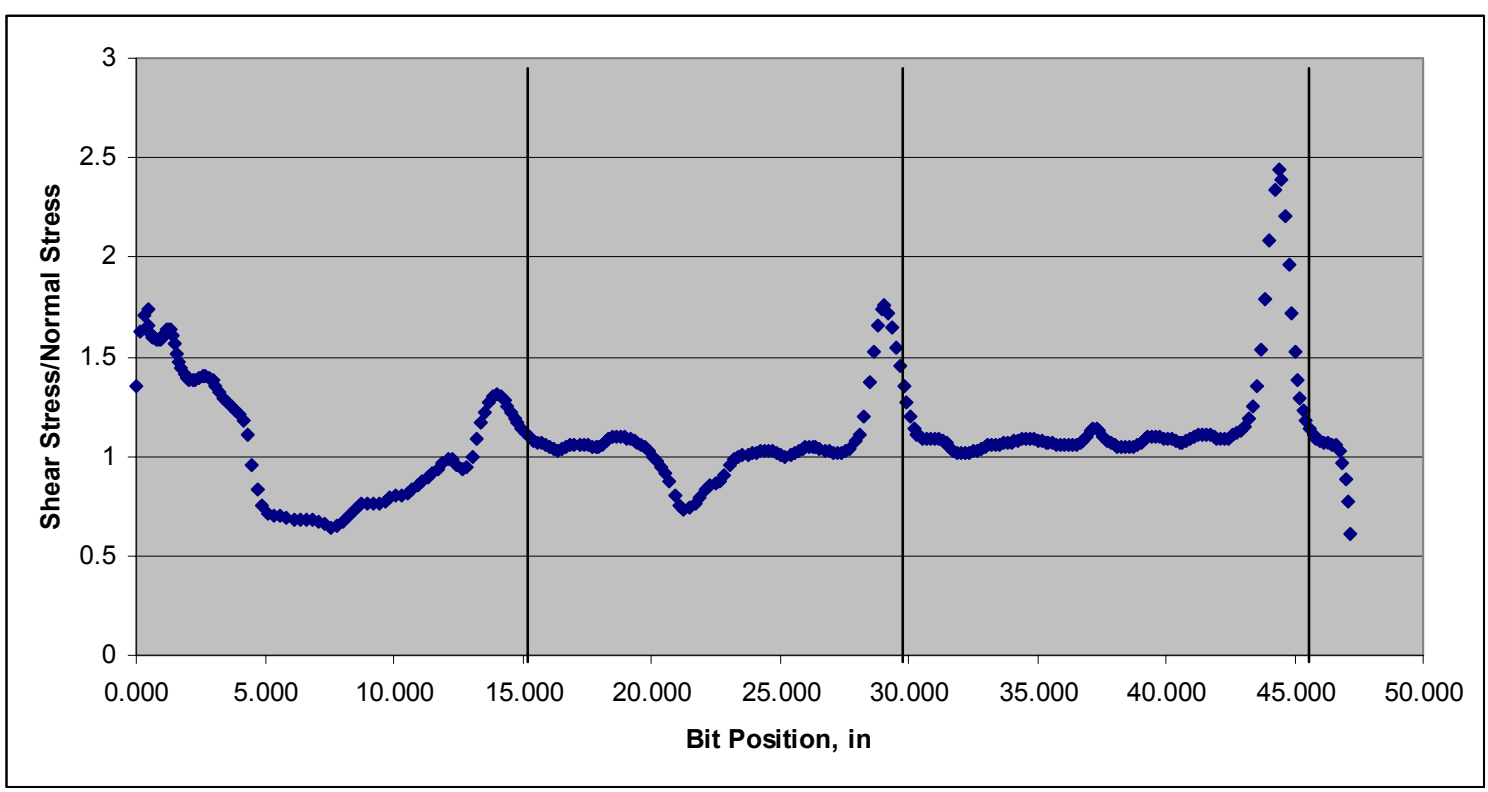

Figure 6.4 Shear Stress/Normal Stress versus Bit Position—Simulated Fracture Block

Three sizes of fractures were simulated with the fracture block A 1/16 in fracture was simulated at the 15 -inch bit position. A $1 / 8$ in fracture was located at 30 -inch, and a 3/8-in fracture was located at 45 inch positions. The $1 / 8$ and $3 / 8$ in fracture appear clearly as data peaks in Figure 6.4. There is a small peak associated with the 1/16 in fracture. However, this peak is not as clearly defined as those associated with the larger fractures.

\subsection{Feature Detection Methodology}

Figures 6.3 and 6.4 indicate that an automated detection program could possibly be used to detect fractures and interfaces between two differing layers of strata. Data from laboratory tests shows that when the drill encounters a feature, (fracture or interface) a sharp change in the 
shear stress/normal stress ratio usually occurs. Additionally, the magnitude of the shear stress/normal stress ratio appears to reflect the relative strength of the material drilled. However, this study will only examine the accuracy of using the shear stress/normal stress ratio to detect features. The ability to distinguish between different types of features will be examined in a future study.

A data analysis software package was used to develop an automated detection system. The system requires minimal operator input; the operator simply inputs the data file name, and the system quantitatively predicts the location of geologic features.

There are four major steps in the automated data analysis program:

- Determination of shear stress/normal stress ratio as outlined in Chapter 5

- Numerical calculation of the slope of ratio

- Statistical analysis of slope

- Display of results

\section{$\underline{\text { 6.1.1 Determination of Shear Stress/Normal Stress Ratio }}$}

The process of determination of the shear stress/normal stress ratio was defined in Chapter 5. The equations listed in Chapter 5 were programmed into the data analysis package to determine the ratio

\subsubsection{Numerical Calculation of the Slope of Shear Stress/Normal Stress Ratio}

The slope of the shear stress/normal stress ratio is used to define locations where a sharp change in the ratio occurs. As mentioned previously (p65-66), these locations generally correspond to the location of some type of geologic feature. A numerical method is used to 
estimate the slope of the ratio at a given data point. The method can be described as backwards difference method. First, the difference between successive ratios is calculated:

$$
\mathrm{dR}_{\mathrm{i}}=\mathrm{R}_{\mathrm{i}}-\mathrm{R}_{\mathrm{i}-1}
$$

Where:

$$
\begin{aligned}
& d R_{i}-\quad \text { Ratio difference at point } i \\
& R_{i}-\quad \text { ratio at point } i \\
& R_{i-1}-\quad \text { ratio at point } i-1
\end{aligned}
$$

Next, the difference between successive bit positions is calculated:

$$
\mathrm{dx}_{\mathrm{i}}=\mathrm{x}_{\mathrm{i}}-\mathrm{x}_{\mathrm{i}-1}
$$

Where:

$$
\begin{array}{ll}
\mathrm{dx}_{\mathrm{i}}- & \text { position difference at point } \mathrm{i} \\
\mathrm{x}_{\mathrm{i}}- & \text { bit position at point } \mathrm{i} \\
\mathrm{x}_{\mathrm{i}-1}- & \text { bit position at point } \mathrm{i}-1
\end{array}
$$

Finally, the slope is estimated

$$
\mathrm{b}_{\mathrm{i}}=\mathrm{dR}_{\mathrm{i}} / \mathrm{dx}_{\mathrm{i}}
$$

Where:

$$
\begin{array}{ll}
b_{i}- & \text { slope of ratio at point } i \\
d R_{i}- & \text { ratio difference at point } i \\
d x_{i}- & \text { position difference at point } i
\end{array}
$$




\subsubsection{Statistical Analysis of Slope}

Points of maximum slope are assumed to be the location of some geologic feature detected in the drilling data. These features could be interfaces between two layers of strata, fractures, or weak zones. A statistical method was used to quantitatively define the locations of maximum slope. Points of maximum slope are defined as points where the value of slope lies outside the positive or negative outer fence. The outer fences are determined for each hole. First, Q1 and Q3 are determined. Q1 is the value of slope at position $0.25(\mathrm{n}+1)$. Where $\mathrm{n}$ is the number of data points in a hole. Q3 is the value of slop at position $0.75(n+1)$. The interquartile range is then determined:

$$
\mathrm{IQR}=\mathrm{Q}_{3}-\mathrm{Q}_{1}
$$

Where:

$$
\begin{aligned}
& \text { IQR - interquartile range } \\
& \mathrm{Q}_{3}-\quad \text { third quartile } \\
& \mathrm{Q}_{1}-\quad \text { first quartile }
\end{aligned}
$$

Next the locations of the outer fences are determined. One outer fence will be positive, while the other will be negative:

$$
\begin{aligned}
& \mathrm{OFP}=\mathrm{Q}_{3}+3(\mathrm{IQR}) \\
& \mathrm{OFN}=\mathrm{Q}_{3}-3(\mathrm{IQR})
\end{aligned}
$$

Where:

$$
\begin{aligned}
& \text { OFP - positive outer fence } \\
& \text { OFN - negative outer fence } \\
& \mathrm{Q}_{3}-\quad \text { third quartile }
\end{aligned}
$$


IQR - interquartile range

Due to operating characteristics of the roof bolter, some data is eliminated from this analysis method. The first 10 inches of drilling data is eliminated because of the influence of the ramp-up feature of the DCU on the drilling data. Also, the last 1 inch of drilling data is eliminated. Drilling of a hole is usually conducted until the drill mast reaches its maximum height. At this point, the drill cannot penetrate any further into the rock mass. Often, the computer control and data collection is still operating at the end of a hole and useless drilling data is collected. By eliminating the last 1 inch of data, this useless data should be removed.

\subsection{Results of Data Analysis}

Data from the three phases of drilling tests were analyzed using the analysis methodology outlined in Section 6.2. The output of the data analysis program was compared to block geometry, a scope log, or a core log depending on the data available. If a prediction was located within $+/-2$ inches of a feature location from a validation source, the prediction was deemed successful. Otherwise, the prediction was classified as a mis-prediction. Any predictions in a homogeneous medium such as the solid concrete block or sandstone roof were classified as mispredictions. Two measures or accuracy are shown in the results. The first percentage is the percentage of total predictions that were classified as successful predictions of features. The second percentage represents the percentage of features present from the validation source that were detected by the analysis program. 


\subsubsection{Phase 1 Laboratory Results}

Data was collected from three blocks during the phase 1 laboratory tests: the solid concrete block, the simulated fracture block, and layer block 6. Table 6.1 shows the data analysis results from the solid concrete block.

Table 6.1: Solid Concrete Block Results_-Phase 1 Lab Tests

1.375" Bit

\begin{tabular}{|c|c|c|c|c|}
\hline Hole & P.R. & RPM & M.P. & M.P. Locations \\
\hline 27 & 1.1 & 300 & 1 & 26.59 \\
\hline 28 & 1.1 & 500 & 4 & n/a \\
\hline 29 & 1.1 & 300 & 0 & $\mathrm{n} / \mathrm{a}$ \\
\hline 30 & 1.1 & 500 & 0 & $\mathrm{n} / \mathrm{a}$ \\
\hline 31 & 1.1 & 300 & 3 & $47.82,48.29,49.09$ \\
\hline 32 & 1.1 & 500 & 0 & \\
\hline
\end{tabular}

\begin{tabular}{|c|c|c|c|c|}
\hline \multicolumn{5}{|c|}{$\mathbf{1 . 0 3 1 " ~ B i t ~}$} \\
\hline Hole & P.R. & RPM & M.P. & M.P. Locations \\
\hline 33 & 1.1 & 300 & 0 & n/a \\
\hline 34 & 1.1 & 500 & 3 & $42.18,42.76,43.24$ \\
\hline 35 & 1.1 & 300 & 2 & $38.99,39.51$ \\
\hline 36 & 1.1 & 500 & 0 & $\mathrm{n} / \mathrm{a}$ \\
\hline 37 & 1.1 & 300 & 0 & $\mathrm{n} / \mathrm{a}$ \\
\hline 38 & 1.1 & 500 & 0 & $\mathrm{n} / \mathrm{a}$ \\
\hline
\end{tabular}

One half of the 1.375 " holes were successful, while two thirds of the 1.031 " holes were successful. There appears to be no particular correlation between control parameters used and the success of a hole.

Table 6.2 shows the data analysis results from the simulated fracture block

Table 6.2: Fracture Block Results_-Phase 1 Lab Tests

\begin{tabular}{|c|c|c|c|c|c|c|c|c|}
\hline & & & \multicolumn{2}{c|}{ 1.031" Bit } \\
\cline { 4 - 9 } Hole & P.R. & RPM & 15 & 30 & 45 & & \multicolumn{3}{c|}{ Porrect/Total } & Pred./Actual \\
\hline 1 & 0.4 & 300 & 2 & $\mathrm{x}$ & $\mathrm{x}$ & 3 & $40.0 \%$ & $33.3 \%$ \\
\hline 2 & 0.8 & 300 & 1 & 2 & 1 & 6 & $40.0 \%$ & $100.0 \%$ \\
\hline 3 & 1.5 & 300 & 1 & 1 & $\mathrm{x}$ & 1 & $66.7 \%$ & $66.7 \%$ \\
\hline 4 & 0.4 & 400 & $\mathrm{x}$ & $\mathrm{x}$ & 3 & 3 & $50.0 \%$ & $33.3 \%$ \\
\hline
\end{tabular}




\begin{tabular}{|c|c|c|c|c|c|c|c|c|}
\hline 5 & 0.8 & 450 & $\mathrm{x}$ & 1 & $\mathrm{x}$ & 8 & $11.1 \%$ & $33.3 \%$ \\
\hline 6 & 1.5 & 500 & 2 & 2 & 1 & 5 & $50.0 \%$ & $100.0 \%$ \\
\hline 7 & 1.5 & 300 & 1 & $\mathrm{x}$ & $\mathrm{x}$ & 7 & $12.5 \%$ & $33.3 \%$ \\
\hline
\end{tabular}

In general, the percentages were relatively low for all holes. Only two of the seven holes detected all 3 fractures. Again, no significant correlation between control parameters and analysis results can be seen. However, two of the three holes drilled at a penetration rate of 1.5 in/sec had the highest correct/total percentage. In addition, one of these holes detected all three fractures.

Table 6.3 shows the analysis results for layer block \#6. Although this block contains 8 interfaces, only 6 were contained within the range of analyzed data.

Table 6.3: Layer Block 6 Results_Phase 1 Lab Tests

\begin{tabular}{|c|c|c|c|c|c|c|c|c|c|c|}
\hline \multicolumn{11}{|c|}{ 1.375" Bit } \\
\hline \multirow[b]{2}{*}{ Hole } & \multirow[b]{2}{*}{ P.R. } & \multirow[b]{2}{*}{ RPM } & \multicolumn{5}{|c|}{$\begin{array}{l}\text { No of Pred. within 2" of Actual } \\
\text { Features }\end{array}$} & \multirow[b]{2}{*}{ M.P. } & \multicolumn{2}{|c|}{ Percentages } \\
\hline & & & 16 & 27 & 33.5 & 45 & 50 & & Correct/Total & Pred./Actual \\
\hline 3 & 1.5 & 300 & $\mathrm{x}$ & $\mathrm{x}$ & $x$ & $x$ & $\mathrm{x}$ & 0 & $0.0 \%$ & $0.0 \%$ \\
\hline 4 & 1.5 & 300 & $\mathrm{x}$ & $\mathrm{x}$ & 2 & $\mathrm{x}$ & $\mathrm{x}$ & 2 & $50.0 \%$ & $16.7 \%$ \\
\hline 5 & 1.5 & 300 & 1 & $x$ & 2 & 1 & $x$ & 0 & $100.0 \%$ & $50.0 \%$ \\
\hline 6 & 1.1 & 300 & 2 & 1 & $x$ & $\mathrm{x}$ & $\mathrm{x}$ & 4 & $42.8 \%$ & $33.3 \%$ \\
\hline 7 & 1.1 & Free & $\mathrm{x}$ & 1 & 2 & 1 & $\mathrm{x}$ & 1 & $80.0 \%$ & $50.0 \%$ \\
\hline 8 & 0.6 & Free & 1 & $x$ & $x$ & $x$ & $x$ & 2 & $33.3 \%$ & $16.7 \%$ \\
\hline 9 & Free & 400 & 2 & $x$ & $x$ & 1 & $\mathrm{x}$ & 0 & $100.0 \%$ & $33.3 \%$ \\
\hline 10 & Free & 500 & 2 & 2 & $x$ & $\mathrm{x}$ & $\mathrm{x}$ & 0 & $100.0 \%$ & $33.3 \%$ \\
\hline 11 & Free & 400 & 1 & $\mathrm{x}$ & 1 & $\mathrm{x}$ & $\mathrm{x}$ & 1 & $66.7 \%$ & $33.3 \%$ \\
\hline 12 & Free & 500 & $x$ & $\mathrm{x}$ & $x$ & $x$ & $x$ & 0 & $0.0 \%$ & $0.0 \%$ \\
\hline 14 & Free & 500 & $x$ & 1 & $x$ & 2 & $x$ & 4 & $42.8 \%$ & $33.3 \%$ \\
\hline 15 & Free & 500 & $\mathrm{x}$ & 1 & 1 & $x$ & $x$ & 1 & $66.7 \%$ & $33.3 \%$ \\
\hline
\end{tabular}

\begin{tabular}{|c|c|c|c|c|c|c|c|c|c|c|}
\hline \multirow[b]{3}{*}{ Hole } & \multirow[b]{3}{*}{ P.R. } & \multirow[b]{3}{*}{ RPM } & \multicolumn{6}{|c|}{ 1.031" Bit } & & \\
\hline & & & & of $P$ & $\begin{array}{l}\text { within } \\
\text { eature }\end{array}$ & $\mathrm{Ac}$ & & \multirow[b]{2}{*}{ M.P. } & \multicolumn{2}{|c|}{ Percentages } \\
\hline & & & 16 & 27 & 33.5 & 45 & 50 & & Correct/Total & Pred./Actua \\
\hline 1 & 1.1 & 300 & $\mathrm{x}$ & $\mathrm{x}$ & 1 & $\mathrm{x}$ & $x$ & 3 & $25.0 \%$ & $16.7 \%$ \\
\hline 2 & 1.5 & 300 & $\mathrm{x}$ & $\mathrm{x}$ & $x$ & $x$ & $x$ & 2 & $0.0 \%$ & $0.0 \%$ \\
\hline 13 & Free & 400 & $x$ & $\mathrm{x}$ & $\mathrm{x}$ & 1 & $x$ & 0 & $100.0 \%$ & $16.7 \%$ \\
\hline
\end{tabular}


Again, there appears to be no correlation between pre-set control parameters and analysis results. Three of the free penetration holes had no mis-predictions. However, these holes only detected a maximum of $1 / 3$ of the features. The hole drilled with $1.1 \mathrm{in} / \mathrm{sec}$ penetration rate and free rotation had only one mis-prediction and detected half of the interfaces in the block. However, when the penetration rate was lowered to $0.6 \mathrm{in} / \mathrm{sec}$, the percentages dropped significantly.

\subsubsection{Underground Mine Test Results}

The drill data analysis systems were tested at four underground coal mines. Mine A data is not shown in these results because there was no validation data collected, and thus no way to quantify the accuracy of the analysis methods. Mines B and C both had roofs consisting of shale and sandstone with an interface present. Mine D had a homogeneous sandstone roof. In addition to holes in the roof, angled holes were drilled to intercept a high angle fracture in the roof, and to intercept the coal rib/sandstone roof interface.

Table 6.4 shows the analysis results for Mine B. Several pre-set control methodologies were tested in this mine

Table 6.4: Mine B Test Results

$1.031 "$ Bit

\begin{tabular}{|c|c|c|c|c|c|c|c|c|}
\hline \multirow[b]{2}{*}{ Hole } & \multirow[b]{2}{*}{ P.R. } & \multirow[b]{2}{*}{ RPM } & \multirow{2}{*}{$\begin{array}{l}\text { Interface } \\
\text { Location }\end{array}$} & \multirow{2}{*}{$\begin{array}{l}\text { No. of Pred. within } \\
2 " \text { of Actual }\end{array}$} & \multirow[b]{2}{*}{ M.P. } & \multicolumn{2}{|c|}{ Percentages } & \multirow[t]{2}{*}{$\begin{array}{c}\begin{array}{c}\text { Validation } \\
\text { Source }\end{array} \\
\end{array}$} \\
\hline & & & & & & Correct/Pred. & Pred./Total & \\
\hline 20 & 1.5 & Free & $35 "$ & 0 & 5 & $0 \%$ & $0 \%$ & Core \\
\hline 21 & 1.5 & Free & $35 "$ & 0 & 5 & $0 \%$ & $0 \%$ & Core \\
\hline 22 & 0.8 & Free & $35 "$ & 0 & 5 & $0 \%$ & $0 \%$ & Core \\
\hline 23 & 0.8 & Free & $35 "$ & 0 & 3 & $0 \%$ & $0 \%$ & Core \\
\hline 24 & Free & 500 & $35 "$ & 0 & 6 & $0 \%$ & $0 \%$ & Core \\
\hline 25 & Free & 500 & $35 "$ & 0 & 10 & $0 \%$ & $0 \%$ & Core \\
\hline 26 & Free & 400 & $35 "$ & 0 & 7 & $0 \%$ & $0 \%$ & Core \\
\hline 27 & Free & 400 & $35 "$ & 0 & 9 & $0 \%$ & $0 \%$ & Core \\
\hline 28 & 1.5 & Free & $35 "$ & 0 & 5 & $0 \%$ & $0 \%$ & Core \\
\hline 29 & 1.5 & Free & $35 "$ & 0 & 2 & $0 \%$ & $0 \%$ & Core \\
\hline
\end{tabular}




\begin{tabular}{|l|c|c|c|c|c|c|c|c|}
\hline 30 & 0.8 & Free & $35^{\prime \prime}$ & 0 & 2 & $0 \%$ & $0 \%$ & Core \\
\hline 31 & 0.8 & Free & $35^{\prime \prime}$ & 0 & 3 & $0 \%$ & $0 \%$ & Core \\
\hline 32 & Free & 500 & $35^{\prime \prime}$ & 0 & 4 & $0 \%$ & $0 \%$ & Core \\
\hline 33 & Free & 500 & $35^{\prime \prime}$ & 0 & 2 & $0 \%$ & $0 \%$ & Core \\
\hline 34 & Free & 400 & $35^{\prime \prime}$ & 0 & 4 & $0 \%$ & $0 \%$ & Core \\
\hline 35 & Free & 400 & $35^{\prime \prime}$ & 0 & 5 & $0 \%$ & $0 \%$ & Core \\
\hline
\end{tabular}

\subsection{5" Bit}

\begin{tabular}{|c|c|c|c|c|c|c|c|c|}
\hline \multirow[b]{2}{*}{ Hole } & \multirow[b]{2}{*}{ P.R. } & \multirow[b]{2}{*}{ RPM } & \multirow{2}{*}{$\begin{array}{l}\text { Interface } \\
\text { Location }\end{array}$} & \multirow{2}{*}{$\begin{array}{c}\text { No. of Pred. within } \\
2 \text { " of Actual }\end{array}$} & \multirow[b]{2}{*}{ M.P. } & \multicolumn{2}{|c|}{ Percentages } & \multirow{2}{*}{$\begin{array}{c}\text { Validation } \\
\text { Source }\end{array}$} \\
\hline & & & & & & Correct/Pred. & Pred./Total & \\
\hline 1 & 1.1 & Free & $35 "$ & 0 & 3 & $0 \%$ & $0 \%$ & Core \\
\hline 2 & 1.1 & Free & $35 "$ & 0 & 7 & $0 \%$ & $0 \%$ & Core \\
\hline 3 & 0.8 & Free & $35 "$ & 0 & 5 & $0 \%$ & $0 \%$ & Core \\
\hline 4 & 0.8 & Free & $35 "$ & 0 & 4 & $0 \%$ & $0 \%$ & Core \\
\hline 5 & 0.8 & Free & $35 "$ & 0 & 2 & $0 \%$ & $0 \%$ & Core \\
\hline 6 & 0.8 & Free & $35 "$ & 0 & 2 & $0 \%$ & $0 \%$ & Core \\
\hline 7 & 1.1 & Free & $35 "$ & 0 & 5 & $0 \%$ & $0 \%$ & Core \\
\hline 8 & 5.1 & Free & $35 "$ & 0 & 4 & $0 \%$ & $0 \%$ & Core \\
\hline $8 a$ & 5.1 & Free & $35 "$ & 0 & 2 & $0 \%$ & $0 \%$ & Core \\
\hline 9 & Free & 502 & $35 "$ & 0 & 0 & $0 \%$ & $0 \%$ & Core \\
\hline 10 & Free & 502 & $35 "$ & 0 & 2 & $0 \%$ & $0 \%$ & Core \\
\hline 11 & Free & 405 & $35 "$ & 1 & 3 & $25 \%$ & $100 \%$ & Core \\
\hline 12 & Free & 405 & $35 "$ & 0 & 4 & $0 \%$ & $0 \%$ & Core \\
\hline 13 & Free & 502 & 33.65 & 1 & 2 & $33.30 \%$ & $100 \%$ & Scope \\
\hline 14 & Free & 502 & 34.25 & 0 & 1 & $0 \%$ & $0 \%$ & Scope \\
\hline 15 & Free & 405 & 34.6 & 0 & 0 & $0 \%$ & $0 \%$ & Scope \\
\hline 16 & Free & 405 & 35.25 & 0 & 0 & $0 \%$ & $0 \%$ & Scope \\
\hline 17 & 1.1 & Free & $35 "$ & 0 & 7 & $0 \%$ & $0 \%$ & Core \\
\hline 18 & 0.8 & Free & 33.5 & 1 & 3 & $25 \%$ & $100 \%$ & Scope \\
\hline 19 & 5.1 & 502 & 35 & 1 & 2 & $33.30 \%$ & $100 \%$ & Scope \\
\hline
\end{tabular}

In general, the correct/total predictions for this mine are very low. There are two likely factors causing these low percentages. First, the value of the ratio is not as consistent with the geology as it is in laboratory tests. This variability causes many mis-predictions when using the slope method to determine the location of geologic feature. Additionally, most of the holes were validated with a single core hole that was located some distance from the actual drilled holes. This is especially true with the 1.031 " holes which could not be scoped.

Table 6.5 shows the results from Mine C. For this mine, all holes were drilled with a free rotation rate. Penetration rates of $0.8,1.1,1.5$, and $1.7 \mathrm{in} / \mathrm{sec}$ were tested. All holes were drilled with 1.375 " diameter bits to facilitate increased scoping as a method of validation 
Table 6.5: Mine C Test Results

\begin{tabular}{|c|c|c|c|c|c|c|c|c|}
\hline \multirow[b]{3}{*}{ Hole } & \multicolumn{7}{|c|}{ 1.375" Bit } & \multirow[b]{3}{*}{ Validation Source } \\
\hline & \multirow[b]{2}{*}{ P.R. } & \multirow[b]{2}{*}{ RPM } & \multirow{2}{*}{$\begin{array}{l}\text { Interface } \\
\text { Location }\end{array}$} & \multirow{2}{*}{$\begin{array}{c}\text { No. of Pred. within 2" } \\
\text { of Actual }\end{array}$} & \multirow[b]{2}{*}{ M.P. } & \multicolumn{2}{|c|}{ Percentages } & \\
\hline & & & & & & Correct/Pred. & Pred./Total & \\
\hline 1 & 0.8 & Free & 28 & 0 & 1 & $0.0 \%$ & $0.0 \%$ & Core \\
\hline 2 & 0.8 & Free & 28 & 0 & 10 & $0.0 \%$ & $0.0 \%$ & Core \\
\hline 3 & 1.1 & Free & 28 & 1 & 3 & $25.0 \%$ & $100.0 \%$ & Core \\
\hline 4 & 1.1 & Free & 28 & 0 & 4 & $0.0 \%$ & $0.0 \%$ & Core \\
\hline 5 & 1.5 & Free & 30.25 & 3 & 5 & $37.5 \%$ & $100.0 \%$ & Scope \\
\hline 6 & 1.5 & Free & 28 & 1 & 6 & $14.3 \%$ & $100.0 \%$ & Core \\
\hline 7 & 0.8 & Free & 28 & 1 & 5 & $16.7 \%$ & $100.0 \%$ & Core \\
\hline 8 & 0.8 & Free & 28 & 1 & 3 & $25.0 \%$ & $100.0 \%$ & Core \\
\hline 9 & 1.1 & Free & 28 & 0 & 6 & $0.0 \%$ & $0.0 \%$ & Core \\
\hline 10 & 1.1 & Free & 26.5 & 0 & 2 & $0.0 \%$ & $0.0 \%$ & Scope \\
\hline 11 & 1.5 & Free & 28 & 0 & 3 & $0.0 \%$ & $0.0 \%$ & Core \\
\hline 12 & 1.5 & Free & 28.1 & 1 & 11 & $8.3 \%$ & $100.0 \%$ & Scope \\
\hline 13 & 1.1 & Free & 42.3 & 1 & 4 & $20.0 \%$ & $100.0 \%$ & Scope \\
\hline 14 & 1.1 & Free & 28 & 0 & 1 & $0.0 \%$ & $0.0 \%$ & Core \\
\hline 15 & 1.1 & Free & 28 & 0 & 2 & $0.0 \%$ & $0.0 \%$ & Core \\
\hline 16 & 1.1 & Free & 28 & 0 & 4 & $0.0 \%$ & $0.0 \%$ & Core \\
\hline 17 & 1.1 & Free & 32.3 & 0 & 5 & $0.0 \%$ & $0.0 \%$ & Scope \\
\hline 18 & 1.5 & Free & 28 & 0 & 6 & $0.0 \%$ & $0.0 \%$ & Core \\
\hline 19 & 1.5 & Free & 28 & 2 & 3 & $40.0 \%$ & $100.0 \%$ & Core \\
\hline 20 & 1.5 & Free & 28 & 2 & 2 & $50.0 \%$ & $100.0 \%$ & Core \\
\hline 21 & 1.5 & Free & 30.7 & 1 & 4 & $20.0 \%$ & $100.0 \%$ & Scope \\
\hline 22 & 1.5 & Free & 28 & 1 & 4 & $20.0 \%$ & $100.0 \%$ & Core \\
\hline 23 & 1.7 & Free & 32.3 & 0 & 4 & $0.0 \%$ & $0.0 \%$ & Scope \\
\hline 24 & 1.7 & Free & 28 & 2 & 4 & $33.3 \%$ & $100.0 \%$ & Core \\
\hline 25 & 1.7 & Free & 28 & 0 & 5 & $0.0 \%$ & $0.0 \%$ & Core \\
\hline 26 & 1.7 & Free & 26.1 & 0 & 3 & $0.0 \%$ & $0.0 \%$ & Scope \\
\hline 27 & 1.7 & Free & 28 & 0 & 9 & $0.0 \%$ & $0.0 \%$ & Core \\
\hline
\end{tabular}

While the correct/total prediction percentages are still quite low, a large number of test holes detected the shale/sandstone interface. 8 of 10 holes drilled at $1.5 \mathrm{in} / \mathrm{sec}$ penetration rate detected the interface. Other penetration rates generally did not detect the interface. Despite the success of some control parameters in detecting the interface, a large number of mis-predictions reduced the correct/total prediction percentage. Again, this factor is likely caused by greater variability of the ratio in actual mine tests, and the use of slope to detect the interface locations. 
Three different types of tests were conducted at Mine D. First, holes were drilled into the sandstone roof to collect data from a relatively homogeneous medium. In addition to the roof holes, the angle drilling feature of the bolter was used to drill across a high-angle roof fracture, and to drill through the coal rib and into the roof. Tables $6.5,6.6$, and 6.7 show results from these tests.

Table 6.6: Mine D Roof Drilling Tests

\subsection{5" Bit}

\begin{tabular}{|c|c|c|c|c|}
\hline Hole & P.R. & RPM & M.P. & M.P. Locations \\
\hline 1 & 1.5 & Free & 0 & n/a \\
\hline 2 & 1.5 & Free & 2 & $15.43,22.68$ \\
\hline 3 & 1.5 & Free & 3 & $15.21,22.3731 .75$ \\
\hline 4 & 1.5 & Free & 3 & $26.42,28.39,42.67$ \\
\hline 5 & 1.5 & Free & 2 & $22.39,22.86$ \\
\hline 6 & 1.5 & Free & 1 & 22.42 \\
\hline 7 & 1.5 & Free & 1 & 22.76 \\
\hline 8 & 1.5 & Free & 0 & $\mathrm{n} / \mathrm{a}$ \\
\hline 16 & 1.5 & Free & 3 & $29.58,30.55,34.93$ \\
\hline 17 & 1.5 & Free & 1 & 18.33 \\
\hline 18 & 1.5 & Free & 1 & 20.6 \\
\hline
\end{tabular}

Table 6.7: Mine D Rib Drilling Tests

1.375" Bit

\begin{tabular}{|c|c|c|c|c|c|c|c|}
\hline \multirow[b]{2}{*}{ Hole } & \multirow[b]{2}{*}{ P.R. } & \multirow[b]{2}{*}{ RPM } & \multirow{2}{*}{$\begin{array}{l}\text { Interface } \\
\text { Location }\end{array}$} & \multirow{2}{*}{$\begin{array}{l}\text { No. of Pred. } \\
\text { within 2" of } \\
\text { Actual }\end{array}$} & \multirow{2}{*}{ M.P } & \multicolumn{2}{|c|}{ Percentages } \\
\hline & & & & & & Correct/Total & Pred/Total \\
\hline $\mathrm{R} 1$ & 1.5 & Free & $20 "$ & 0 & 1 & $0.0 \%$ & $0.0 \%$ \\
\hline $\mathrm{R} 2$ & 1.5 & Free & $18 "$ & 0 & 4 & $0.0 \%$ & $0.0 \%$ \\
\hline R3 & 1.5 & Free & 17" & 0 & 2 & $0.0 \%$ & $0.0 \%$ \\
\hline
\end{tabular}

Table 6.8: Mine D Roof Fracture Drilling Tests

1.375" Bit

\begin{tabular}{|c|c|c|c|c|c|c|c|}
\hline \multirow[b]{2}{*}{ Hole } & \multirow[b]{2}{*}{ P.R. } & \multirow[b]{2}{*}{ RPM } & \multirow{2}{*}{$\begin{array}{c}\text { Fracture } \\
\text { Location(s) }\end{array}$} & \multirow{2}{*}{$\begin{array}{c}\text { No. of Pred. } \\
\text { within 2" of } \\
\text { Actual } \\
\end{array}$} & \multirow{2}{*}{ M.P } & \multicolumn{2}{|c|}{ Percentages } \\
\hline & & & & & & Correct/Total & Pred/Total \\
\hline C1 & 1.5 & Free & $16.5^{\prime \prime}$ & 2 & 4 & $33.3 \%$ & $100.0 \%$ \\
\hline $\mathrm{C} 2$ & 1.5 & Free & 5.5-6.5" & n/a & $\mathrm{n} / \mathrm{a}$ & n/a & $n / a$ \\
\hline C3 & 1.5 & Free & $\begin{array}{l}\text { 16.25-18", } \\
\text { 33.25-35" }\end{array}$ & $0 / 1$ & 2 & $33.3 \%$ & $50.0 \%$ \\
\hline $\mathrm{C} 4$ & 1.5 & Free & 17-20.5" & 2 & 3 & $40.0 \%$ & $100.0 \%$ \\
\hline
\end{tabular}


Results from these tests show poor results. Only 2 of the 11 holes drilled in the homogeneous sandstone could be considered correct. These 2 holes detected no features. 4 of the 11 holes had only one mis-prediction. None of the rib drilling holes detected the coal/sandstone interface. Two of the four fracture holes correctly detected the high-angle fracture. One hole detected a weak zone, but not the fracture. Hole C2 was not analyzed due to errors in the data. All of the fracture holes contained at least two mis-predictions.

\section{$\underline{6.2 .3 \text { Phase } 2 \text { Laboratory Test Results }}$}

Despite poor data analysis results in the field, graphs of ratio versus bit position showed some strong correlation with roof geology. This was especially true when drilling with a free rotation rate. Since very few holes were drilled in the laboratory with a free rotation rate, a laboratory testing plan focusing on free rotation holes was developed. In addition to free rotation holes, a low penetration rate drilling program was tested. For these tests, penetration rate was set at the machine minimum of $0.4 \mathrm{in} / \mathrm{sec}$, and rotation rate was varied at levels of 300,400 , and free. The second phase of laboratory tests were conducted on the simulated fracture block and layer block \#5.

Table 6.9 shows the test results from the simulated fracture block.

Table 6.9: Fracture Block Results—Phase 2 Lab Tests

1.375" Bit

\begin{tabular}{|c|c|c|c|c|c|c|c|c|}
\hline & & & \multicolumn{3}{|c|}{ No of Pred. within 2" of Actual } & & \multicolumn{2}{|c|}{ Percentages } \\
\cline { 9 - 10 } \cline { 8 - 8 } Hole & P.R. & RPM & 15 & 30 & 45 & \multirow{2}{*}{ M.P. } & Correct/Total & Pred./Actual \\
\hline 1 & 1.5 & Free & 1 & 1 & $\mathrm{x}$ & 0 & $100.0 \%$ & $66.7 \%$ \\
\hline 2 & 1.5 & Free & $\mathrm{x}$ & 1 & $\mathrm{x}$ & 2 & $33.3 \%$ & $33.3 \%$ \\
\hline 3 & 1.5 & Free & $\mathrm{x}$ & 1 & 1 & 1 & $66.7 \%$ & $66.7 \%$ \\
\hline 4 & 1.1 & Free & $\mathrm{x}$ & 1 & 3 & 1 & $80.0 \%$ & $66.7 \%$ \\
\hline 5 & 1.1 & Free & $\mathrm{x}$ & 2 & 2 & 1 & $80.0 \%$ & $66.7 \%$ \\
\hline 6 & 1.1 & Free & $\mathrm{x}$ & 3 & 3 & 1 & $85.7 \%$ & $66.7 \%$ \\
\hline 7 & 1.1 & Free & $\mathrm{x}$ & 1 & 3 & 2 & $66.7 \%$ & $66.7 \%$ \\
\hline
\end{tabular}




\begin{tabular}{|c|c|c|c|c|c|c|c|c|}
\hline 8 & 0.8 & Free & $\mathrm{x}$ & $\mathrm{x}$ & $\mathrm{x}$ & 2 & $0.0 \%$ & $0.0 \%$ \\
\hline 9 & 0.8 & Free & $\mathrm{x}$ & 2 & $\mathrm{x}$ & 1 & $66.7 \%$ & $33.3 \%$ \\
\hline 10 & 0.8 & Free & $\mathrm{x}$ & 3 & 3 & 0 & $100.0 \%$ & $66.7 \%$ \\
\hline 11 & 1.1 & Free & $\mathrm{x}$ & 3 & 2 & 0 & $100.0 \%$ & $66.7 \%$ \\
\hline 12 & 1.1 & Free & $\mathrm{x}$ & $\mathrm{x}$ & 1 & 4 & $20.0 \%$ & $33.3 \%$ \\
\hline 13 & 1.1 & Free & 1 & 3 & 4 & 0 & $100.0 \%$ & $100.0 \%$ \\
\hline 14 & 0.4 & Free & $\mathrm{x}$ & 2 & 2 & 2 & $66.7 \%$ & $66.7 \%$ \\
\hline 15 & 0.4 & Free & $\mathrm{x}$ & 2 & 1 & 0 & $100.0 \%$ & $66.7 \%$ \\
\hline 16 & 0.4 & 400 & 2 & 1 & $\mathrm{x}$ & 0 & $100.0 \%$ & $66.7 \%$ \\
\hline 17 & 0.4 & 400 & $\mathrm{x}$ & $\mathrm{x}$ & 1 & 2 & $33.3 \%$ & $33.3 \%$ \\
\hline 18 & 0.4 & 300 & $\mathrm{x}$ & 3 & $\mathrm{x}$ & 1 & $75.0 \%$ & $33.3 \%$ \\
\hline
\end{tabular}

These results show a significant improvement over previous laboratory tests and field tests. All but one hole detected at least one fracture. 11 of the 18 holes detected two of the three fractures. One hole detected all of the fractures. The data analysis results imply that the first fracture (1/16") is probably too small to be reliably detected with theses pre-set drilling parameters. While there is no significant difference in the results of the $0.8,1.1$, and $1.5 \mathrm{in} / \mathrm{sec}$ holes, all holes with a penetration rate of $0.8 \mathrm{in} / \mathrm{sec}$ and above appear to have better results than the $0.4 \mathrm{in} / \mathrm{sec}$ holes.

Table 6.10 shows the results from layer block \#5. Although there are 8 interfaces present in the block, only 6 were within the range of data analysis. Therefore, only those 6 interfaces are shown in the results.

Table 6.10: Layer Block \#5 Results-Phase 2 Lab Tests

1.375" Bit

\begin{tabular}{|c|c|c|c|c|c|c|c|c|c|c|}
\hline \multirow[b]{2}{*}{ Hole } & \multirow[b]{2}{*}{ P.R. } & \multirow[b]{2}{*}{ RPM } & \multicolumn{5}{|c|}{ No of Pred. within 2" of Actual Features } & \multirow[b]{2}{*}{ M.P. } & \multicolumn{2}{|c|}{ Percentages } \\
\hline & & & 16 & 24 & 31.5 & 43 & 48.5 & & Correct/Total & Pred./Actual \\
\hline 1 & 1.1 & Free & $\mathrm{x}$ & $\mathrm{x}$ & 1 & 1 & $x$ & 0 & $100.0 \%$ & $33.3 \%$ \\
\hline 2 & 1.1 & Free & $x$ & 1 & 1 & 1 & 1 & 0 & $100.0 \%$ & $83.3 \%$ \\
\hline 3 & 1.5 & Free & $\mathrm{x}$ & 1 & 2 & 1 & $x$ & 0 & $100.0 \%$ & $66.7 \%$ \\
\hline 4 & 1.5 & Free & 1 & 1 & 1 & 1 & $x$ & 2 & $66.7 \%$ & $83.3 \%$ \\
\hline 5 & 0.4 & Free & $x$ & $x$ & $x$ & $x$ & $x$ & 1 & $0.0 \%$ & $0.0 \%$ \\
\hline 6 & 0.4 & Free & 1 & 2 & $x$ & $x$ & $x$ & 0 & $100.0 \%$ & $33.3 \%$ \\
\hline 7 & 0.4 & 400 & $x$ & $\mathrm{x}$ & $x$ & 1 & $x$ & 5 & $16.7 \%$ & $16.7 \%$ \\
\hline 9 & 0.4 & 300 & $x$ & $x$ & $x$ & $x$ & $x$ & 0 & $0.0 \%$ & $0.0 \%$ \\
\hline 10 & 0.4 & 300 & $x$ & $x$ & $x$ & $x$ & 2 & 0 & $100.0 \%$ & $16.7 \%$ \\
\hline
\end{tabular}


These tests showed a significant improvement over previous laboratory tests. However, no holes were able to detect all of the interfaces. The sandstone/concrete interface at 16 in location is unlikely to be reliably detected. The graph of ratio versus bit position shows only a small difference between the shear stress/normal stress ratio for sandstone and that of concrete. Additionally, the white marble/concrete interface at 48.5-in location was not reliably detected. There is a significant difference in the ratio between these two layers. Drilling of most of the holes was stopped near $50 \mathrm{in}$. This factor may influence the poor detection results at the 48.5 in interface. Results also clearly show that the higher penetration rates of 1.1 and $1.5 \mathrm{in} / \mathrm{sec}$ produce better results than the $0.4 \mathrm{in} / \mathrm{sec}$ penetration rates. All but 1 of the 1.1 and $1.5 \mathrm{in} / \mathrm{sec}$ holes had no mis-predictions. 


\section{CHAPTER 7}

\section{DISCUSSION OF RESULTS}

A reliable system of sensors and processors that can control the drilling process of a roof bolter currently exists. The sensors and processors can also be used to collect drilling data during the drilling process. Extensive laboratory and field tests have demonstrated the reliability of the system.

Drilling parameters such as torque, thrust, penetration rate, and rotation rate should show some correlation with geology drilled. Higher order drilling parameters can be calculated from the basic drilling parameters. These higher order parameters include: bite depth, normal contact area, shear contact area, normal stress, shear stress, and shear stress/normal stress ratio. Laboratory and field tests have shown that the shear stress/normal stress ratio reflects the relative strength of material drilled. Sharp changes in the ratio indicate the location of interfaces,

fractures, and weak zones. A quantitative prediction model was developed to automatically locate these features.

Three phase of testing were conducted to test the data collection equipment and analysis methodology. The first phase was a series of laboratory tests. The second and third phases were a series of underground tests, and another series of laboratory tests respectively. Laboratory tests were conducted on a number of manufactured blocks intended to simulate geological conditions typically found in underground coal mines. A solid concrete block was used to simulate drilling a homogeneous material. A simulated fracture block was constructed with simulated fractures of $1 / 16,1 / 8$ and $3 / 8$ inches. Two layer blocks containing various layers of rock interbedded with concrete were tested to simulate interfaces between strata layers. 
Quantitative results from initial laboratory tests and underground tests were not concordant with validation data. Several factors contributed to the discrepancy between quantitative results and validation data. Early tests were conducted with a variety of pre-set control parameters. While quantitative results showed no major difference between the results of different pre-set control parameter, qualitative visualizations showed that the best correlation between geology existed when drilling with a free rotation rate. In phase 1 laboratory tests, only 2 holes were drilled with a free rotation rate.

The method of validation also affects some of the quantitative results. In mines $\mathrm{B}$ and $\mathrm{C}$, many holes were validated with a core log. Two major problems arise when validating data with a core log. First, sections of core are often lost or destroyed during the core drilling and collection process. These lost sections cannot be accounted for, and often lead to erroneous locations of features in the core log. Second, one core is usually used to validate a data set. Some holes may be drilled at a far enough distance from the core location for geology to change significantly.

The slope method of locating features likely has the most influence on the poor results from phase 1 lab tests and underground tests. The plot of ratio versus bit position correlates well with geology from a qualitative stand point. However, small variances of the ratio within one rock unit are often detected with the slope method. This leads to a large number of mispredictions. Furthermore, the issue of confinement increasing the normal stress at high bite depth has not been accounted for. This confinement issue probably causes some of the variance of ratio within one rock type. 
Results from the phase 2 lab tests show a higher correct prediction/total prediction percentage. Most of the hole drilled during the phase 2 lab tests were free rotation. Additionally, the materials tested were much more consistent than those of underground tests. 


\section{CHAPTER 8}

\section{CONCLUSIONS AND RECOMMENDATIONS}

\subsection{Conclusions}

The quantitative method outlined in this study is not sufficiently accurate to be used in an underground coal mining environment. Additionally validation of data with core logs is not sufficient unless the data collection holes are located very close to the core hole. The second phase of laboratory tests shows a significant improvement in prediction results, especially when using pre-set control parameters with a free rotation rate. The shear stress/normal stress ratio does correlate well with geological conditions encountered during drilling. A new quantitative prediction method is required in order to use the shear stress/normal stress ratio in an underground setting.

Observation of shear/normal stress ratio versus bit position shows that the value of the ratio does reflect the relative strength of the rock mass, and sharp peaks in the ratio correspond with fracture locations. The best correlations occur when using pre-set parameters of free rotation rate and a penetration rate of at least $1.1 \mathrm{in} / \mathrm{sec}$. Phase 2 laboratory tests indicate that these higher penetration rates $(1.1,1.5$, and $1.7 \mathrm{in} / \mathrm{sec})$ may not detect some smaller features such as the $1 / 16^{\text {th }}$-inch fracture in the simulated fracture block. In order to obtain a balance between optimizing the penetration rate to best suit the data analysis methodology and optimizing the penetration rate to detect smaller-size features, any use of the ratio method for geological prediction should use pre-set parameters of free rotation and penetration rates of 1.1 or $1.5 \mathrm{in} / \mathrm{sec}$ 


\subsection{Recommendations}

The predictions made using the quantitative methodology outlined in this thesis are not accurate enough to be used in an actual production environment. There are a number of studies that can be conducted to improve the accuracy of the prediction model

The plots of normal stress versus bite depth and shear stress versus bite depth should be studied in more detail. Currently, these plots indicate that some influences on stress levels required for drilling have not been accounted for. Ideally these plots should form a horizontal line. Since these plots are not horizontal, different drill rates will produce different values of normal stress and shear stress, even in a homogeneous material. Consequently, changes in drill rates will change the value of the shear/normal stress ratio in a homogeneous material. The normal stress at high bite depths is affected by confinement. The confinement should be quantified, and used to normalize the plot of normal stress versus bite depth. . A horizontal line would indicate that factors due to bit geometry and bite depth do not affect the stress level required to drill a rock mass. The shear stress at low bite depths is very high due to the effects of friction at the bit-rock interface. Quantifying this frictional force should allow the shear stress versus bite depth to be normalized.

Future underground tests should be validated with scope data as much as possible. Since the scope is used in holes that have been drilled to collect data, scope data eliminates validation errors due to distance between the drilled hole and core hole.

Finally, the slope method of determining feature locations appears to be unreliable for underground data. Another method should be developed to quantify locations where the ratio changes. 


\section{REFERENCES}

1. Teale R. The Concept of Specific Energy in Rock Drilling. Int. J. Rock Mech. Min. Sci. \& Geomech, 2, 1965, pp. 57-73.

2. Thomas B, Wilson G. Control Technology for Roof Drill Operations. Proceedings of the 18th International Conference on Ground Control in Mining, Morgantown, WV, 1999, pp. 216-221.

3. Finfinger, G.L., S.S. Peng, Q.Z. Gu, G. Wilson and B. Thomas. An Approach to Identifying Geological Properties from Roof Bolter Drilling Parameters. Proceedings of the 19th International Conference on Ground Control in Mining, Morgantown, WV, 2000, pp. 1-11.

4. Luo, Y., S.S. Peng, B. Mirabile, G. Finfinger, G. Wilson. Estimating Rock Strengths Using Drilling Parameters During Roof Bolting Operations - Progress Report, Proceedings of the $21^{\text {st }}$ International Conference on Ground Control in Mining, Morgantown, WV, 2002, pp. 288-293.

5. Itakura K, Sato K, Deguchi G, Ichihara Y, Matsumoto H, Eguchi H. Development of a Roof Logging System by Rock Bolt Drilling. Trans of the Institution of Mining and Metallurgy, Vol. 106, A95-184, Section A, 1997, pp. A118-A123.

6. Itakura K, Sato K, Deguchi G, Ichihara Y, Matsumoto H. Visualization of Geostructure by Mechanical Data Logging of Rockbolt Drilling and Its Accuracy. Proceedings of the $20^{\text {th }}$ International Conference on Ground Control in Mining, Morgantown, WV, 2001, pp. 184-190. 
VITA

Benjamin T. Mirabile

$\underline{\text { Education }}$

West Virginia University, BS, 2001

West Virginia University, 2001-Present

Professional Experience

Consolidation Coal Company, 1997

Jennmar Corporation, 1999-Present 